January 2014

\title{
Evaluation Of CMIP5 Simulated Clouds And TOA Radiation Budgets Using NASA Satellite Observations
}

Erica Kay Dolinar

How does access to this work benefit you? Let us know!

Follow this and additional works at: https://commons.und.edu/theses

\section{Recommended Citation}

Dolinar, Erica Kay, "Evaluation Of CMIP5 Simulated Clouds And TOA Radiation Budgets Using NASA Satellite Observations" (2014). Theses and Dissertations. 1644.

https://commons.und.edu/theses/1644

This Thesis is brought to you for free and open access by the Theses, Dissertations, and Senior Projects at UND Scholarly Commons. It has been accepted for inclusion in Theses and Dissertations by an authorized administrator of UND Scholarly Commons. For more information, please contact und.commons@library.und.edu. 


\title{
EVALUATION OF CMIP5 SIMULATED CLOUDS AND TOA RADIATION BUDGETS USING NASA SATELLITE OBSERVATIONS
}

\author{
by
}

\section{Erica Kay Dolinar}

Bachelor of Science, Millersville University, 2011

\author{
A Thesis \\ Submitted to the Graduate Faculty \\ of the \\ University of North Dakota \\ in partial fulfillment of the requirements \\ for the degree of \\ Master of Science \\ Grand Forks, North Dakota \\ August \\ 2014
}


Copyright 2014 Erica Dolinar 
This thesis, submitted by Erica Dolinar in partial fulfillment of the requirements for the Degree Master of Science from the University of North Dakota, has been read by the Faculty Advisory Committee under whom the work has been done and is hereby approved.
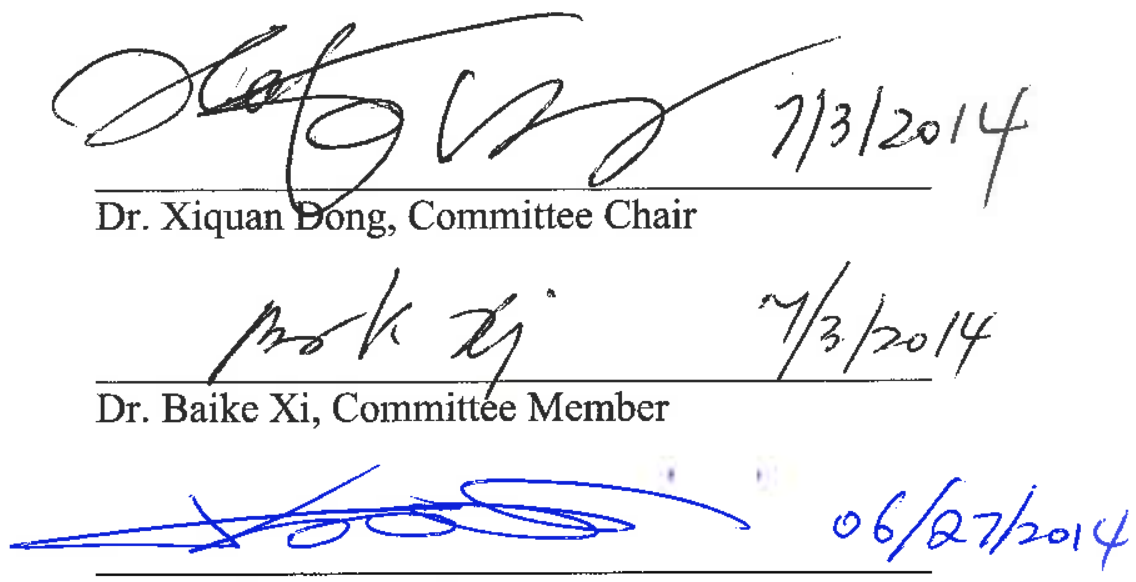

Dr. Jonathan Jiang, Committee Member

This thesis is being submitted by the appointed advisory committee as having met all the requirements of the School of Graduate Studies at the University of North Dakota and is hereby approved.

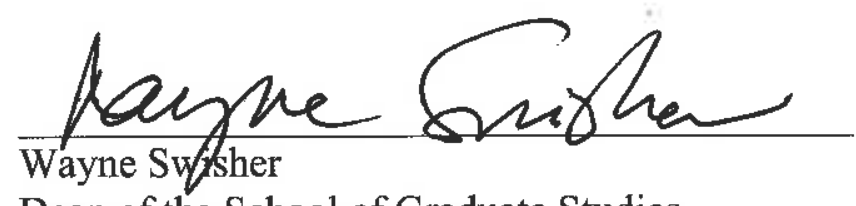

Dean of the School of Graduate Studies

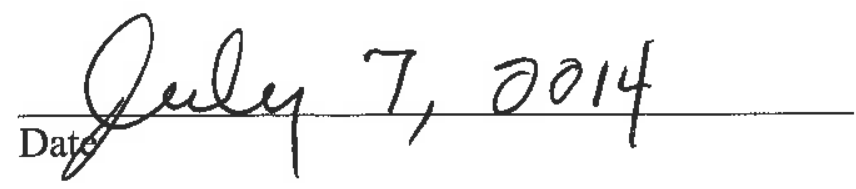




\section{PERMISSION}

Title Evaluation of CMIP5 Simulated Clouds and TOA Radiation Budgets Using NASA Satellite Observations

Department Atmospheric Sciences

Degree Master of Science

In presenting this thesis in partial fulfillment of the requirements for a graduate degree from the University of North Dakota, I agree that the library of this University shall make it freely available for inspection. I further agree that permission for extensive copying for scholarly purposes may be granted by the professor who supervised my thesis work or, in his absence, by the Chairperson of the Department or the Dean of the School of Graduate Studies. It is understood that any copying or publication or other use of this thesis or part thereof for financial gain shall not be allowed without my written permission. It is also understood that due recognition shall be given to me and to the University of North Dakota in any scholarly use which may be made of any material in my thesis. 


\section{TABLE OF CONTENTS}

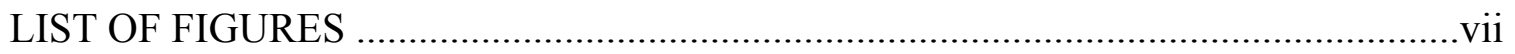

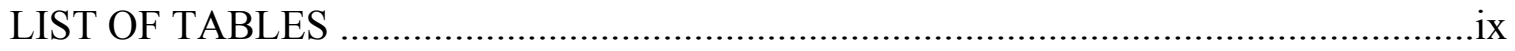

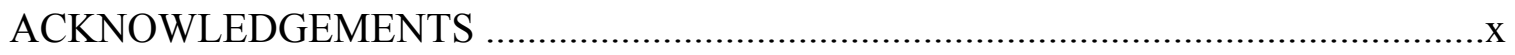

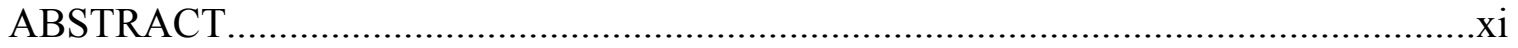

\section{CHAPTER}

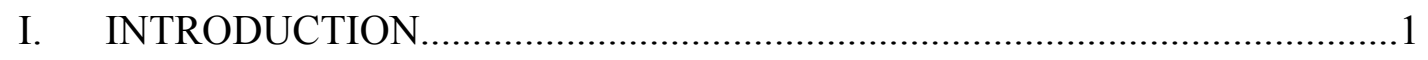

II. DATA AND METHODOLOGY ..............................................................

Coupled Model Intercomparison Project Phase 5 (CMIP5) Model

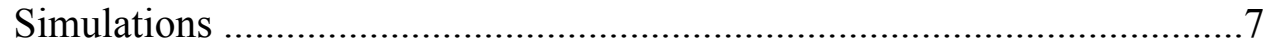

Atmospheric Model Intercomparison Project (AMIP) .................

Model Ensemble Members ...................................................10

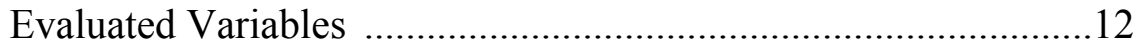

NASA Satellite Observations ..........................................................15

Clouds and Earth's Radiant Energy System (CERES) ................15

Moderate Resolution Imaging Spectroradiometer (MODIS).........16

Energy Balanced and Filled (EBAF) ..................................... 17

International Satellite Cloud Climatology Project (ISCCP) ........17

CloudSat and Cloud-Aerosol Lidar and Infrared Pathfinder Satellite Observation (CALIPSO) ..........................................17

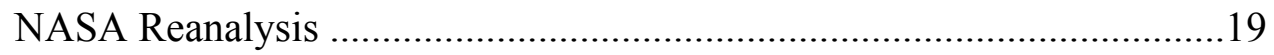


Modern Era Retrospective Analysis for Research and Application (MERRA)

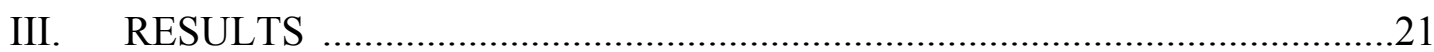

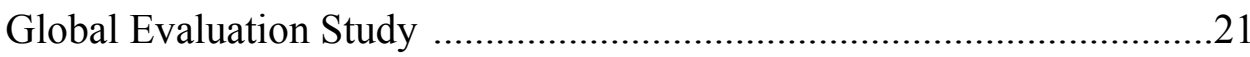

Cloud Fraction and Cloud Water Path ..........................................21

Top-of-Atmosphere (TOA) Radiation Budgets ............................26

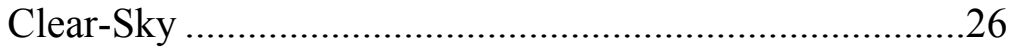

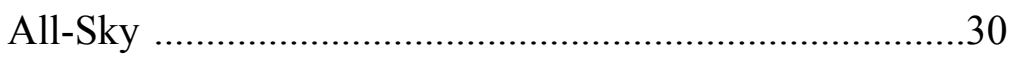

Cloud Radiative Forcings (CRFs) ......................................33

Tropical and Mid-latitude $\left( \pm 45^{\circ}\right)$ Evaluation study ..................................38

Vertical Velocities (Omega) at $500 \mathrm{hPa}$.......................................39

Regional Simulated Biases in Vertical Velocity Regimes .............41

Taylor Diagram Analysis .................................................44

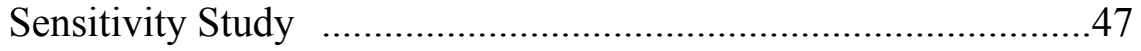

Error Analysis - where are these errors coming from? .................52

Residual Errors.................................................................57

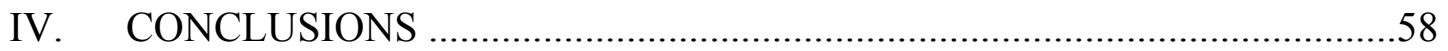

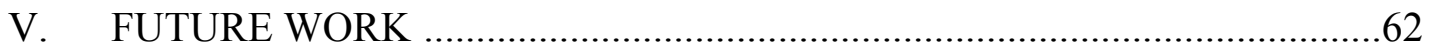

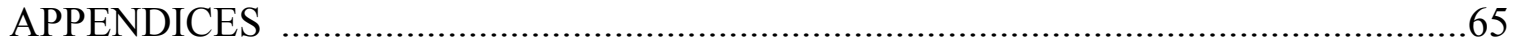

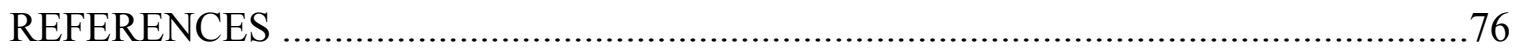




\section{LIST OF FIGURES}

Figure $\quad$ Page

1. The zonal cloud fraction distribution from several ensemble members in two GCMs, MRI-AGCM3.2H (a) and CSIRO Mk3.6.0 (b), during the time period of this study

2. The globally averaged cloud fraction (a) and cloud water path (b) from 28 AMIP models (grey bars) and satellite observations; CERES MODIS (red), ISCCP (green), and CloudSat/CALIPSO (black)

3. The zonal cloud fraction (a) and cloud water path (b) distribution from CERESMODIS (red), ISCCP (green), CloudSat/CALIPSO (black), and the multimodel ensemble mean (blue)

4. Global distribution of the observed cloud fraction (a) and cloud water path (d), the multimodel ensemble simulated CF (b) and CWP (e), and the multimodel ensemble simulated biases (model minus observations, $\Delta$ ) in CF (c) and CWP (f).

5. Same as Figure 2 but for the global means in simulated and observed (CERES EBAF) TOA reflected shortwave (a) and outgoing longwave fluxes (b) under clear-sky conditions

6. Same as Figure 3 but for the simulated and observed zonal distribution of TOA reflected shortwave (a) and outgoing longwave (b) fluxes under clear-sky conditions

7. Same as Figure 4 but for the observed, simulated, and simulated bias maps of shortwave (left) and longwave (right) clear-sky results

8. Same as Figure 2 but for the global means in simulated and observed TOA reflected shortwave (a) and outgoing longwave fluxes (b) under the all-sky conditions

9. Same as Figure 3 but for the simulated and observed zonal distribution of TOA reflected shortwave (a) and outgoing longwave (b) fluxes under all-sky conditions 
10. Same as Figure 4 but for the observed (a) and simulated (b) TOA reflected shortwave (left) and outgoing longwave (right) under the all-sky conditions, as well as their differences (model - observations) $(\mathrm{c}, \mathrm{f})$.

11. Same as Figure 2 but for the global means in simulated and observed shortwave (a), longwave (b), and net (c) cloud radiative forcing results

12. Same as Figure 3 but for the simulated and observed zonal distribution of shortwave (a), longwave (b), and net (c) CRF results

13. Same as Figure 4 but for the observed, simulated, and simulated bias maps of shortwave (left), longwave (middle), and net (right) CRF results

14. Global distributions of the MERRA reanalyzed (a) and multimodel ensemble simulated (b) vertical velocities at $500 \mathrm{hPa}$ over the oceans

15. From Wang and $\mathrm{Su}$ (2013) "The comparison between the 12 models and the CERES EBAF in the composites of (a) SW CRF, (b) LW CRF, (c) net CRF, and (d) the ratio of SW CRF to $\mathrm{LW} \mathrm{CRF}$ in different tropical circulation regimes defined from $\omega 500$

16. Relatively strong upwelling $\left(\omega 500<-25 \mathrm{hPa}^{-1 a y}{ }^{-1}\right.$, blue $)$ and downwelling $\left(\omega 500>25 \mathrm{hPa}\right.$ day $^{-1}$, red) regimes over the tropical and mid-latitude $\left( \pm 45^{\circ}\right.$ latitude) oceans are identified from MERRA reanalysis of the omega field at 500 $\mathrm{hPa}(\mathrm{a})$

17. Taylor Diagrams displaying the 28 AMIP model simulations of $\mathrm{CF}(\mathrm{a}-\mathrm{b})$ and CWP $(\mathrm{c}-\mathrm{d})$ in the upwelling (left) and downwelling (right) regimes over tropical and mid-latitude $\left( \pm 45^{\circ}\right.$ latitude) oceans.

18. Same as Figure 17 but for TOA CRFs: SW $(a-b)$, LW $(c-d)$, and net $(e-f)$. Values are normalized by CERES EBAF observations

19. Sensitivities of TOA SW (a,d), LW (b,e), and net (c,f) CRFs to CF in the upwelling (blue) and downwelling (red) regimes

20. Same as Figure 19 but for the observed and simulated sensitivities of CRFs to CWP 


\section{LIST OF TABLES}

Table

1. The 28 CMIP5 AMIP climate models evaluated in this study. .8

2. GCM simulated variables available from the suite of models chosen for this study

3. Level-3 Global monthly mean gridded data products

4. Summary of globally averaged (cosine-latitude weighted) mean observed and multimodel ensemble simulated results

5. Summary of the different error sources in the simulated SW/LW/net CRFs with contributions from CRF sensitivities to CF or CWP, CF or CWP biases, and covariations in the upwelling and downwelling regimes, separately

6. Summary of total errors in SW/LW/net CRFs by model contributed by simulated $\mathrm{CF}$ biases in both upwelling and downwelling regimes

7. Summary of total errors in SW/LW/net CRFs by model contributed by simulated CWP biases in both upwelling and downwelling regimes 


\section{ACKNOWLEDGEMENTS}

I would first like to thank my thesis committee. I could not see myself working with any other group of people and my success is a reflection of their hard work and dedication. It was with their help and persistence that I was able to spend a summer at the Jet Propulsion Laboratory, publish a peer-reviewed journal article, and make invaluable connections with scientists around the world. Thank you Xiquan, Baike, Jonathan, and Hui (although not on my committee, I acknowledge her for her input and ideas on quantifying errors in this study).

I would also like to thank my friends and family who have shown me support in times of frustration and praise in my accomplishments. It was their encouragement that helped get me through the hard times and insisted that little mishaps should not taken too seriously. They have always believed that I had a good handle on life and trusted my judgment, which has provided me with a strong confidence in my choices. Thank you Mom, Bob, Jess (Jason, Jay, and Jules), Dad, Mary, and Heather (Brooke and Joey). Love you!

The results presented henceforth were completed under the support of NASA EPSCoR from Grant NNX11AM15A and the NASA CERES project under Grant NNX10AI05G at the University of North Dakota. The summer 2013 work at JPL/Caltech was supported by the NASA COUND project. All financial support from the past two years is greatly appreciated. 


\begin{abstract}
A large degree of uncertainty in global climate models (GCMs) can be attributed to the representation of clouds and how they interact with incoming solar and outgoing longwave (Earth emitted) radiation. In this study, the simulated total cloud fraction (CF), cloud water path (CWP), top-of-atmosphere (TOA) radiation budgets and cloud radiative forcings (CRFs) from 28 CMIP5 AMIP models are evaluated and compared to multiple satellite observations from CERES, MODIS, ISCCP, CloudSat, and CALIPSO. The multimodel ensemble mean $\mathrm{CF}(58.6 \%)$ is, on global average, under estimated by nearly $7 \%$ compared to CERES-MODIS (CM) and ISCCP results, with an even larger negative bias $(16.7 \%)$ compared to the CloudSat/CALIPSO result. The CWP bias is similar in comparison to the CF result; the multimodel ensemble mean is under estimated (16.4 $\mathrm{gm}^{-2}$ ) when compared to CM. The model simulated and CERES EBAF observed TOA reflected shortwave (SW) and outgoing longwave (LW) radiation fluxes, on average, differ by 1.6 and $-0.9 \mathrm{Wm}^{-2}$, respectively, and is contrary to physical theory. The global averaged SW, LW, and net CRFs form CERES EBAF are $-47.2,26.2$, and $-21.0 \mathrm{Wm}^{-2}$, respectively, indicating a net cooling effect due to clouds on the TOA radiation budget. Global biases in the SW and LW CRFs from the multimodel ensemble mean are -1.1 and $-1.3 \mathrm{Wm}^{-2}$, respectively, resulting in a greater net cooling effect of $2.4 \mathrm{Wm}^{-2}$ in the model simulations. A further investigation of cloud properties and CRFs reveals the GCM biases in atmospheric upwelling $\left(15^{\circ} \mathrm{S}-15^{\circ} \mathrm{N}\right.$, ocean-only) regimes are much less than their downwelling $\left(15^{\circ}-45^{\circ} \mathrm{N} / \mathrm{S}\right.$, ocean-only) counterparts. Sensitivity studies
\end{abstract}


have shown that the magnitude of SW cloud radiative cooling increases significantly with increasing $\mathrm{CF}$ at similar rates $\left(-1.20\right.$ and $\left.-1.31 \mathrm{Wm}^{-2} \%^{-1}\right)$ in both regimes. The LW cloud radiative warming increases with increasing CF but is regime dependent, demonstrated by the different slopes over the upwelling and downwelling regimes $(0.81$ and $0.22 \mathrm{Wm}^{-2} \%^{-1}$, respectively). Through a comprehensive error analysis, we found that $\mathrm{CF}$ is a primary modulator of warming (or cooling) in the atmosphere. The comparisons and statistical results from this study may provide helpful insight for improving GCM simulations of clouds and TOA radiation budgets in future versions of CMIP. 


\section{CHAPTER I}

\section{INTRODUCTION}

The Intergovernmental Panel on Climate Change (IPCC) continues to recognize that simulations of clouds and their feedbacks are one of the largest uncertainties in current climate model simulations (IPCC, AR5, http://www.ipcc.ch/report/ar5/wg1/). Due to their complex interactions with incoming solar (shortwave, SW) and emitted terrestrial (longwave, LW) radiation, clouds induce both warming and cooling effects on the Earth system (atmosphere and surface). For simplicity, these effects are commonly estimated at the top of the atmosphere (TOA) and the surface, and depend greatly upon the fraction of sky covered by clouds, cloud height, and cloud microphysical properties (Wielicki et al. 1996). Zhang et al. (2005) compared global climate model (GCM) simulated clouds with data from the National Aeronautics and Space Administration (NASA) Clouds and Earth's Radiant Energy System (CERES) experiment (Wielicki et al. 1996, 1998) and the International Satellite Cloud Climatology Project (ISCCP) and found that most GCMs under estimated mid-latitude total cloud fractions (CF) but over simulated their optical depth. The under estimated CF and over estimated optical depth in the models will tend to offset each other in calculating TOA radiation budgets.

For the last three decades clouds have been acknowledged to be one of the largest modifiers of the global climate system (Cess et al. 1990; Senior and Mitchell 1993; Zhang et al. 2005; Bony et al. 2006; Jiang et al. 2012; IPCC 2001; Yao and Del Genio 2002; Su et al. 2013; Stanfield et al. 2014). The Coupled Model Intercomparison Project 
Phase 5 (CMIP5) was implemented in response to these realities as an extension to earlier versions of CMIP (e.g. CMIP3) to make available contemporary global climate simulations from several participating modeling centers. CMIP5 inherently takes on the challenge of understanding the issues concerning discrepancies among similarly forced models and their simulations of clouds (Taylor et al. 2012). Recent studies have investigated the progress of simulated clouds and their corresponding radiative forcings between CMIP5 and its predecessor, CMIP3. Although many improvements have been made in CMIP5 (Lauer and Hamilton 2012; Jiang et al. 2012; Wang and Su 2013; Li et al. 2013; Klein et al. 2013; Chen et al. 2013), clouds and their feedbacks continue to be problematic in climate models, as concluded in the IPCC AR5 Chapter 9 (2013).

Cloud vertical distribution and overlap are some of the major uncertainties in determining the heating/cooling profiles by radiative and precipitable/evaporative processes (e.g. Stephens and Webster 1984; Morcrette and Jakob 2000; Stephens et al. 2002). The spread of climate warming predictions by a multimodel ensemble is, arguably, a result of the oversimplification of cloud vertical distributions and overlap assumptions (Stephens et al. 2002). Simulated cloud vertical distributions under the random overlap assumption produces a better agreement with observations than those under other assumptions (i.e. maximum, minimum, and maximum-random). Yet still, the maximum-random overlap assumption has been used by most GCMs (e.g. Hogan and Illingworth 2000; Collins 2001).

Lauer and Hamilton (2012) have revealed the model simulated cloud radiative forcings (CRFs) tend to outperform CF results, suggesting that models are not accurately depicting fundamental cloud processes; rather, the models are being tuned to provide 
simulations that converge to observations. However, model developers cannot tune all parameters to match observations. Jiang et al. (2012) developed a grading scale in an attempt to rate each model based upon spatial means, standard deviation, and correlation of combined clouds and water vapor fields. Furthermore, they highlighted that there exists large model spread and a high degree of discrepancy from observations, particularly in the upper troposphere. In many instances when evaluating a multimodel ensemble, absolute model error is rather small. However, when evaluating models independently, the spread of model results is fairly large; most GCMs use different cloud parameterization and radiation schemes, offering more complexity to evaluation studies.

A recent study by $\mathrm{Su}$ et al. (2013) suggests that most of the errors in modelsimulated clouds are a result of cloud parameterization errors, rather than the large-scale dynamics. Jiang et al. (2012) and Li et al. (2012) both reported that improvements were made in the representation of ice clouds form CMIP3 to CMIP5; advances in cloud parameterization, such as the use of a double-moment cloud microphysical scheme and two separate prognostic equations for ice and liquid clouds in some models, are associated with this result. Through their analysis, a $50 \%$ reduction of error was apparent in the multimodel mean bias and root mean squared error (RMSE). Wang and $\mathrm{Su}$ (2013) investigated the relationships between CRFs and atmospheric vertical velocities in 12 uncoupled CMIP5 simulations and concluded that the over estimated net CRF (stronger cooling) was primarily a result of over estimated SW cloud radiative cooling and under estimated LW cloud radiative warming. They further analyzed these models' results based upon vertically driven dynamic regimes in an attempt to quantitatively estimate the biases in upwelling/convective and downwelling/subsidence 
(at $500 \mathrm{hPa}$ ) regions of the tropical oceans. In this study, through an integrative analysis of multimodel ensemble means and NASA satellite observations, simulated and observed clouds and CRFs, in atmospheric upwelling and downwelling regimes in the tropics and mid-latitudes (ocean-only), are investigated.

By applying a thorough error analysis technique, Zhu et al. (2007) quantified the errors from cloud amount and cloud condensate with the response of doubled $\mathrm{CO}_{2}$ and 2 K sea surface temperature (SST) perturbations. Due to its statistical significance, they instigated the multiple linear regression (MLR) method, which is an appropriate technique for identifying cloud feedbacks in climate sensitivity experiments. By applying this approach, they also quantified the errors in radiation feedbacks due to cloud fraction and cloud condensate, and characterized their corresponding implications on climate simulations. We employ a similar technique to quantify the errors in simulated CFs and cloud water path (CWP) on CRF simulations.

The general objective of this study is to determine the overall representation of clouds and their consequent radiative forcings in uncoupled CMIP5 models, while inherently providing the practical foresight and motivation for climate model advancement. We separate our analysis into atmospheric upwelling and downwelling regimes based upon $500 \mathrm{hPa}$ vertical velocities, considering that different cloud types, such as deep convective clouds associated with upwelling and stratiform clouds in downwelling regimes, have different cloud radiative effects ( $\mathrm{Su}$ et al. 2008; Bony et al. 2004). Also, climate models have shown significantly different behaviors and a relatively large degree of multimodel spread in these two regimes (Su et al. 2013). Cloud parameterization schemes oftentimes use in-cloud vertical velocities to distinguish 
convective and stratiform-type cloud predictions. By identifying systematic details (consistent with parameterizations) between clouds and TOA radiation in both the observations and the GCMs in these regimes, more suitable constraints may be applied to parameterizations. Considering the sensitivity between clouds and their radiative forcings in different dynamic regimes will provide insight as to whether errors form clouds or their microphysical properties (i.e. CWP) are contributing more to the overall CRF bias. Again, a quantitative assessment of these complex variables will support the improvement of climate models regarding the physical representation of clouds and their radiative feedbacks. This study evaluates the outputs from 28 uncoupled CMIP5 models using a combination of satellite observations from CERES, MODIS, ISCCP, CloudSat, and CALIPSO, as well as contemporary reanalysis data. Through an integrative analysis of 28 CMIP5 GCM outputs and multiple satellite observations, we quantitatively assess the strengths and weaknesses in current climate model simulations and provide the information useful for model improvements. If the current climate is accurately predicted, there may be more confidence in future-climate simulations.

This document details the AMIP model simulations from CMIP5 along with the referenced satellite observations in the Methodology section while the Results section presents the simulated and observed CF, CWP, TOA radiation budgets, and CRF results in the recent climate. We investigate the common biases and the sensitivity characteristics between CRFs and clouds (CF and CWP) in tropical and mid-latitude atmospheric upwelling and downwelling regions over oceans and determine the overall ability of the models to simulate clouds and TOA CRFs in these regimes. CRF biases are ultimately quantified in each regime on a model-to-model basis and in the multimodel 
ensemble via a comprehensive error analysis. A summary of the results and suggestions for further analysis has been made at the end of this document. 


\section{CHAPTER II}

\section{DATA AND METHODOLOGY}

\section{Coupled Model Intercomparison Project Phase 5 (CMIP5) Model Simulations}

CMIP5 is the result of a conglomeration of modeling centers whose ultimate goal is to mitigate the discrepancies and uncertainties in contemporary global climate models (Taylor et al. 2012). The main objectives of CMIP5 include:

1) "assessing the mechanisms responsible for model differences in poorly understood feedbacks associated with the carbon cycle and with clouds;

2) examining climate "predictability" and exploring the predictive capabilities of forecast systems on decadal time scales; and, more generally,

3) determining why similarly forced models produce a range of responses."

There are three different types of temporal experiments that range from long-term (century time scale), decadal, and short-term time scales. For this study, we evaluate the (Atmospheric Model Intercomparison Project) AMIP-type simulations, which falls within the category of decadal time-scale predictions. A more comprehensive summary about the CMIP5 project and the framework for other prediction experiments can be found in Taylor et al. (2012).

This study analyzes the outputs from 28 models submitted to the AMIP in CMIP5, which are available from the Earth System Grid Federation (ESGF) through the Program for Climate Model Diagnosis and Intercomparison (PCMDI). These modeled results are available at http://pcmdi9.1lnl.gov/esgf-web-fe/, and their associated center (or group) name, model name, horizontal and vertical grid spacing, and number of ensemble 
members are summarized in Table 1. These models were chosen based upon data availability at the onset of this study (August 2012). Post-CMIP5 simulations have recently been released, by request, by some modeling groups; however, they are not being considered in this study (Stanfield et al. 2014 compares CMIP5 and post-CMIP5 GISS-E2-R simulations). The AMIP output is designed for historical climate simulations (1979 - 2008), while the NASA observations used in the evaluation process begins in March 2000. Therefore, the period between March 2000 and February 2008 is chosen for this study.

Table 1. The 28 CMIP5 AMIP climate models evaluated in this study. Specific model names are listed along with the modeling center (or group) from which it was created. Horizontal grid spacings (longitude $\times$ latitude) are listed together with the number of vertical grid levels (L\#) and the number of ensemble members available from each specific model.

\begin{tabular}{|c|c|c|c|}
\hline Modeling Center (or Group) & Model Name & $\begin{array}{l}\text { Grid Spacing (lon } \times \text { lat }), \\
\text { Vertical Levels }\end{array}$ & $\begin{array}{l}\text { Ensemble } \\
\text { Members }\end{array}$ \\
\hline $\begin{array}{c}\text { Commonwealth Scientific and Industrial } \\
\text { Research Organization (CSIRO) and } \\
\text { Bureau of Meteorology (BOM), } \\
\text { Australia }\end{array}$ & ACCESS 1.0 & $1.875^{\circ} \times 1.25^{\circ}, \mathrm{L} 38$ & 1 \\
\hline $\begin{array}{l}\text { Beijing Climate Center, China } \\
\text { Meteorological Administration }\end{array}$ & $\begin{array}{c}\text { BCC-CSM1.1 } \\
\text { BCC-CSM1.1 (m) }\end{array}$ & $\begin{array}{c}1.25^{\circ} \times 1.25^{\circ}, \mathrm{L} 26 \\
2.8125^{\circ} \times 2.815^{\circ}, \mathrm{L} 26\end{array}$ & $\begin{array}{l}3 \\
3\end{array}$ \\
\hline $\begin{array}{c}\text { College of Global Change and Earth } \\
\text { System Science, Beijing Normal } \\
\text { University, China }\end{array}$ & BNU-ESM & $2.8125^{\circ} \times 2.8125^{\circ}, \mathrm{L} 26$ & 1 \\
\hline $\begin{array}{l}\text { Canada Centre for Climate Modeling } \\
\text { and Analysis }\end{array}$ & CanAM4 & $2.8125^{\circ} \times 2.8125^{\circ}, \mathrm{L} 35$ & 4 \\
\hline $\begin{array}{l}\text { National Center for Atmospheric } \\
\text { Research (NCAR), USA }\end{array}$ & CCSM4 & $1.25^{\circ} \times 0.9375^{\circ}, \mathrm{L} 26$ & 6 \\
\hline $\begin{array}{c}\text { Community Earth System Model } \\
\text { Contributors (NSF-DOE-NCAR), USA }\end{array}$ & CESM1 (CAM5) & $1.25^{\circ} \times 0.9375^{\circ}, \mathrm{L} 30$ & 2 \\
\hline $\begin{array}{l}\text { Centro-Euro-Mediterraneo per I } \\
\text { Cambiamenti Climatici, Italy }\end{array}$ & CMCC-CM & $0.75^{\circ} \times 0.75^{\circ}, \mathrm{L} 31$ & 3 \\
\hline $\begin{array}{c}\text { Centre National de Recherches } \\
\text { Meteorologiques/Centre Europeen de } \\
\text { Recherche et Formation Avancees en } \\
\text { Calcul Scientifique, France }\end{array}$ & CNRM-CM5 & $1.4^{\circ} \times 1.4^{\circ}, \mathrm{L} 31$ & 1 \\
\hline $\begin{array}{l}\text { Commonwealth Scientific and Industrial } \\
\text { Research Organization in collaboration } \\
\text { with Queensland Climate Change Centre } \\
\text { of Excellence, Australia }\end{array}$ & CSIRO-Mk3.6.0 & $1.875^{\circ} \times 1.875^{\circ}, \mathrm{L} 18$ & 10 \\
\hline
\end{tabular}


Table 1 cont.

\begin{tabular}{|c|c|c|c|}
\hline Modeling Center (or Group) & Model Name & $\begin{array}{l}\text { Grid Spacing (lon } \times \text { lat }), \\
\text { Vertical Levels }\end{array}$ & $\begin{array}{l}\text { Ensemble } \\
\text { Members }\end{array}$ \\
\hline $\begin{array}{c}\text { LASG, Institute of Atmospheric } \\
\text { Physics, Chinese Academy of Sciences } \\
\text { CESS, Tsinghua University }\end{array}$ & $\begin{array}{l}\text { FGOALS-g2 } \\
\text { FGOALS-s } 2\end{array}$ & $\begin{array}{l}2.8125^{\circ} \times 1.666^{\circ}, \mathrm{L} 26 \\
2.8125 \times 3.0^{\circ}, \mathrm{L} 26\end{array}$ & $\begin{array}{l}1 \\
3\end{array}$ \\
\hline $\begin{array}{c}\text { NOAA Geophysical Fluid Dynamics } \\
\text { Laboratory, USA }\end{array}$ & $\begin{array}{c}\text { GFDL-CM3 } \\
\text { GFDL-HIRAM-C180 } \\
\text { GFDL-HIRAM-C360 } \\
\end{array}$ & $\begin{array}{c}2.5^{\circ} \times 2.0^{\circ}, \mathrm{L} 48 \\
0.625^{\circ} \times 0.5^{\circ}, \mathrm{L} 32 \\
0.3125^{\circ} \times 0.25^{\circ}, \mathrm{L} 32\end{array}$ & $\begin{array}{l}5 \\
3 \\
2\end{array}$ \\
\hline $\begin{array}{c}\text { NASA Goddard Institute for Space } \\
\text { Studies }\end{array}$ & GISS-E2-R & $2.5^{\circ} \times 2.0^{\circ}, \mathrm{L} 29$ & 10 \\
\hline $\begin{array}{c}\text { Met Office Hadley Centre, United } \\
\text { Kingdom } \\
\end{array}$ & HadGEM2-A & $1.875^{\circ} \times 1.25^{\circ}, \mathrm{L} 38$ & 6 \\
\hline $\begin{array}{c}\text { Institute for Numerical Mathematics, } \\
\text { Russia }\end{array}$ & INM-CM4 & $2.0^{\circ} \times 1.5^{\circ}, \mathrm{L} 21$ & 1 \\
\hline Institut Pierre-Simon Laplace, France & $\begin{array}{l}\text { IPSL-CM5A-LR } \\
\text { IPSL-CM5A-MR } \\
\text { IPSL-CM5B-LR } \\
\end{array}$ & $\begin{aligned} 3.75^{\circ} & \times 1.875^{\circ}, \mathrm{L} 39 \\
2.5^{\circ} & \times 1.25^{\circ}, \mathrm{L} 39 \\
3.75^{\circ} & \times 1.875^{\circ}, \mathrm{L} 39\end{aligned}$ & $\begin{array}{l}6 \\
3 \\
1 \\
\end{array}$ \\
\hline $\begin{array}{c}\text { Atmosphere and Ocean Research } \\
\text { Institute (The University of Tokyo), } \\
\text { National Institute for Environmental } \\
\text { Studies, and Japan Agency for Marine- } \\
\text { Earth Science and Technology }\end{array}$ & MIROC5 & $1.4^{\circ} \times 1.4^{\circ}, \mathrm{L} 40$ & 2 \\
\hline $\begin{array}{l}\text { Max Planck Institute for Meteorology, } \\
\text { Germany }\end{array}$ & $\begin{array}{l}\text { MPI-ESM-LR } \\
\text { MPI-ESM-MR }\end{array}$ & $\begin{array}{l}1.875^{\circ} \times 1.875^{\circ}, \mathrm{L} 47 \\
1.875^{\circ} \times 1.875^{\circ}, \mathrm{L} 95\end{array}$ & $\begin{array}{l}3 \\
3\end{array}$ \\
\hline $\begin{array}{l}\text { Meteorological Research Institute, } \\
\text { Japan }\end{array}$ & $\begin{array}{l}\text { MRI-AGCM3.2H } \\
\text { MRI-AGCM3.2S } \\
\text { MRI-CGCM3 } \\
\end{array}$ & $\begin{array}{c}0.5625^{\circ} \times 0.5625^{\circ} \\
0.1875^{\circ} \times 0.1875^{\circ} \\
1.125^{\circ} \times 1.125^{\circ}, \mathrm{L} 35 \\
\end{array}$ & $\begin{array}{l}3 \\
1 \\
3\end{array}$ \\
\hline Norwegian Climate Centre & NorESM1-M & $2.5^{\circ} \times 1.875^{\circ}, \mathrm{L} 26$ & 3 \\
\hline
\end{tabular}

\section{Atmospheric Model Intercomparison Project (AMIP)}

The AMIP simulations are uncoupled models with climatologically prescribed sea surface temperature (SST) and sea ice observations. For cloud simulations, the AMIP models are comparable with their coupled counterparts (named Historical Runs), which are linked to fully dynamic ocean models, although both versions have their own biases (Lauer and Hamilton, 2012). Therefore it is suggested that the issues related to clouds and CRF uncertainties are not originating from discrepancies in the representation of SST fields, but rather the cloud simulations themselves, such as in convective and boundary layer cloud parameterizations. A study by Li et al. (2012) has found that the uncoupled models (prescribed SSTs) can produce a more accurate depiction of the field if there are 
no extreme (e.g. ENSO) events. This study focuses on the AMIP runs and evaluates the simulated clouds and respective TOA radiation budgets.

Although the physical parameterization schemes are different for each model, facilitating an intercomparison encourages the application of well-performed parameterization schemes. $\mathrm{Li}$ et al. (2012) provided cloud physics schemes for the models used in their study, of which 11 are evaluated in this study. All modeled and observed results are averaged and interpolated to a standard $2.0^{\circ} \times 2.5^{\circ}$ (latitude $\times$ longitude) grid for a side-by-side comparison and evaluation. A large degree of multimodel spread is apparent in Polar Regions (on average $\sim 42 \%$ in $\mathrm{CF}$ simulations with a maximum of approximately $60 \%$ ), and should be interpreted with caution. We must also acknowledge the intrinsic disadvantage in using monthly mean gridded data. Lin et al. (2010) stated that different cloud types (i.e. convective and stratiform) are likely mixed together at longer time scales and at relatively coarse, non cloud-resolving spatial grids. This will create even larger uncertainty in model-observation comparisons.

\section{Model Ensemble Members}

Each modeling group has the freedom to run their models with different initial conditions and perturbed physics schemes. Every model run that contains a different model framework is to be distinguished from one another by a distinct realization, initialization, and physical scheme number $(\mathrm{r}<\mathrm{N}>\mathrm{i}<\mathrm{M}>\mathrm{p}<\mathrm{L}>)$. The realization number (N) "is used to distinguish among members of an ensemble typically generated by initializing a set of runs with different, but equally realistic, initial conditions" (Taylor et al. 2011). Considering the GCMs used in this study, the realization is most commonly changed within a model-specific ensemble. The initialization number (M) is determined 
by the use of initial conditions, whether from different methods or different observational datasets. Only one model (HadGEM2-A) uses different initial conditions in its ensemble of runs. Lastly, the perturbed physics (L) may also be changed (referring to a unique set of forcing combinations) between ensembles for each model. For example, the GISS-E2$\mathrm{R}$ uses three different perturbed physics in its set of ensemble members. The first scheme uses pre-calculated aerosol and ozone fields where the aerosol indirect effect (AIE) is parameterized. The second option calculates aerosols and atmospheric chemistry as a function of atmospheric state and transient emissions, where AIE is also parameterized. The third and final option is consistent with the second option in terms of calculating the aerosol and atmospheric chemistry; however, the aerosol impact on clouds (and hence the AIE) is actually calculated, not parameterized (Schmidt et al. 2014).

Figure 1a effectively demonstrates the difference in the zonal cloud fraction distribution, and weighted global means, between three ensemble members with a combination of different realizations and physical schemes in the MRI-AGCM3.2H GCM. The ensemble member denoted as r2ilp2 (blue) has the largest global average CF with $62.3 \%$. The first ensemble member (r1i1p1, black) generates the smallest global average CF with $54.6 \%$, resulting in a $7.7 \%$ difference between two ensemble members from the same model. The largest CF discrepancy is apparent in the southern tropics but then values converge at the latitudes $\sim 60^{\circ} \mathrm{S}$. CSIRO-Mk3.6.0 has 10 ensemble members with different realizations (Figure $1 b)$. The global average CF $(67.3 \%)$ is the same for every ensemble member, except for r $1 \mathrm{il} 1 \mathrm{p} 1$ and $\mathrm{r} 4 \mathrm{i} 1 \mathrm{p} 1$ where the global average is $0.1 \%$ less. Little, if any, spread in the zonal CF distribution is noticeable through all latitudes except at the poles $\left(>80^{\circ} \mathrm{N} / \mathrm{S}\right)$ where some separation is visible. 

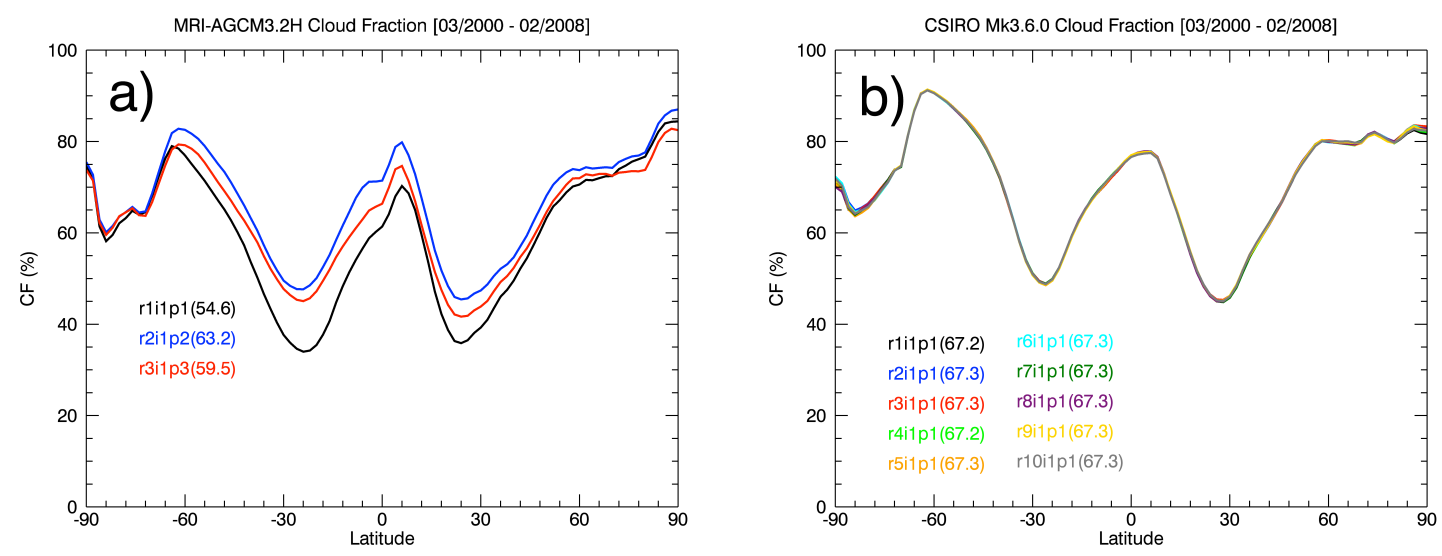

Figure 1. The zonal cloud fraction distribution from several ensemble members in two GCMs, MRI-AGCM3.2H (a) and CSIRO Mk3.6.0 (b), during the time period of this study. The effects of different physical schemes, initializations, and realizations are portrayed. Each colored line represents a different ensemble member and the values in parenthesis are the weighted global means.

Although some models may have several ensemble members (right-most column of Table 1), the first output member is used for the analysis of each specific model (i.e. r1ilp1). There is no systematic approach for determining which model in the ensemble to choose; therefore, the first available simulation run is selected. The difference between ensemble members was not thoroughly examined and could potentially provide a different result in this study. Determining the differences between ensemble members would be an extremely cumbersome task but should be investigated.

\section{Evaluated Variables}

As the title of the manuscript suggests, this study evaluates the observed and multiple GCM simulated clouds and TOA radiation budgets. The model outputs are available on several different temporal scales (3-hourly, 6-hourly, daily, and monthly) depending on the model. This study utilizes the monthly averaged model output to study the long-term, large-scale effects of clouds on the TOA radiation budget. This section attempts to better explain what these parameters are, physically, and the method for 
determining them in the observations and model simulations. It is imperative that the definitions of each variable in both the observations and model simulations be consistent, so that a reasonable comparison can be made. Some adjustments have been made and will be noted. Table 2 lists all available variables from the AMIP GCM simulations chosen for this study.

Total cloud fraction (clt) is the overall distribution (horizontal only) of clouds. More specifically, total cloud fraction is the percentage of a grid box covered by cloudy pixels from a top-view (meaning that there could be overlapping clouds contributing to the overall cloud fraction). Condensed water path (clwvi) is what we call CWP in this study. The models describe CWP to be the mass of condensed (liquid + ice) water in the column divided by the area of the column (not just the area of the cloudy portion of the column). This includes hydrometeors only if the precipitating hydrometeor affects the calculation of radiative transfer in the model. CERES MODIS (CM) observed CWP has been normalized by the cloud fraction observations since the passive sensor cannot differentiate between liquid and ice clouds. Therefore, the observed CWP is the sum of ice and liquid water path multiplied by the cloud fraction $([\mathrm{IWP}+\mathrm{LWP}] \times \mathrm{CF})$.

The simulated TOA outgoing LW/SW radiation (rlut/rsut) and the clear-sky counterparts (rlutcs/rsutcs) are needed for the calculation of TOA CRFs. Again, the radiation budget for each grid box is averaged to output a single value. Ramanathan et al. (1989) defines TOA CRFs to be the difference between clear- and all-sky radiation fluxes (clear - all). CERES EBAF provides monthly means of clear- and all-sky TOA radiation fluxes, where we can calculate SW and LW CRFs using the CRF definition. 
Table 2. GCM simulated variables available from the suite of models chosen for this study. The variable long name is listed along with its corresponding CMIP5 abbreviation. Variables denoted with a ${ }^{*}$ are those evaluated in this study.

\begin{tabular}{|c|c|c|c|}
\hline Variable Long Name & Abbreviation & Variable Long Name & Abbreviation \\
\hline Cloud Fraction Area & $\mathrm{cl}$ & $\begin{array}{l}\text { TOA Outgoing Longwave } \\
\text { Radiation }\end{array}$ & rlut $*$ \\
\hline Mass Fraction of Cloud Ice & cli & $\begin{array}{l}\text { TOA Outgoing Longwave } \\
\text { Radiation (Clear-Sky) }\end{array}$ & rlutcs * \\
\hline Ice Water Path & clivi & $\begin{array}{l}\text { Surface Downwelling Shortwave } \\
\text { Radiation }\end{array}$ & rsds \\
\hline Total Cloud Fraction & clt $*$ & $\begin{array}{l}\text { Surface Downwelling Shortwave } \\
\text { Radiation (Clear-Sky) }\end{array}$ & rsdscs \\
\hline $\begin{array}{l}\text { Mass Fraction of Cloud Liquid } \\
\text { Water }\end{array}$ & $\mathrm{clw}$ & TOA Incident Shortwave Radiation & rdst \\
\hline Condensed Water Path & clwvi * & $\begin{array}{l}\text { Surface Upwelling Shortwave } \\
\text { Radiation }\end{array}$ & rsus \\
\hline Evaporation & evspsbl & $\begin{array}{l}\text { TOA Outgoing Shortwave } \\
\text { Radiation }\end{array}$ & rsut $*$ \\
\hline $\begin{array}{l}\text { Surface Upward Latent Heat } \\
\text { Flux }\end{array}$ & hfls & $\begin{array}{l}\text { TOA Outgoing Shortwave } \\
\text { Radiation (Clear-Sky) }\end{array}$ & rsutcs * \\
\hline $\begin{array}{l}\text { Surface Upward Sensible Heat } \\
\text { Flux }\end{array}$ & hfss & $\begin{array}{l}\text { Net Downward Flux at Top of } \\
\text { Model }\end{array}$ & rtmt \\
\hline Relative Humidity & hur & Air Temperature & ta \\
\hline Specific Humidity & hus & Near-Surface Air Temperature & tas \\
\hline Near-Surface Specific Humidity & huss & $\begin{array}{l}\text { Daily Maximum Near-Surface Air } \\
\text { Temperature }\end{array}$ & tasmax \\
\hline Precipitation & $\mathrm{pr}$ & $\begin{array}{l}\text { Daily Minimum Near-Surface Air } \\
\text { Temperature }\end{array}$ & tasmin \\
\hline Convective Precipitation & prc & $\begin{array}{l}\text { Surface Downward Eastward Wind } \\
\text { Stress }\end{array}$ & tauu \\
\hline Snowfall Flux & prsn & $\begin{array}{l}\text { Surface Downward Northward } \\
\text { Wind Stress }\end{array}$ & tauv \\
\hline Water Vapor Path & prw & Mole Fraction of $\mathrm{O}_{3}$ & tro3 \\
\hline Surface Air Pressure & ps & Surface Temperature & ts \\
\hline Sea Level Pressure & psl & Eastward Wind & ua \\
\hline $\begin{array}{l}\text { Surface Downwelling } \\
\text { Longwave Radiation }\end{array}$ & rlds & Northward wind & va \\
\hline $\begin{array}{l}\text { Surface Downwelling } \\
\text { Longwave Radiation (Clear- } \\
\text { Sky) }\end{array}$ & rldses & Omega $(=\mathrm{dp} / \mathrm{dt})$ & wap * \\
\hline $\begin{array}{l}\text { Surface Upwelling Longwave } \\
\text { Radiation }\end{array}$ & rlus & Geopotential Height & $\mathrm{zg}$ \\
\hline
\end{tabular}

The last parameter relevant to this study is the omega (wap) field at $500 \mathrm{hPa}$. Satellites do not directly measure vertical velocities; therefore, reanalyses are used to reference the model-simulated values. More on the reanalysis is presented in the next section. Although a comprehensive analysis is not performed on the simulated omega 
field, it is still important to determine whether the models simulate vertical velocities with relative accuracy.

\section{NASA Satellite Observations}

Satellites can provide a global view of cloud and radiation fields through either direct observations or retrieved from physical and empirical methods. These global satellite products are an excellent tool for evaluating past and current climate model simulations (within the range of historical satellite observations). However, the uncertainties and potential biases of these products must be understood before they are used as a reference for comparison. Table 3 offers a quick glance into the observational data products used in this study and their associated uncertainties.

\section{Clouds and Earth's Radiant Energy System (CERES)}

As being one of the highest priority scientific satellite systems for observing the Earth, CERES can provide global measurements of TOA and surface, reflected (solar) shortwave and emitted terrestrial longwave radiation. Satellites equipped with instruments capable of providing co-located (spatial and temporal) cloud and radiation measurements are of great interest to this type of evaluation study. There are two satellites equipped with this type of setup, Terra and Aqua, and are near-polar orbiting (at an altitude of $705 \mathrm{~km}$ ) and sun synchronous. The CERES instrument has three spectral channels; a SW channel that ranges from $0.3-5.0 \mu \mathrm{m}$ to measure reflected sunlight (SW flux), a window channel to measure the Earths emitted LW radiation is contained within $8-12 \mu \mathrm{m}$, and the total spectral range spans from 0.3 to $>100 \mu \mathrm{m}$. Filtered radiance measurements are converted from raw counts with a complex algorithm taking into account several corrections (spectral, geometric, sensor, etc.) (Cooper et al. 2013). 


\section{Moderate Resolution Imaging Spectroradiometer (MODIS)}

This study applies eight years (March 2000 - February 2008) of monthly mean combined MODIS retrievals from two satellites, Terra and Aqua, for the evaluation of total column CF and CWP (liquid and ice water). The data used for this study is from the Level-3 SYN1deg product, Edition 2.6 and is gridded to a $1.0^{\circ} \times 1.0^{\circ}$ (latitude $\times$ longitude) grid. MODIS has 36 spectral channels ranging from visible to thermal infrared (IR) wavelengths $(0.4-14.4 \mu \mathrm{m})$. The swath width is $2330 \mathrm{~km}$ across track with a $10 \mathrm{~km}$ along track at nadir width. Spatial resolutions are available at 250, 500, and $1000 \mathrm{~m}$ for certain spectral bands. Cloud properties are generally derived from channels in the near- to thermal IR bands $(\sim 3.6-14.4 \mu \mathrm{m})$.

Due to the large uncertainties in nighttime CWP retrievals $\left(>50 \mathrm{gm}^{-2}\right)$, only daytime retrievals are used for the evaluation of CF and CWP (Stanfield et al. 2014). The CERES-MODIS (CM) cloud properties have been extensively validated with other spaceborne satellites (Minnis et al. 1999, 2002, 2011) and ground-based measurements (Dong et al. 2008a; Xi et al. 2010, 2014). For example, Dong et al. (2008a) documented the uncertainties in the CM retrieved cloud liquid water path (LWP) and found that the mean differed by $0.6 \pm 49.9 \mathrm{gm}^{-2}$ when compared to the Department of Energy (DOE) Atmospheric Measurement (ARM) program ground-based microwave radiometer retrieved LWPs at the Southern Great Plains (SGP) Central Facility site. Minnis et al. (2011b) found that the CM LWP over the ocean was, on average, $0.2 \pm 53.6 \mathrm{gm}^{-2}$ less than the LWP from matched overcast Advanced Microwave Scanning Radiometer Earth Observing System (AMSR-E) footprints. CM ice water path (IWP) retrievals show an average negative bias of $3.3 \pm 16.2 \mathrm{gm}^{-2}$ when compared to ground-based radar 
measurements (Mace et al. 2005). A more detailed survey of CM cloud microphysical property descriptions and uncertainties shall be found in Minnis et al. (2011b).

\section{Energy Balanced And Filled (EBAF)}

The CERES Energy Balanced and Filled at the TOA (EBAF-TOA) Edition 2.7 dataset (Loeb et al. 2012; Doelling et al. 2013) is used for radiation budget and CRF comparisons in this study. The CERES-EBAF-TOA is an expansion of the CERES SYN1deg product designed for climate modelers that require a net imbalance constrained to the ocean heat storage term (Hansen et al. 2005). Edition 2.7 was released during the summer of 2013 with improvements in TOA clear-sky SW and LW fluxes in the regions with snow and sea-ice cover. CERES EBAF clear- and all-sky radiation budgets are differentiated by cloud imager (from MODIS) classifications, where $99 \%$ of the pixels in a $20 \mathrm{~km}$ footprint are to be classified as clear.

\section{International Satellite Cloud Climatology Project (ISCCP)}

The International Satellite Cloud Climatology Project (ISCCP) provides another passive remote sensing CF product for comparison. The ISCCP CF has an estimated uncertainty of $\sim 10 \%$ (Rossow et al. 1993; Han et al. 1994). Although no comprehensive analysis is performed with the ISCCP CF as a reference in this study, the excellent agreement between CM and ISCCP CFs (global average difference $\sim 0.1 \%, \mathrm{R}^{2}=0.84$ ) may provide more confidence for modelers to use the long-term ISCCP results to evaluate their cloud-climate simulations in the future.

\section{CloudSat and Cloud-Aerosol Lidar and Infrared Pathfinder Satellite Observation (CALIPSO)}

In addition to the $\mathrm{CM}$ and ISCCP cloud products, the integrated CloudSat, CALIPSO, CERES, and MODIS (CCCM) Rel1B merged lidar/radar product provides 
instantaneous retrieved cloud properties and vertical profiles in the CloudSat/CALIPSO (CC) ground track (Kato et al. 2010). For this study, only the CC cloud fractions from this product have been compared with other observations and GCMs because no statistical difference between the MODIS-in-CC swath and Single Scanner Footprint (SSF) products has been found (Xi et al. 2014). The CC CF data are from the CCCM dataset where the uncertainty of CC combined cloud fraction profiles has been estimated to be $5 \%$ (Mace et al. 2005; Su et al. 2013). Although the CCCM data product represents a time period different than that of the other observations and model simulations, the record represents the recent annual cloud fraction climatology, which has been used to establish representative statistics for model-observation comparisons (e.g. Jiang et al. 2012; Li et al. 2012; Su et al. 2013).

CloudSat is equipped with a $94-\mathrm{GHz}$ cloud profiling radar (CPR) that vertically derives the amount of backscatter from clouds with a limitation of detecting clouds below $1 \mathrm{~km}$ and optically thin clouds $(\tau<0.3)$. Similarly, the Cloud-Aerosol Lidar with Orthogonal Polarization (CALIOP) cloud profiling lidar on board CALIPSO operates like a ground-based micropulse lidar (MPL) at either 532 or $1064 \mathrm{~nm}$ wavelengths with high sensitivity to detect optically thin clouds but its signals are attenuated within optically thick clouds. Since CALIPSO (an active sensor; lidar) is more sensitive than CM (passive remote sensor) to optically thin clouds (optical depth, $\tau<0.3$ ) (Chiriaco et al. 2007; Minnis et al. 2008), we use the CC derived CF as an upper bound. The CC dataset offers vertically derived and total column CFs, however, only total column $\mathrm{CF}$ is used in this study. 
Table 3. Level-3 Global monthly mean gridded data products. Reference: a. Minnis et al. (2011b); b. Rossow and Schiffer (1999); c. Mace et al. (2009); d. CERES EBAF Ed2.7 Data Quality Summary

\begin{tabular}{|c|c|c|c|}
\hline Satellite Product & Original Grid Spacing & Complete Temporal Extent & $\begin{array}{l}\text { Standard Error/ } \\
\text { Uncertainty }\end{array}$ \\
\hline CERES-MODIS & $1.0^{\circ} \times 1.0^{\circ}$ & $03 / 2000-12 / 2011$ & \\
\hline$C F$ & & & $7 \%{ }^{a}$ \\
\hline$C W P$ & & & $15 \%{ }^{\mathrm{a}}$ \\
\hline ISCCP & $2.5^{\circ} \times 2.5^{\circ}$ & $07 / 1983-12 / 2009$ & \\
\hline$C F$ & & & $<5 \%{ }^{\mathrm{b}}$ \\
\hline CloudSat/CALIPSO & $2.0^{\circ} \times 2.5^{\circ}$ & $07 / 2006-06 / 2010$ & \\
\hline$C F$ & & & $5 \%{ }^{c}$ \\
\hline CERES EBAF (TOA) & $1.0^{\circ} \times 1.0^{\circ}$ & $03 / 2000-02 / 2013$ & \\
\hline Reflected SW (all-sky) & & & $4.0 \mathrm{Wm}^{-2 \mathrm{~d}}$ \\
\hline Reflected SW (clear-sky) & & & $2.6 \mathrm{Wm}^{-2 \mathrm{~d}}$ \\
\hline Outgoing LW (all-sky) & & & $2.0 \mathrm{Wm}^{-2 \mathrm{~d}}$ \\
\hline Outgoing LW (clear-sky) & & & $3.6 \mathrm{Wm}^{-2 \mathrm{~d}}$ \\
\hline
\end{tabular}

\section{NASA Reanalysis}

\section{Modern Era Retrospective Analysis for Research and Applications (MERRA)}

MERRA reanalysis focuses on analyzing the hydrological cycle on different weather and climate time scales (Rienecker et al. 2011). In short, the reanalyzed dataset is a result of assimilating approximately $2 \times 10^{6}$ randomly distributed observations from radiosondes, satellites, and surface-based instrumentation into a model. The data are available during the satellite era, 1979 through the present day (with some time lag of a couple months). The analysis is performed on a $0.66^{\circ} \times 0.5^{\circ}$ (longitude $\times$ latitude) horizontal grid on 72 vertical levels (Lucchesi et al. 2012). The data can be temporally averaged from hourly to monthly time scales, and can also be spatially averaged from coarser horizontal and vertical grid spacings (e.g. $1.25^{\circ} \times 1.25^{\circ}$ and 42 vertical levels). Only the reanalyzed vertical velocities are used in this analysis, although many other 
variables are available, such as temperature, pressure, and horizontal wind fields, among others. 


\section{CHAPTER III}

\section{RESULTS}

The current status of simulated cloud properties, CF and CWP, and their corresponding effects on TOA radiation budgets are evaluated and shown in this section. The purpose is to identify the biases and deterministic relationships between observations and the model simulations, and to provide aid to the advancement of model development. Multimodel ensemble means are used frequently in this analysis. The reader should be aware that this multimodel ensemble mean is simply the average of all 28-modeled values at each (common interpolated) grid box to form a single solution for comparison. Additionally, global means are area-weighted averages using the cosine of latitude as weighting. This section is split into two parts; the first emphasizes on global evaluations, biases and distribution characteristics, to determine the current state of climate simulations. The second section focuses on the tropics and mid-latitudes; detailing specific relationships between observed characteristics and how they are simulated in the models, and ultimately quantifies the errors in the simulations.

\section{Global Evaluation Study}

\section{Cloud Fraction and Cloud Water Path}

Satellite derived and model simulated global CFs are shown in Figure 2a. The modeled CFs are, on average, under estimated by 6.9 and $6.8 \%$ when compared to $\mathrm{CM}$ and ISCCP results, respectively, with an even larger negative bias when compared to CC $(-16.7 \%)$. Given the high sensitivity of CC to optically thin cirrus clouds, the CC CF 
result can be used as the upper bound of satellite observations and model simulations. Similar to Stanfield et al. (2014), CC derived CF would be close to both CM and modeled CF values if its results were averaged only with cloud optical depths $>0.3$ (not shown). Furthermore, the standard deviation $(\sigma=5.8 \%)$ of models CFs does not fall within the range of observations. Only four model (CSIRO-Mk3.6.0 and the three GFDL models; C180, C360, and CM3) simulated CFs are slightly larger than the CM and ISCCP results, while none are larger than the CC CF.

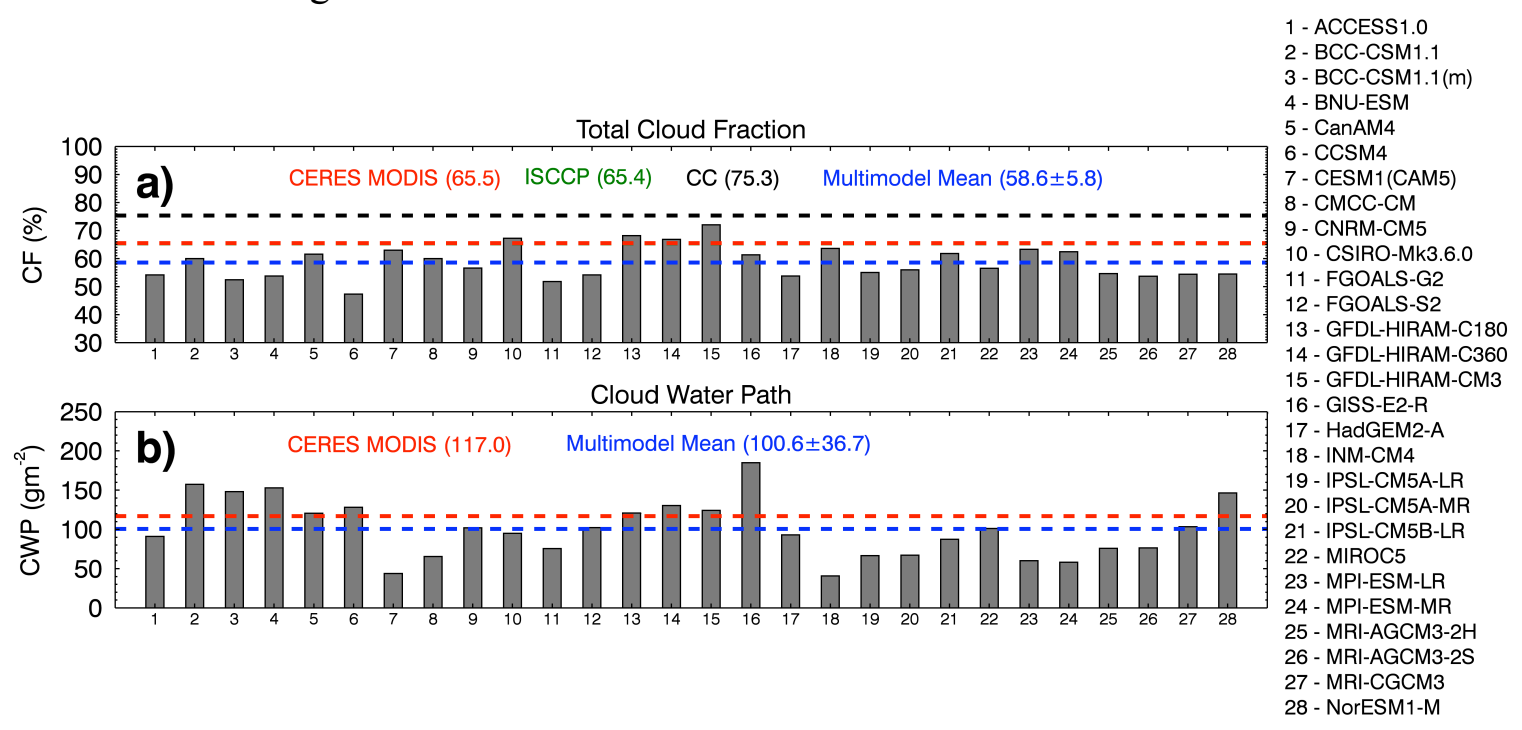

Figure 2. The globally averaged cloud fraction (a) and cloud water path (b) from 28 AMIP models (grey bars) and satellite observations; CERES MODIS (red), ISCCP (green), and CloudSat/CALIPSO (black). The blue dashed line signifies the multimodel ensemble mean. The standard deviations of the simulated results are also noted.

The CWP comparison (Figure 2b) is similar to the CF comparison in that the multimodel ensemble mean is under estimated $\left(-16.4 \mathrm{gm}^{-2}\right)$ when compared to CM. The standard deviation $\left(\sigma=36.7 \mathrm{gm}^{-2}\right)$ of the modeled results is rather large due to the broad range of modeled results from a minimum of 40.7 (INM-CM4) and to a maximum of $184.8 \mathrm{gm}^{-2}$ (GISS-E2-R). Ten models (BCC-CSM1.1, BCC-CSM1.1 (m), BNU-ESM, CanAM4, CCSM4, GFDL: C180, C360, and CM3, GISS-E2-R, and NorESM1-M) have simulated CWPs larger than observations. 
To study their latitudinal variations, the zonally averaged CF and CWP simulations and observations are shown in Figure 3. Most model simulated CFs and the multimodel ensemble mean agree fairly well with both CM and ISCCP CFs in the tropics $\left(5^{\circ} \mathrm{S}-15^{\circ} \mathrm{N}\right)$, but then begin to diverge pole ward with a large discrepancy in the southern mid-latitudes, consistent with Stanfield et al. (2014). Again, the CC derived CF is an upper bound of model simulated CFs and only a few models exceed the CC result (at higher latitudes). Large multimodel spread in the CF simulations is apparent in the polar latitudes, as illustrated by the large grey shaded areas in Figure 3a.
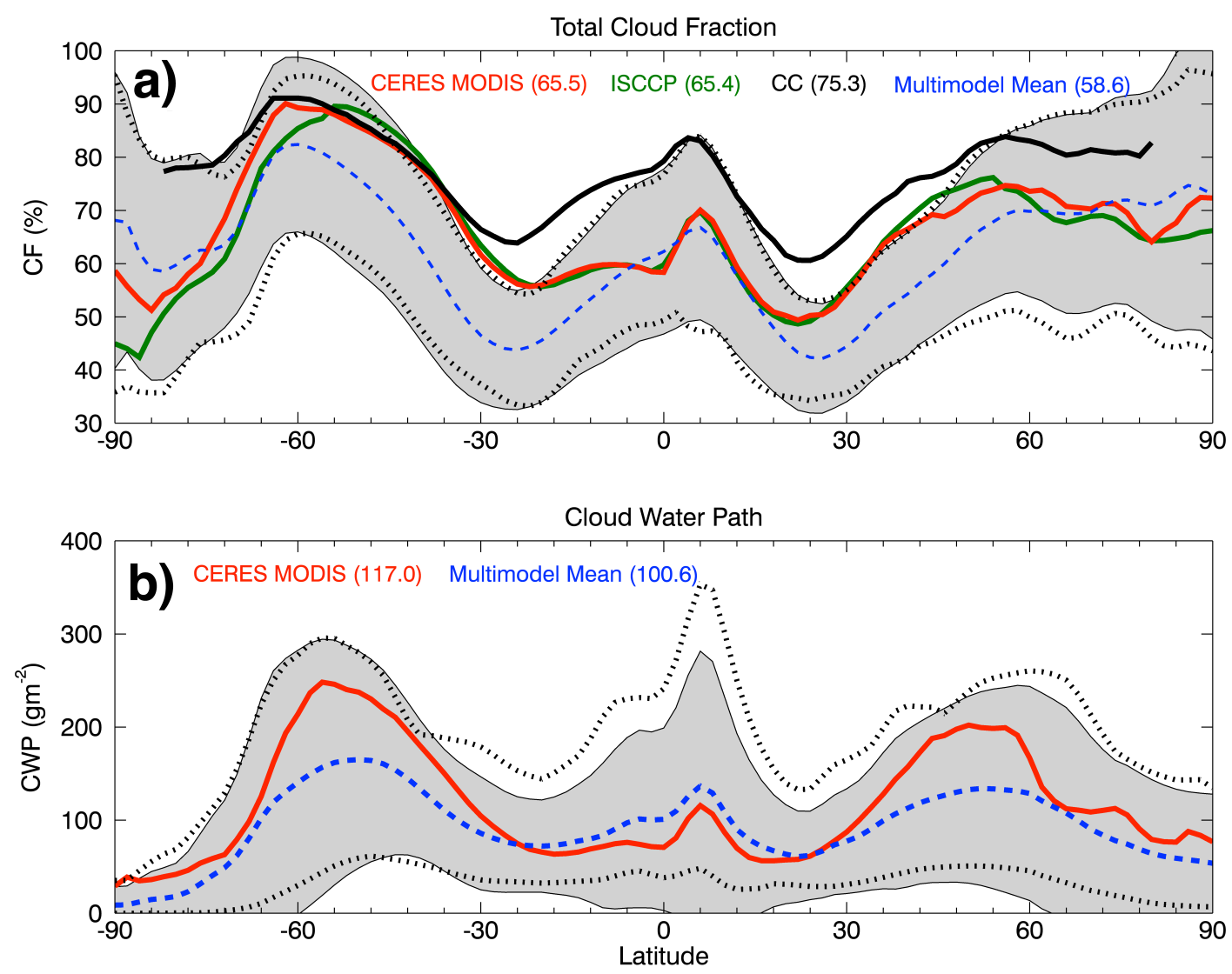

Figure 3. The zonal cloud fraction (a) and cloud water path (b) distribution from CERESMODIS (red), ISCCP (green), CloudSat/CALIPSO (black), and the multimodel ensemble mean (blue). The grey shaded area represents the $2 \sigma$ of the model simulations and the black dotted lines are the maximum and minimum simulated values. Values in parenthesis correspond to the weighted global mean. 
Figure $3 b$ displays the zonal distribution of CWP in the model simulations and observations form CM. The multimodel ensemble mean is slightly larger than the CM result in the tropics (between $\sim 20^{\circ} \mathrm{N} / \mathrm{S}$ ) then transition to values less than what is observed by CM. A large degree of multimodel spread in the CWP results exists in the mid-latitudes as evidenced by the broad grey shaded area ( $2 \sigma$ standard deviation). CWP is the sum of liquid and ice water paths, as previously stated. CM does not differentiate between ice and liquid clouds, therefore, these characteristics have not been explicitly evaluated in this study, however, Stanfield et al. (2014) elaborates on the distinction between ice and liquid water paths, and the discrepancies between CloudSat observations and those simulated in a single GCM (GISS-E2-R). Their analysis suggests that IWP (LWP) is generally over (under) estimated in the tropics where the opposite holds true in the mid- and high-latitudes, at least in the one GCM. It could be beneficial to evaluate our ensemble to determine whether any systematic errors exist.

Global distributions of the observed and multimodel simulated CFs and CWPs are exhibited in Figure 4. Their regional biases are also pictured to easily identify geographic areas of repeated deficiencies in this suite of models. An over estimation of $\mathrm{CF}$ is apparent in higher latitudes indicated by the positive (Figure 4c, red) values, especially over the Antarctic continent (bias $\geq 25 \%$ ) and a slightly positive bias around the northern pole (upwards of $12 \%$ ) where the Arctic ice sheet is present during most of the year. $\mathrm{CM}$ retrievals are less reliable in these regions due to the snow/ice covered surfaces, temperature inversions, and no direct sunlight during the winter. Therefore, the $\mathrm{CM}$ retrievals at latitudes greater than about $65^{\circ}$ should be used with caution. 

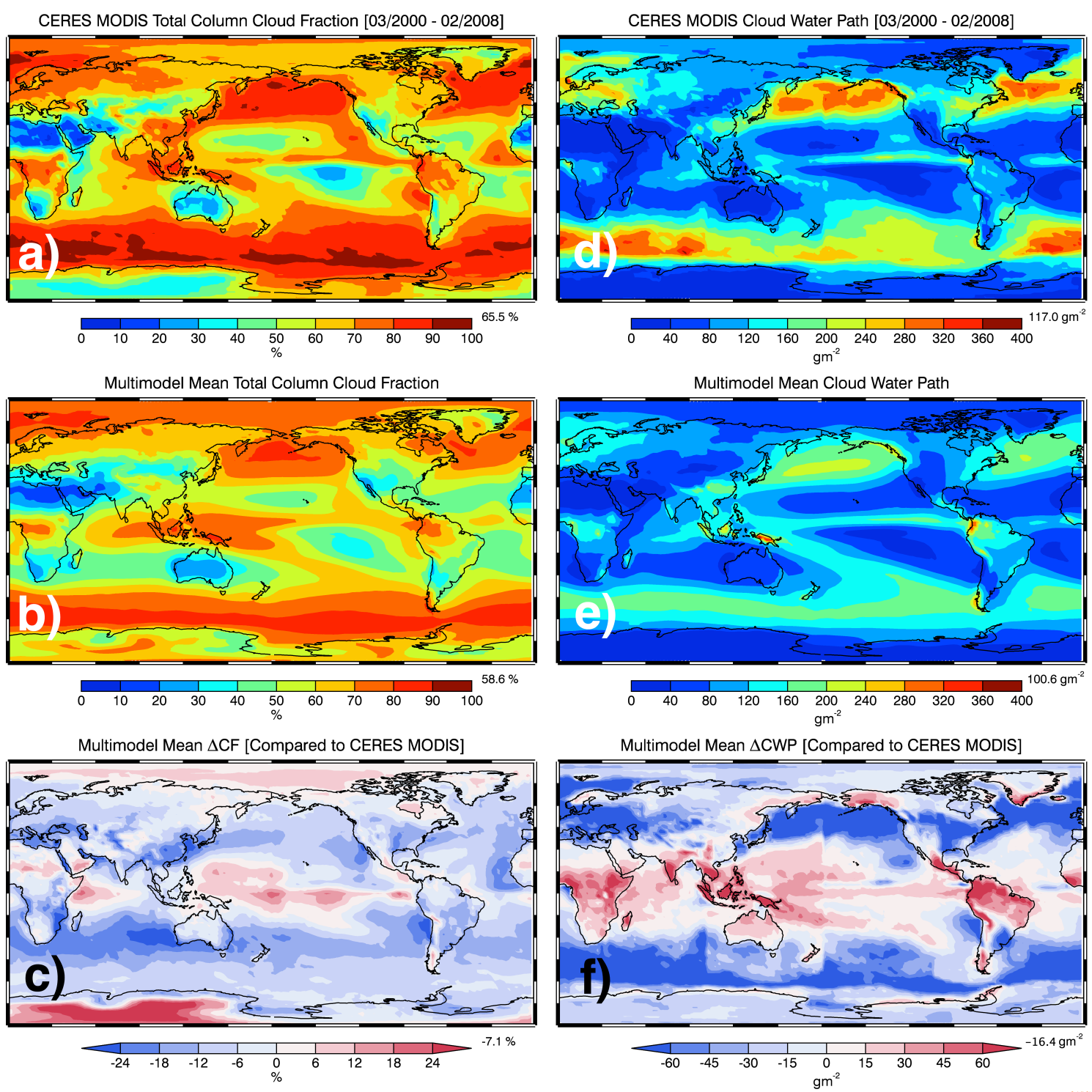

Figure 4. Global distributions of the observed cloud fraction (a) and cloud water path (d), the multimodel ensemble simulated CF (b) and CWP (e), and the multimodel ensemble simulated biases (model minus observations, $\Delta$ ) in CF (c) and CWP (f). Global averages are also noted in the bottom right corner of each map.

As demonstrated in Figure 4c, the modeled CF is under estimated in the midlatitudes over both the ocean and land areas. The slight over estimation of CF centered at the equator is contained mainly to the Pacific Ocean at the Intertropical Convergence Zone (ITCZ) and over some landmass, such as the Saharan Desert. Consistent with Figure $3 \mathrm{~b}$, the positive bias in CWP is constrained to the tropics (ocean and land); however, there are some regions outside of the tropics where CWP is over estimated (e.g. 
Alaska, Southern Greenland, and Southern South America). The areas with the largest over estimates (bias $\geq 60 \mathrm{gm}^{-2}$ ) of CWP are the East Indies and Northern South America. Otherwise, CWP is greatly under estimated, especially in the Southern Ocean (bias $\leq$ $\left.-60.0 \mathrm{gm}^{-2}\right)$.

\section{Top-of-Atmosphere (TOA) Radiation Budgets}

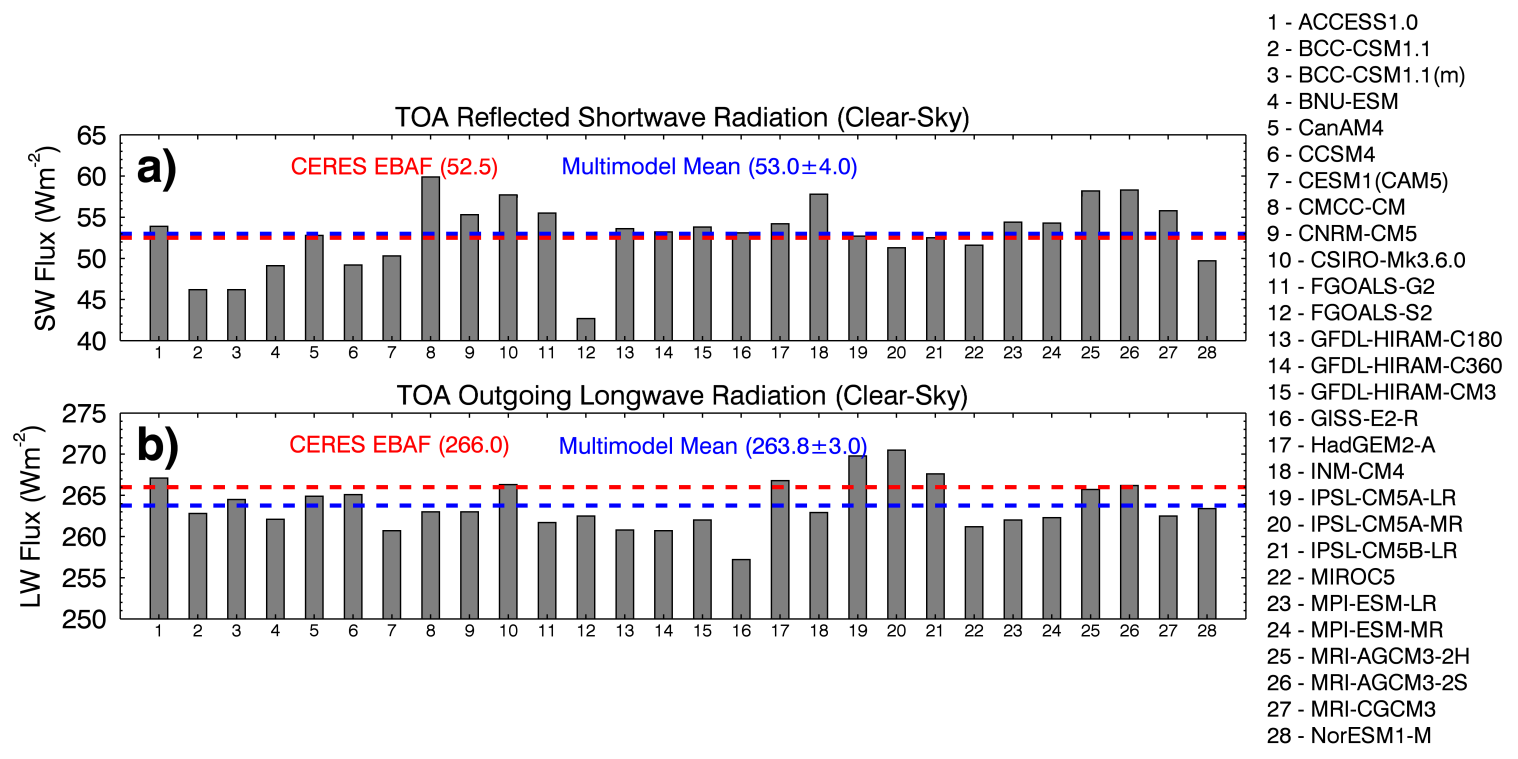

Figure 5. Same as Figure 2 but for the global means in simulated and observed (CERES EBAF) TOA reflected shortwave (a) and outgoing longwave fluxes (b) under clear-sky conditions.

Clear-Sky. The clear-sky radiation budgets are needed for calculating TOA CRFs because they will serve as reference to the all-sky conditions when investigating how clouds affect the radiation budget (TOA or surface). It is a well-known fact that clear-sky radiation budgets strongly depend on the surface type, such as land, ocean, snow etc., with some influence from the emissive and absorptive properties of the atmosphere. The observed global TOA clear-sky reflected SW and outgoing LW fluxes are 52.5 and 266.0 $\mathrm{Wm}^{-2}$, respectively (Figure 5). The multimodel ensemble mean results are 53.0 \pm 4.0 and $263.8 \pm 3.0 \mathrm{Wm}^{-2}$, respectively. Several models' simulated clear-sky SW and LW results 
fall outside of the 1-sigma standard deviation range, and should be investigated further (i.e. FGOALS-S2 for the SW flux and IPSL-CM5A-LR for the LW flux).
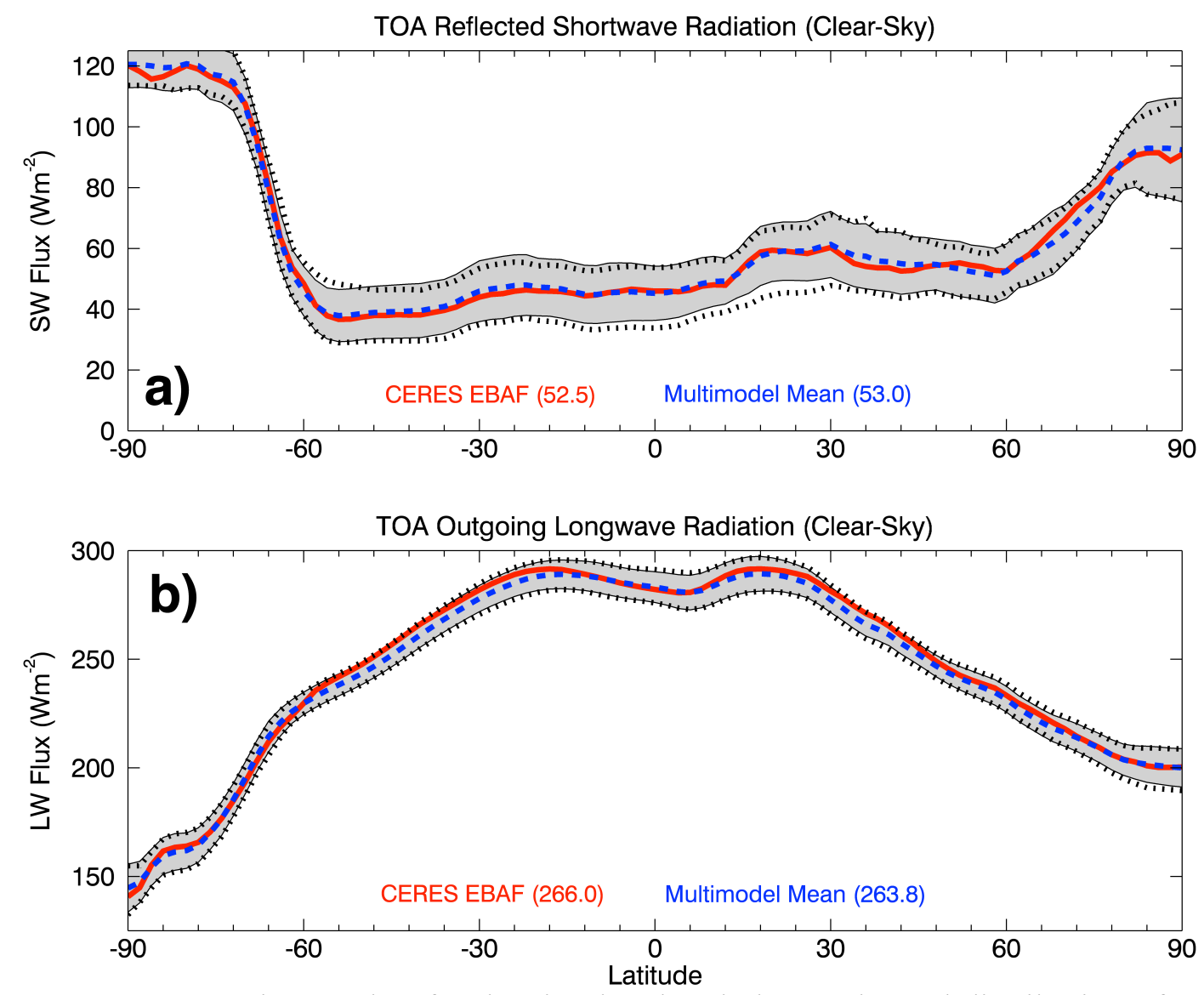

Figure 6. Same as Figure 3 but for the simulated and observed zonal distribution of TOA reflected shortwave (a) and outgoing longwave (b) fluxes under clear-sky conditions.

Figure 6 presents the zonal distribution of the clear-sky TOA radiation fluxes. The TOA reflected SW flux does not deviate too much between $60^{\circ} \mathrm{N} / \mathrm{S}$ but increases significantly toward to the southern and northern poles. This increase is primarily a result of the increased surface albedo due to the longer periods of snow and ice covered surfaces toward to the poles. It is reasonable to have higher TOA reflected SW flux over the Antarctic region than the Arctic region because of its permanent snow/ice covered surfaces, while the Arctic has a seasonal variation of sea ice. The oceans control surface albedos fairly well, explaining the little deviation between $60{ }^{\circ} \mathrm{N} / \mathrm{S}$. There is a slight 
increase in the SW flux in the northern hemisphere because of the larger percentage of landmass (and increase in surface albedo, especially during the wintertime). The model simulations depict these conditions with accuracy; however, there is relatively large multimodel spread in the Polar Regions. The observed and simulated clear-sky LW radiation results follow the same general pattern and are mainly controlled by the surface emitted temperature; a unimodal distribution where the maximum occurs in the tropics and the minimum values are at the poles, with the LW flux over the southern pole being $50 \mathrm{Wm}^{-2}$ less than that over the northern pole.

Figure 7 clearly illustrates the global distributions of the TOA fluxes under clearsky conditions. The SW clear-sky radiation (left panels) is governed by the land-ocean contrast, with higher flux values over the land areas because of their higher surface albedos. The overall distribution is simulated fairly well by the models over the oceans (bias $\leq 4.0 \mathrm{Wm}^{-2}$ ). Over land, the models also do a fairly good job in most areas except for a few regions. The areas over the Saharan Desert, the Arabian Peninsula, the East Indies, and parts of Northern North America have a relatively large under estimation of clear-sky SW radiation at the TOA (bias $\leq-16 \mathrm{Wm}^{-2}$ ). Conversely, areas such as the Tibetan Plateau and the Pacific Coast of Alaska are greatly over estimated by approximately the same amount (bias $\geq 16 \mathrm{Wm}^{-2}$ ).

A stratification of the clear-sky LW flux is visible in the observations (Figure 7d) from CERES EBAF and in the model simulations, with larger flux values in the tropics and decreases toward the poles. Again, the clear-sky LW is mainly a result of surface emitted temperatures, so we can expect this result. Oceanic regions are consistently 
under estimated, with an exception in the Southern Ocean around Antarctica where the

LW flux is over estimated. There is a dipole in the bias over South America where the
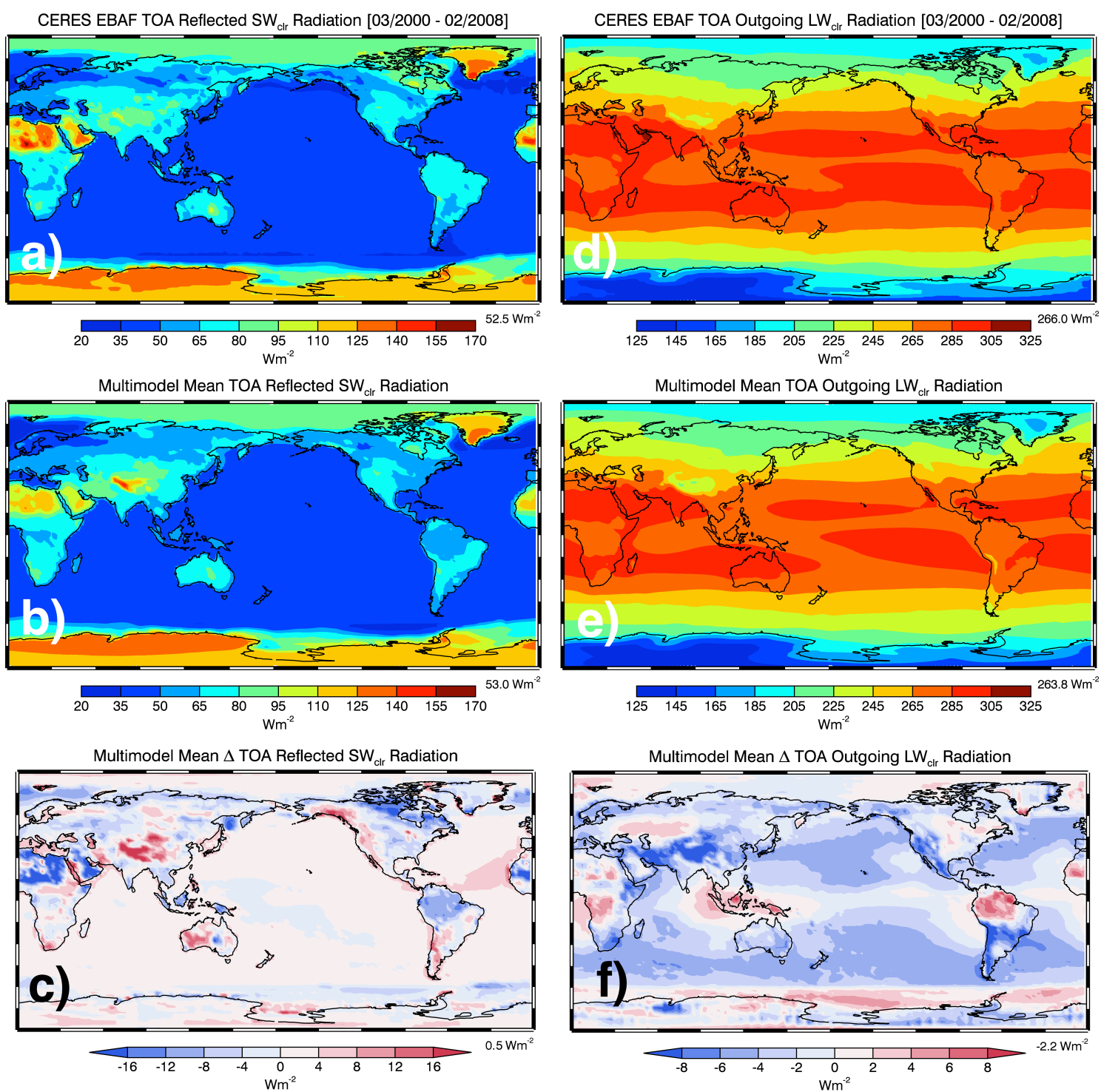

Figure 7. Same as Figure 4 but for the observed, simulated, and simulated bias maps of shortwave (left) and longwave (right) clear-sky results.

northern half is over estimated and the southern half is under estimated, potentially due to different surface and land coverage (i.e. rainforest in the North and primarily agriculture and farming in the South). An over estimation of the LW clear-sky flux is apparent in the East Indies where an under estimation occurs in the Tibetan Plateau area. These regions 
with large biases should be of interest to modelers to develop better parameterizations and decrease the discrepancies in later versions on CMIP.

All-Sky. Figures 8a and 8b show the modeled and CERES EBAF observed global mean TOA all-sky SW and LW fluxes, with averaged differences of $1.6 \pm 3.0$ and $-0.9 \pm$ 2.9 $\mathrm{Wm}^{-2}$, respectively. Although the differences between ensemble means and observations are small, a few model results are not physically consistent with their CF and CWP comparisons. The TOA radiative fluxes, in particular the reflected SW flux, depend primarily on CF and CWP. A good agreement in the reflected SW flux should be consistent with good agreements in both CF and CWP (e.g. CanAM4), or complementary between CF and CWP, such as lower (higher) CF and larger (smaller) CWP (e.g. BCCCSM1.1(m), BNU-ESM, GISS-E2-R, or NorESM1-M), to achieve radiative balance. However, it does not make sense, physically, if the good agreement in reflected SW flux follows the same bias in both $\mathrm{CF}$ and CWP, as illustrated in the simulations of

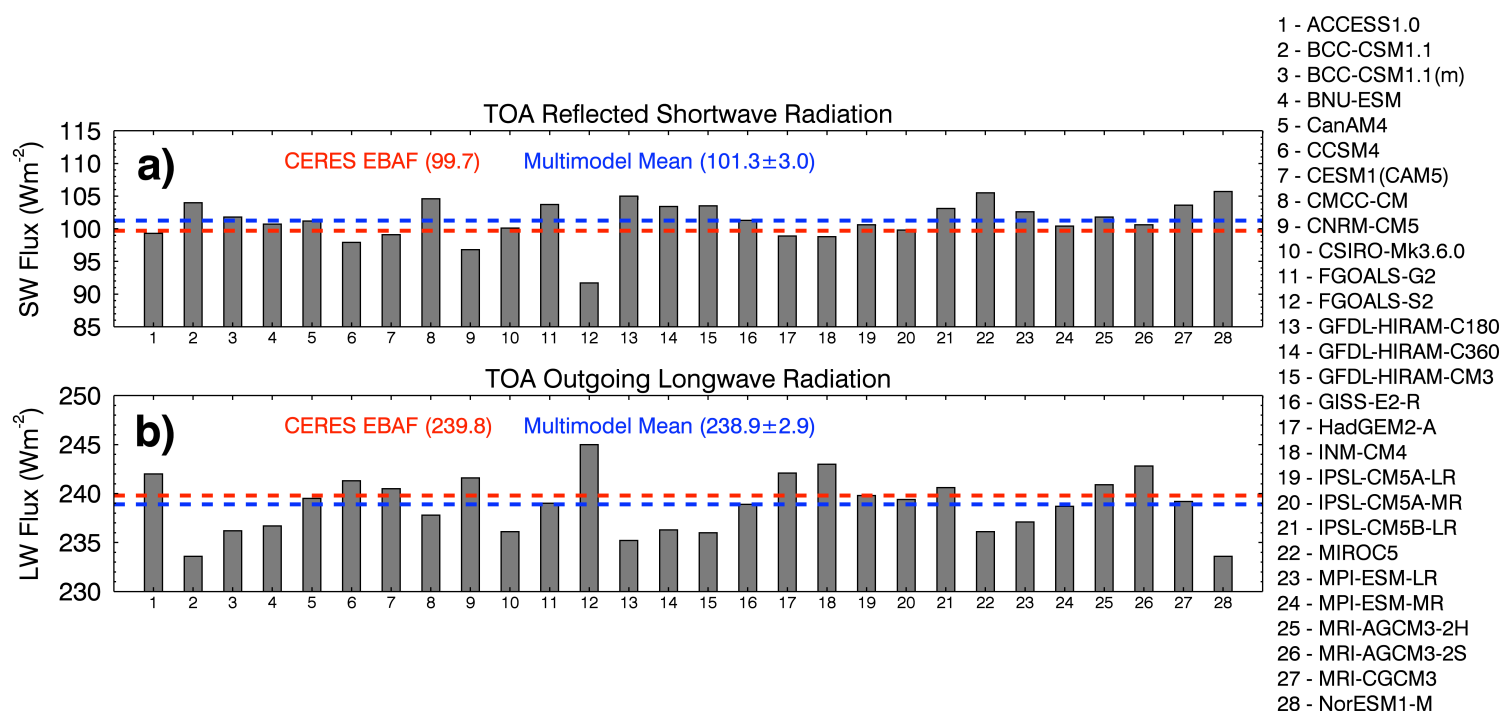

Figure 8. Same as Figure 2 but for the global means in simulated and observed TOA reflected shortwave (a) and outgoing longwave fluxes (b) under the all-sky conditions. 
ACCESS1.0, GFDL-HIRAM-CM3, IPSL-CM5A-MR, and MPI-ESM-MR. The simulated all-sky reflected SW flux has a negative correlation with OLR, which is selfconsistent.

The zonal all-sky radiation flux comparisons in Figure 9 are much better than their CF and CWP counterparts (Figure 3). Both the reflected SW and outgoing LW radiation flux multimodel means converge to the CERES EBAF observations through most latitudes; there is an exception for the SW flux simulations near the tropics $\left(\sim 25^{\circ} \mathrm{S}\right.$ $-25^{\circ} \mathrm{N}$ ) and the southern latitudes near $60^{\circ} \mathrm{S}$, where CWP is similarly biased. The zonal
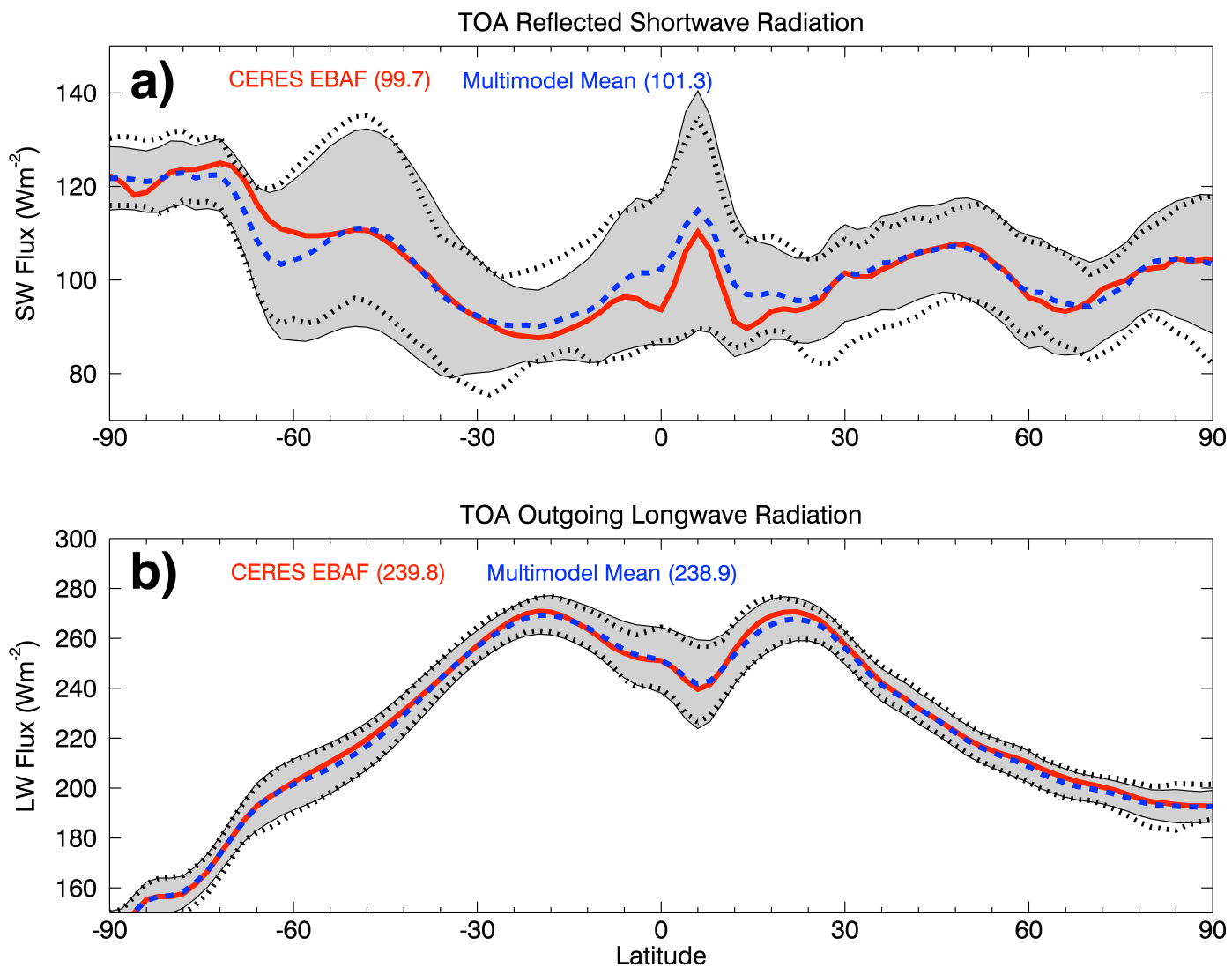

Figure 9. Same as Figure 3 but for the simulated and observed zonal distribution of shortwave (a) and longwave (b) all-sky results.

variation of both modeled and observed all-sky reflected SW fluxes generally follow the zonal variations of CF and CWP with relatively large disparity over the southern mid- 
latitude ocean. Simulated reflected SW and OLR fluxes and their corresponding ensemble means fluctuate around the observations. As expected, the OLR comparison agrees much better than the SW comparison because the SW flux is strongly CF and CWP dependent. The peak of reflected SW flux and the corresponding dip in OLR, as well as relatively large variations in the model simulations near $5-10^{\circ} \mathrm{N}$, are expected due to the frequent occurrence of deep convective clouds in that region.
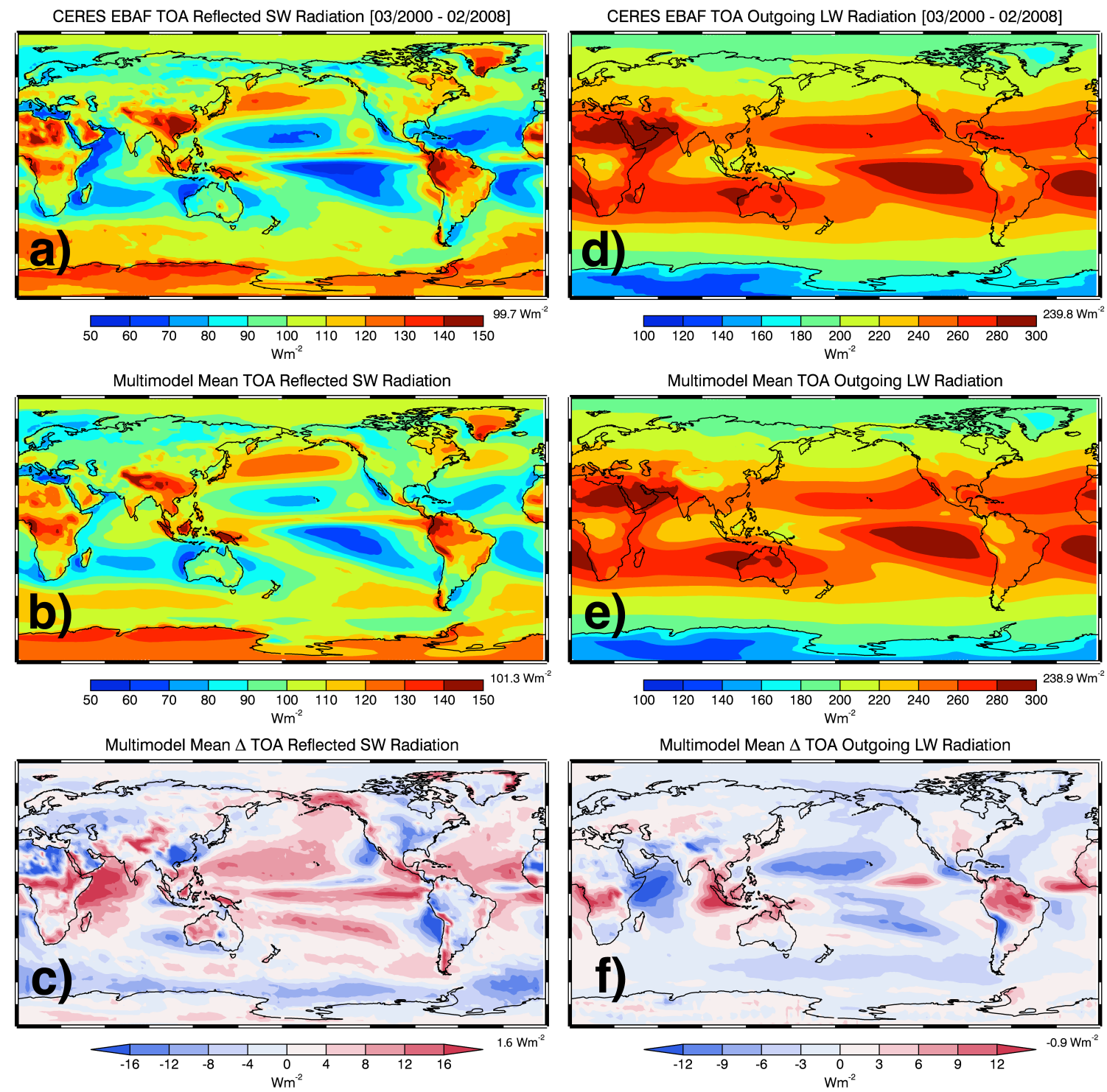

Figure 10. Same as Figure 4 but for the observed (a) and simulated (b) TOA reflected shortwave (left) and outgoing longwave (right) under the all-sky conditions, as well as their differences (model - observations) $(\mathrm{c}, \mathrm{f})$. 
The observed and simulated global distribution of TOA all-sky SW and LW radiation fluxes in Figure 10 shed light on to the persistent regional biases apparent in the model simulations. More distinct atmospheric features are evident in these results, when compared to the clear-sky results, such as the ITCZ and large-scale circulations (e.g. Hadley Cell). Consistent with the CWP results, the model simulations over estimate the all-sky SW radiation by more than $16 \mathrm{Wm}^{-2}$ in the East Indies, as well as in the Indian Ocean (Figure 10c). There are only a few regions with under estimates, such as the South American Pacific Coast where MBL clouds persist, and Southeastern China. The Southern Ocean is also slightly under estimated, which is a common feature in the model simulations. The all-sky LW radiation flux (Figure 10d) is greatest in the tropics and in locations of persistent high-pressure systems (i.e. Northern Africa/Arabian Peninsula and the Eastern Pacific). In terms of the LW flux biases (Figure 10f), the largest differences occur in the tropics, such as relatively large under estimates in the Central Pacific and the Eastern Indian Ocean, while large positive biases occur in the western Indian Ocean and Northern South America.

Cloud Radiative Forcings (CRFs). The SW (LW) CRF at the TOA is defined in Ramanathan et al. (1989) as the SW (LW) flux difference between the all-sky and clearsky conditions where a negative (positive) SW (LW) CRF denotes a cooling (warming) effect at the TOA. As shown in Figure 11, the global average SW, LW, and net (SW + LW) CRFs from CERES EBAF are $-47.2,26.2$, and $-21.0 \mathrm{Wm}^{-2}$, respectively, indicating a net cooling effect of clouds on the TOA radiation budget. The multimodel ensemble global means (biases) are $-48.3 \pm 4.3(-1.1), 24.9 \pm 3.5(-1.3)$, and $-23.4 \pm 4.4$ $(-2.4) \mathrm{Wm}^{-2}$ for the $\mathrm{SW}, \mathrm{LW}$, and net CRFs, respectively, resulting in a larger net 
cooling effect in the simulations. These comparisons are consistent with the result in Wang and $\mathrm{Su}$ (2013). However, the CRF biases in some models can amount to $10 \mathrm{Wm}^{-2}$. Such biases are apparent in the simulated SW CRFs in BCC-CSM1.1 $\left(-10.5 \mathrm{Wm}^{-2}\right.$ more cooling) and the simulated net CRF in FGOALS-S2 $\left(-10.5 \mathrm{Wm}^{-2}\right.$ more cooling). The lack of net cooling in CSIRO-Mk3.6.0 is also quite impressive, however, it can be easily explained. The SW CRF cooling is under estimated and the LW CRF warming is over estimated. A further investigation into these models is imperative to understand these results.

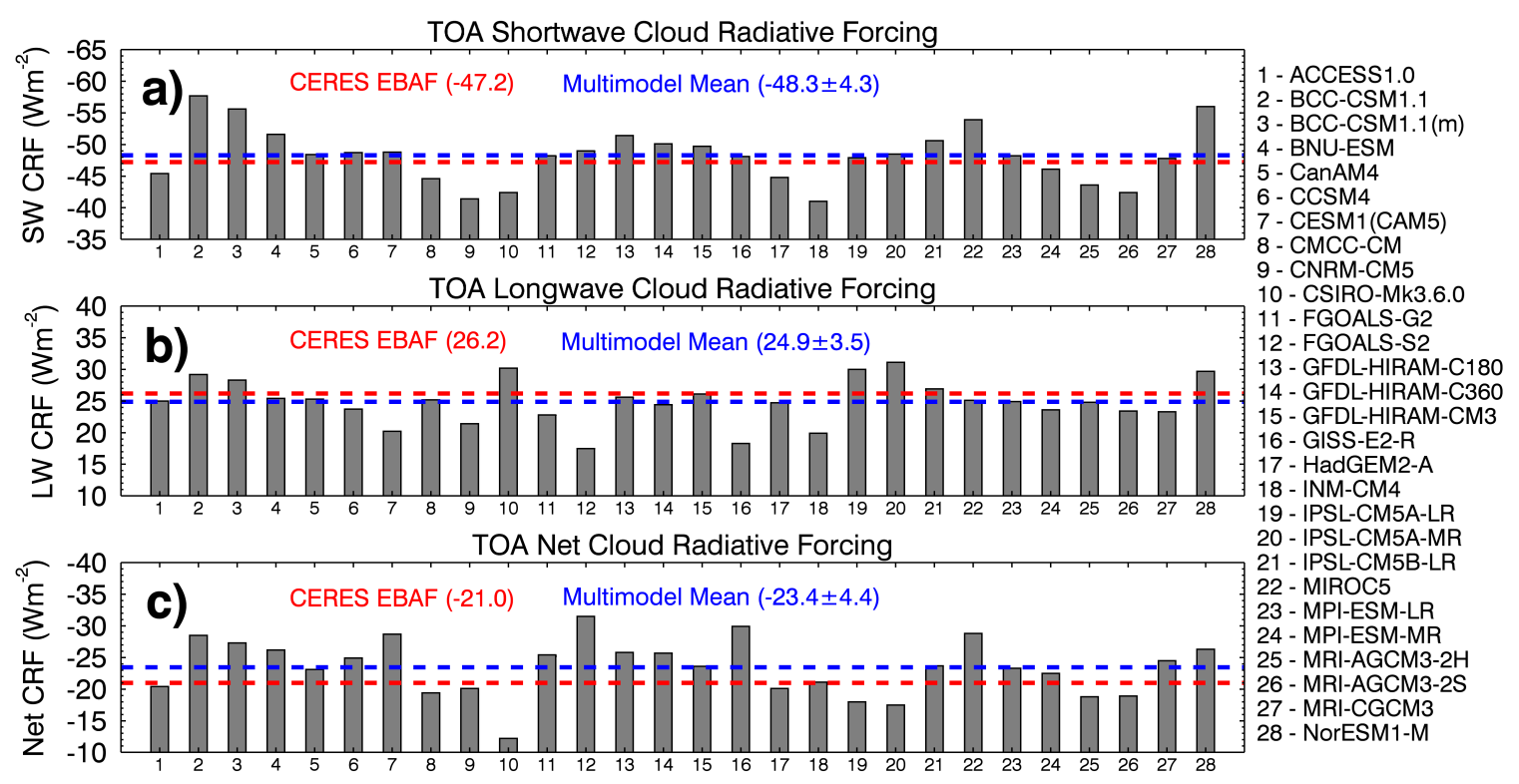

Figure 11. Same as Figure 2 but for the global means in simulated and observed shortwave (a), longwave (b), and net (c) cloud radiative forcing results.

The zonal variations of SW and LW CRFs in Figures 12a and 12b seemingly mimic their corresponding clear- and all-sky SW and LW flux variations (Figures $6 \mathrm{a}-\mathrm{b}$ and Figures $9 \mathrm{a}-\mathrm{b}$, respectively), presumably due to the TOA CRF calculations ( $\mathrm{SW} \uparrow_{\mathrm{clr}}-$ $\mathrm{SW} \uparrow_{\text {all }}$ and $\left.\mathrm{LW} \uparrow_{\mathrm{clr}}-\mathrm{LW} \uparrow_{\text {all }}\right)$. The strong $\mathrm{SW}$ cooling and $\mathrm{LW}$ warming effects between 5 ${ }^{\circ} \mathrm{N}$ and $10{ }^{\circ} \mathrm{N}$ are primarily contributed by deep convective clouds where the cloud albedo is nearly 0.7 and cloud-top height and temperature are $\sim 10 \mathrm{~km}$ and $\sim 220 \mathrm{~K}$, 
respectively (Dong et al. 2008b). Over the southern mid-latitude ocean, MBL clouds are dominant (Stanfield et al. 2014), which can attribute to strong SW cooling and moderate LW warming effects. With the magnitude of SW cooling dominating over the LW warming, the zonal variation of the net CRF more closely resembles that of the SW CRF with an overall cooling effect, but to a lesser degree of magnitude of the SW CRF. The
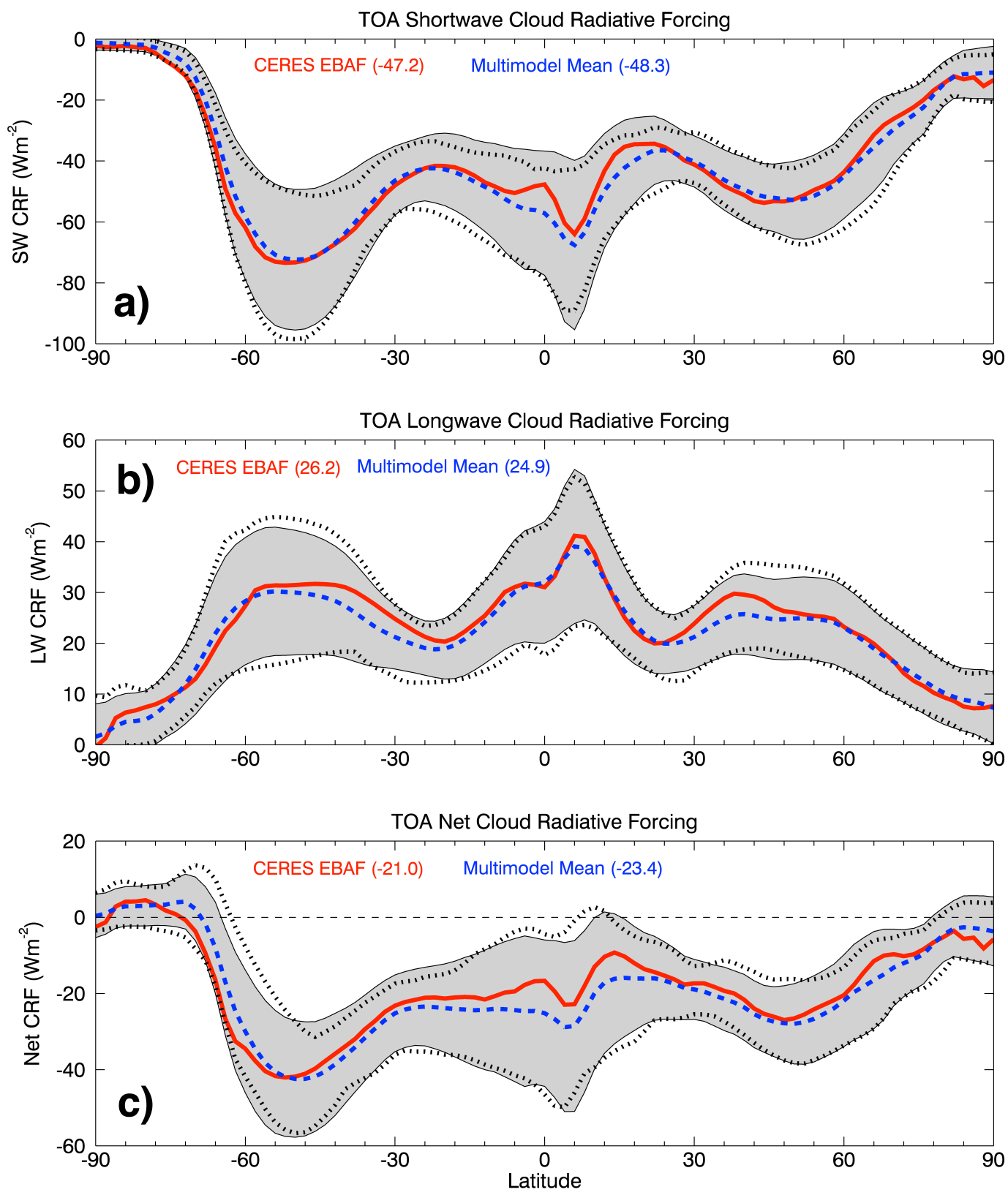

Figure 12. Same as Figure 3 but for the simulated and observed zonal distribution of shortwave (a), longwave (b), and net (c) CRF results. 
strong SW cooling and LW warming effects over these two regions has motivated a further investigation into whether clouds and CRFs associate well with atmospheric vertical motions. Note that deep convective clouds are associated with upward motion, while MBL clouds are normally related to strong sinking motion.

The global horizontal distribution of TOA CRFs can be found in Figure 13. The largest SW (LW) cooling (warming) can be identified to be in the Western Pacific near the East Indies and Northern South America (Figure 13a and 13d). The net CRF cooling is maximized in the Eastern and Northern Pacific and in the Southern Ocean (Figure 13g). Although the modeled SW, LW and Net CRFs resemble observed ones, there still exists some bias. When the biases in SW and LW CRF are combined, the net CRF bias is available and shown in Figure 13i. The net CRF bias is interpreted in terms of the
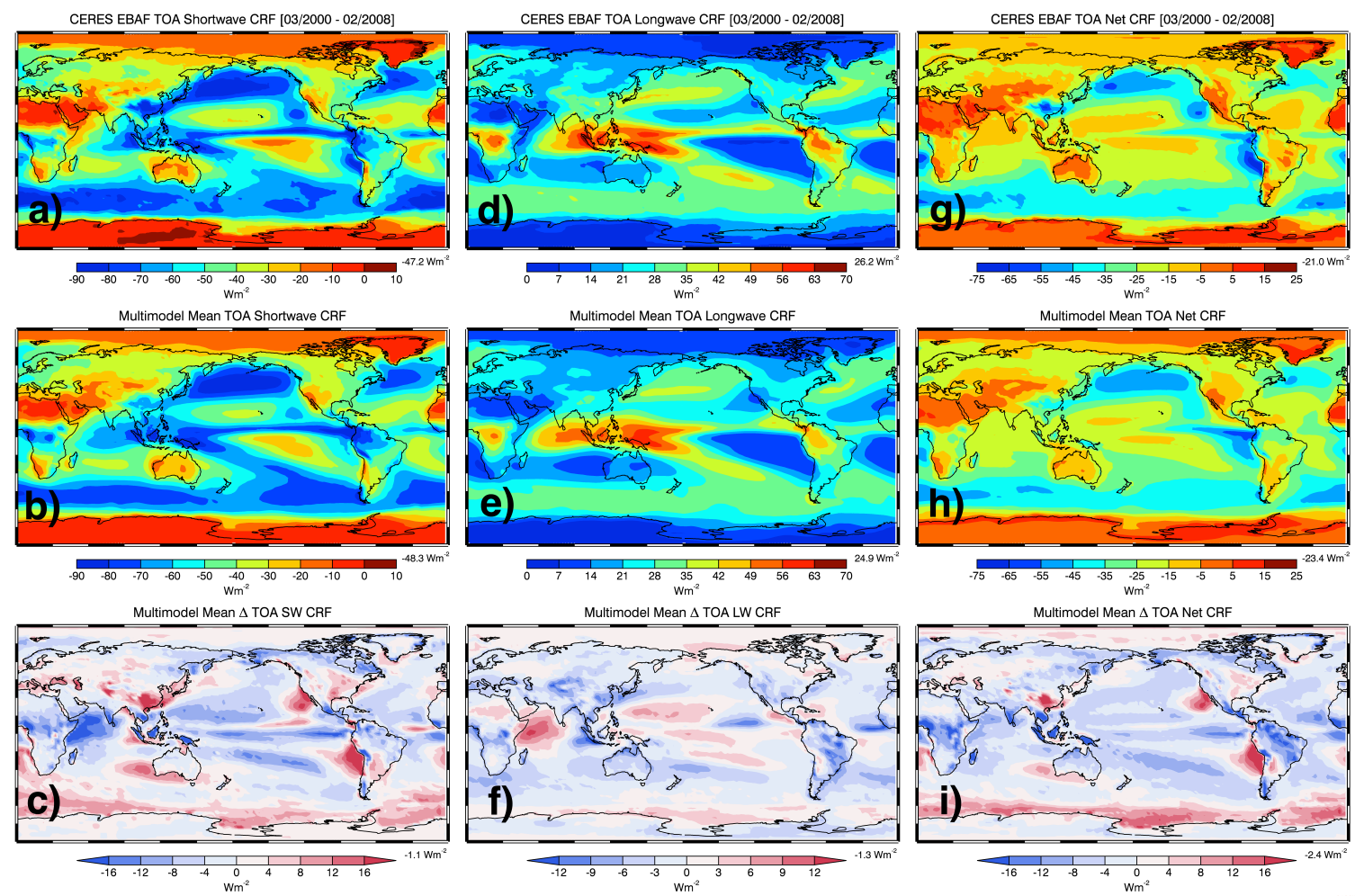

Figure 13. Same as Figure 4 but for the observed, simulated, and simulated bias maps of shortwave (left), longwave (middle), and net (right) CRF results. 
magnitude of cooling or warming; positive values indicate a weaker cooling effect while negative values represent stronger cooling effect in the model simulations. Again, we identify the areas of persistent model deficiencies in simulating the appropriate impact of clouds on the TOA radiation budget. For example, the net CRF cooling is $16 \mathrm{Wm}^{-2}$ larger than the observations in the East Indies, Central Africa, and in parts of Northern South America. On the other hand, the net CRF cooling is much weaker in the Southern Ocean, Southeastern China, and the Western Coast of South America and Southern California where MBL clouds frequently occur.

Table 4 provides a summary of the globally averaged observed and simulated results and their respective biases. Several regions have been identified to show persistent model deficiencies and should be paid close attention by modelers and special interest groups. Therefore, it is necessary to delve into interrelating these biases and to develop a systematic approach for correlating and quantifying the biases in CRF. In the next section we will investigate the impacts of CF and CWP on the radiation budgets and CRFs in tropical and mid-latitude oceanic regions.

Table 4. Summary of globally averaged (cosine-latitude weighted) mean observed and multimodel ensemble simulated results. Values in parenthesis are the 1-sigma standard deviation and the biases are in comparison to CERES MODIS/EBAF results.

\begin{tabular}{|ccccc|cc|}
\hline Observations & \multicolumn{7}{c|}{} & \multicolumn{2}{|c|}{ Simulations } \\
\hline & $\begin{array}{c}\text { CERES } \\
\text { MODIS }\end{array}$ & ISCCP & $\begin{array}{c}\text { CloudSat/C } \\
\text { ALIPSO }\end{array}$ & $\begin{array}{c}\text { CERES } \\
\text { EBAF }\end{array}$ & $\begin{array}{c}\text { 28 Model Mean } \\
(\mathbf{1 - \sigma})\end{array}$ & Bias \\
\hline $\begin{array}{c}\text { Total Cloud } \\
\text { Fraction }\end{array}$ & 65.5 & 65.4 & 75.3 & - & $58.6(5.8)$ & -6.9 \\
\hline $\begin{array}{c}\text { Cloud Water } \\
\text { Path }\end{array}$ & 117.0 & - & - & - & $100.6(36.7)$ & -16.4 \\
\hline $\begin{array}{c}\text { TOA Reflected } \\
\text { Shortwave }\end{array}$ & - & - & - & 99.7 & $101.3(3.0)$ & 1.6 \\
\hline $\begin{array}{c}\text { TOA Outgoing } \\
\text { Longwave }\end{array}$ & - & - & - & 239.8 & $238.9(2.9)$ & -0.9 \\
\hline $\begin{array}{c}\text { TOA Reflected } \\
\text { Shortwave } \\
\text { (Clear-Sky) }\end{array}$ & - & - & - & 52.5 & $53.0(4.0)$ & 0.5
\end{tabular}


Table 4 cont.

\begin{tabular}{|lllll|ll|}
\hline Observations & & & & Simulations & \\
\hline & $\begin{array}{c}\text { CERES } \\
\text { MODIS }\end{array}$ & ISCCP & $\begin{array}{c}\text { CloudSat/C } \\
\text { ALIPSO }\end{array}$ & $\begin{array}{c}\text { CERES } \\
\text { EBAF }\end{array}$ & $\begin{array}{c}\text { 28 Model Mean } \\
(1-\sigma)\end{array}$ & Bias \\
\hline $\begin{array}{c}\text { TOA Outgoing } \\
\text { Longwave } \\
\text { (Clear-Sky) }\end{array}$ & - & - & - & 266.0 & $263.8(3.0)$ & -2.2 \\
\hline $\begin{array}{c}\text { TOA Shortwave } \\
\text { CRF }\end{array}$ & - & - & - & -47.2 & $-48.3(4.3)$ & -1.1 \\
\hline $\begin{array}{c}\text { TOA Longwave } \\
\text { CRF }\end{array}$ & - & - & - & 26.2 & $24.9(3.5)$ & -1.3 \\
\hline TOA Net CRF & - & - & - & -21.0 & $-23.4(4.4)$ & -2.4 \\
\hline
\end{tabular}

\section{Tropical and Mid-latitude $\left( \pm 45^{\circ}\right)$ Evaluation Study}

Large-scale dynamic forcings play a major role in the development of clouds and their residence in the atmosphere. The persistent synoptic patterns in the tropical and mid-latitude regions are oftentimes responsible for cloud occurrence and their microphysical properties. Cloud-type will ultimately depend upon which dynamic regime is present at the time of cloud formation at through its lifetime (Berry and Mace 2013; Su et al. 2013). Low-pressure systems, and the corresponding upward velocities, are commonly responsible for convective-type clouds (i.e. convective core and anvil), while high-pressure systems are generally stable, associated with sinking motions and stratiform-type clouds (i.e. MBL clouds). Cloud-radiative properties will depend on cloud-type and eventually the radiation budgets at the surface and TOA.

Common areas of upwelling and downwelling are identified in the atmosphere (over the oceans) to better differentiate between convective- and stratiform-type clouds (in a climatology sense). We can then determine which cloud-type is better simulated and the corresponding effects on the TOA radiation budget. MERRA reanalysis of the omega field at $500 \mathrm{hPa}$ will be used to classify and separate the two different regimes. Using the reanalysis may introduce error in the establishment of the regimes because the 
simulated field may not be similar in placement or magnitude; however, reanalyses are the best reference available for this study at this time.

\section{Vertical Velocities (Omega) at $500 \mathrm{hPa}$}

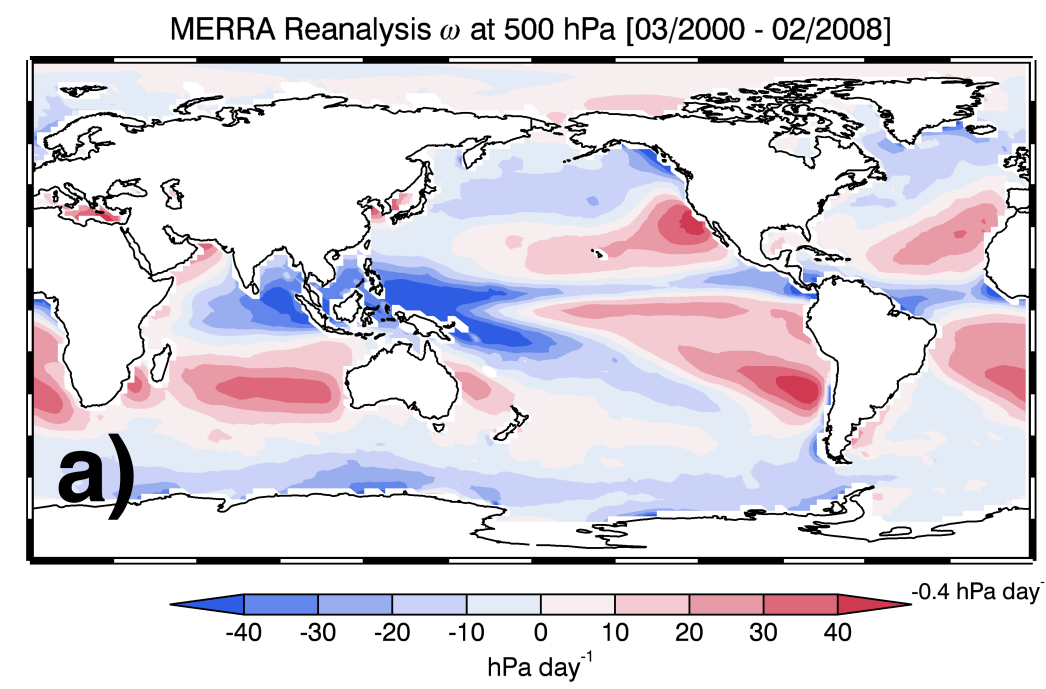

Multimodel Mean $\omega$ at $500 \mathrm{hPa}$

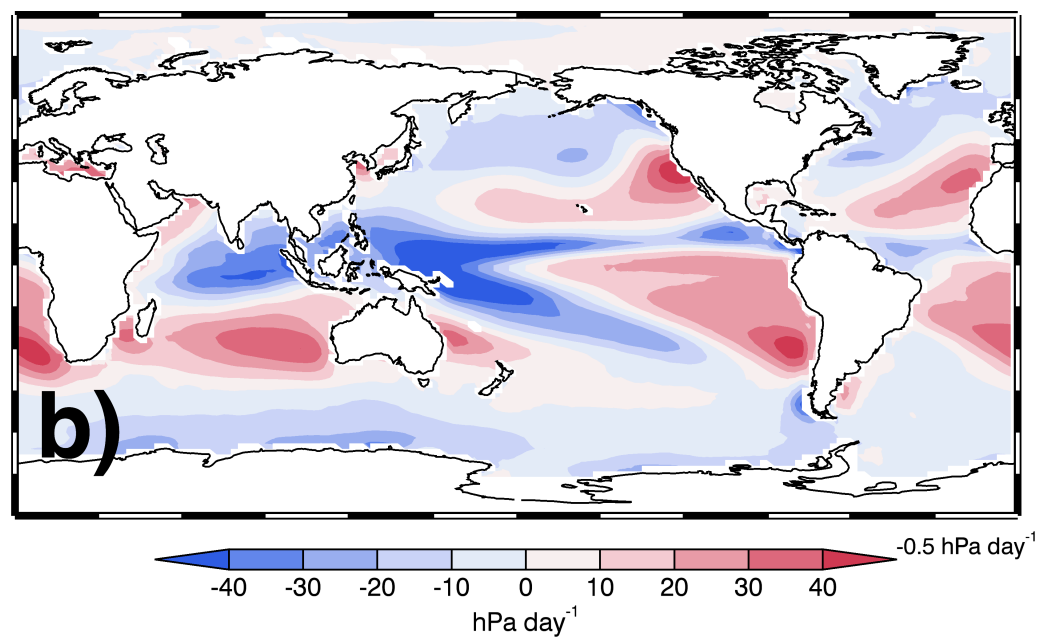

Figure 14. Global distributions of the MERRA reanalyzed (a) and multimodel ensemble simulated (b) vertical velocities at $500 \mathrm{hPa}$ over the oceans. Negative values (blue) are characteristic of upwelling motions while positive values (red) indicate downwelling motions in the atmosphere.

Vertical velocities within the atmosphere are difficult to measure directly, thus we must use reanalyzed data as a reference for estimating its value. Modern-Era Retrospective Analysis for Research and Applications (MERRA) reanalyzed vertical velocities (omega at $500 \mathrm{hPa}, \omega 500)$ are used to identify predominant large-scale areas of convection and subsidence (i.e. the Hadley Cell and Walker Circulation) so that an investigation may be 
made in the relationship between cloud properties and CRFs. Errors in the MERRA reanalyzed vertical velocities may be large, such as described in the Kennedy et al. (2011) study over the ARM SGP region, which may affect our selected vertical velocity regimes. The MERRA reanalyzed and multimodel ensemble vertical velocities at 500 $\mathrm{hPa}$ over the oceans only are depicted in Figures $14 \mathrm{a}$ and $14 \mathrm{~b}$, respectively.

The large-scale circulations (i.e. Hadley Cell, Ferrell Cell, and Walker Circulations) are seemingly placed in the appropriate locations; however, the magnitude and spatial extent of these persistent vertical regimes is questionable. For example, the
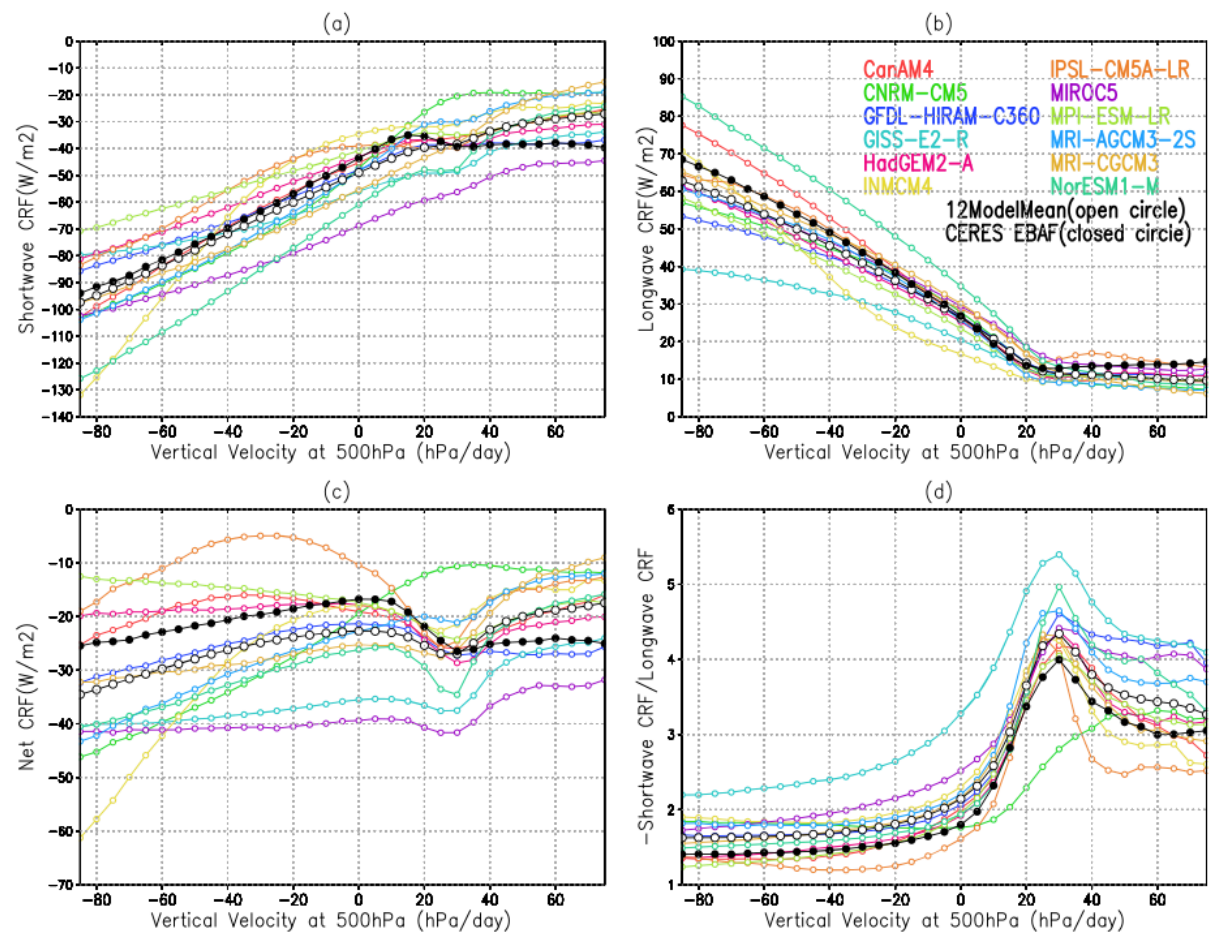

Figure 15. From Wang and $\mathrm{Su}$ (2013) "The comparison between the 12 models and the CERES EBAF in the composites of (a) SW CRF, (b) LW CRF, (c) net CRF, and (d) the ratio of SW CRF to LW CRF in different tropical circulation regimes defined from $\omega 500$. The monthly data over January 2001 to December 2008 are used. The $\omega 500$ from the ERA-Interim reanalysis is used for the CERES EBAF, and 1500 from each of the CMIP5 AMIP simulations is used for the CRFs in that model. Units are $\mathrm{Wm}^{-2}$." 
ascending branch of the Walker Circulation (north of Australia) and a portion of the descending branch of the Hadley Cell (west of South America) are stronger in the reanalysis than in the simulations. We adopt a suitable threshold for defining predominant upwelling and downwelling regimes in the atmosphere from the reanalysis. Wang and Su (2013) showed that tropical SW and LW CRFs are independent of $\omega 500$ (from ERA-Interim, reanalysis) when $\omega 500$ is greater than $\sim 25 \mathrm{hPa} \mathrm{day}^{-1}$, while a linear dependence is apparent when $\omega 500$ is less than $-25 \mathrm{hPa}$ day $^{-1}$ (Figure 15a and 15b).

\section{Regional Simulated Biases in the Designated Vertical Velocity Regimes}

The regions with strong upwelling $\left(\omega 500<-25 \mathrm{hPa} \mathrm{day}^{-1}\right.$, blue $)$ and downwelling ( $\omega 500>25 \mathrm{hPa} \mathrm{day}^{-1}$, red) over the tropical and mid-latitude $\left(45^{\circ} \mathrm{N}\right.$ to 45 $\left.{ }^{\circ} \mathrm{S}\right)$ oceans are determined by MERRA reanalysis and are shown in Figure 16a. Upwelling regions (blue areas with black contours) are typically representative of deep convective clouds and their accompanied anvil or cirrus clouds, while downwelling regions (red areas with black contours) in the atmosphere are normally associated with high-pressure systems where marine boundary layer (MBL) clouds persist. The multimodel ensemble mean biases (model - observations) of CF, CWP, and TOA SW, LW and net CRFs are illustrated in Figure 16 (left column), along with their regimebased bias averages (right column). The good agreement in CF over the upwelling regime $(+0.7 \%$ bias $)$ is expected because parameterized convective clouds are strongly associated with upward vertical velocity. The downwelling CF is under estimated by the multimodel mean by nearly $18 \%$, suggesting that a more robust parameterization for clouds in these atmospheric conditions is warranted. Kennedy et al. (2010) compared the NASA GISS single column model (SCM) simulated CF with ARM SGP radar-lidar 
observations during the period 1999 - 2001. They found that the SCM simulated most of the high clouds over upwelling cases because of their strong upward velocities and positive relative humidity $(\mathrm{RH})$ bias; however, the SCM missed some low clouds in downwelling regimes due to a negative $\mathrm{RH}$ bias associated with subsidence. The slightly positive CWP bias in the upwelling regions $\left(13.9 \mathrm{gm}^{-2}\right)$ indicates that the models, in general, over simulated CWP even though they correctly simulated CF compared to observations. The multimodel ensemble CWP bias in the downwelling regime $(-25.1$ $\mathrm{gm}^{-2}$ ) is even larger than its upwelling counterpart, consistent with the CF result.

Biases in the CRFs (Figure 16d - 16f) are representative of their relative magnitude of warming or cooling. For example, a negative bias in the SW/net CRF corresponds to an over estimate of cooling due to clouds. Conversely, a positive bias in the LW CRF relates to an over estimate in warming due to clouds. The CF and CWP biases are relatively large $\left(-17.7 \%\right.$ and $-25.1 \mathrm{gm}^{-2}$, respectively) in the downwelling regime, whereas the $\mathrm{CRF}$ biases are relatively small, less than $\sim 5 \mathrm{Wm}^{-2}$. A more detailed summary of model-specific biases in the upwelling and downwelling regimes may be found in Appendix A and Appendix B, respectively. The cloud and radiation biases over these two regimes are consistent with our previous results. However, due to the large variations in $\mathrm{CF}$ and CWP in these two regimes, we will investigate the sensitivities of SW, LW, and net CRFs to CF and CWP to further understand why such relationships are concurrent. 

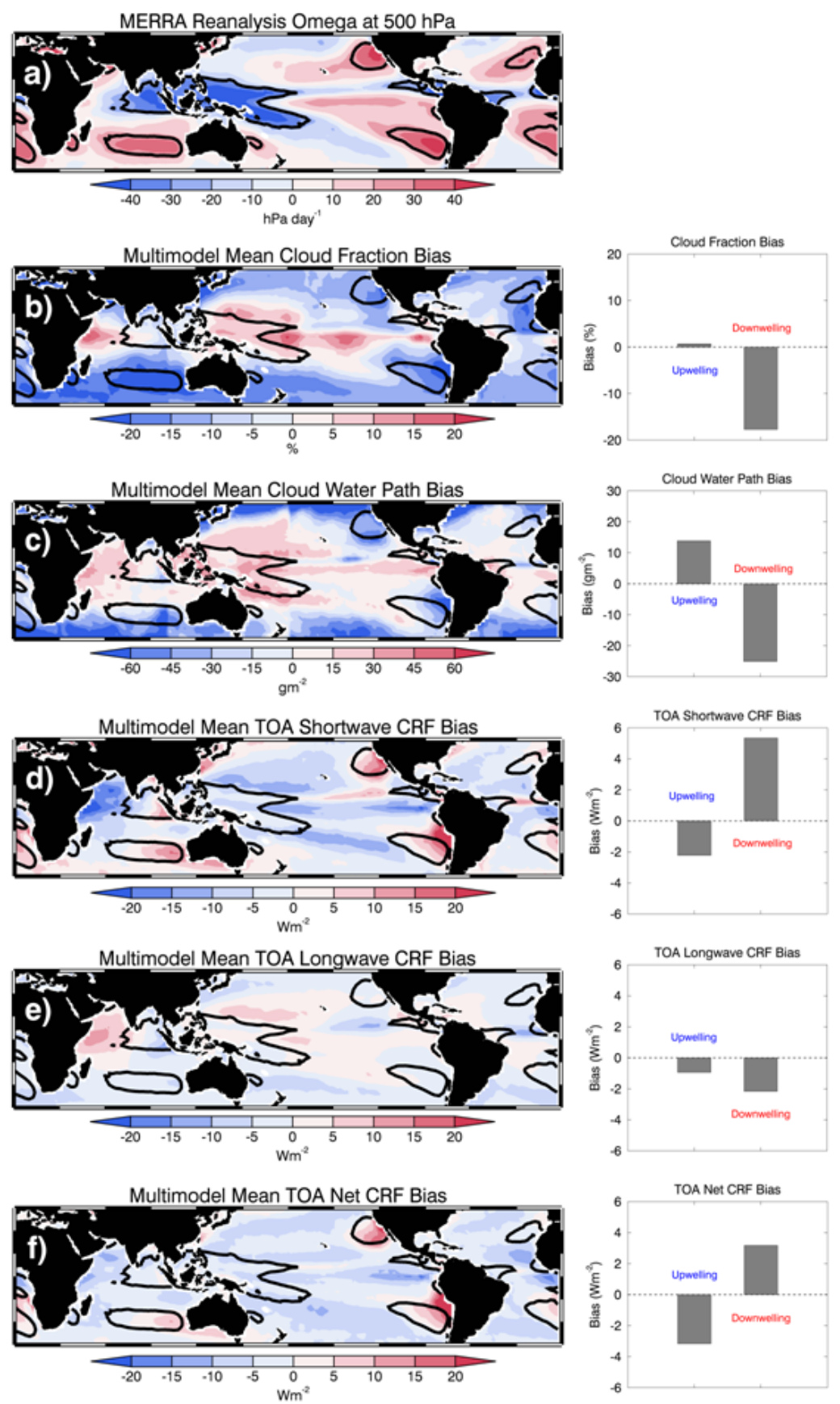

Figure 16. Relatively strong upwelling $\left(\omega 500<-25 \mathrm{hPa}^{-1 a y}{ }^{-1}\right.$, blue) and downwelling $\left(\omega 500>25 \mathrm{hPa} \mathrm{day}^{-1}\right.$, red) regimes over the tropical and mid-latitude $\left( \pm 45^{\circ}\right.$ latitude) oceans are identified from MERRA reanalysis of the omega field at $500 \mathrm{hPa}$ (a). Biases (multimodel ensemble minus CERES observations) in CF, CWP, and SW/LW/net CRFs $(\mathrm{b}-\mathrm{f})$ are also shown. Black contours $\left( \pm 25 \mathrm{hPa} \mathrm{day}^{-1}\right)$ help to visualize the relatively strong vertical velocity regimes in (a). Biases in both the upwelling and downwelling regions are averaged and presented to the right of each map. 
Taylor Diagram Analysis. Taylor Diagrams have been generated using the 1sigma spatial standard deviations and correlations to compare the 28 AMIP model simulations with the CERES MODIS/EBAF data products. The CF and CWP results in the upwelling and downwelling regimes are found in Figure 17, where the CRF results are located in Figure 18. Taylor diagrams are an excellent tool for displaying many
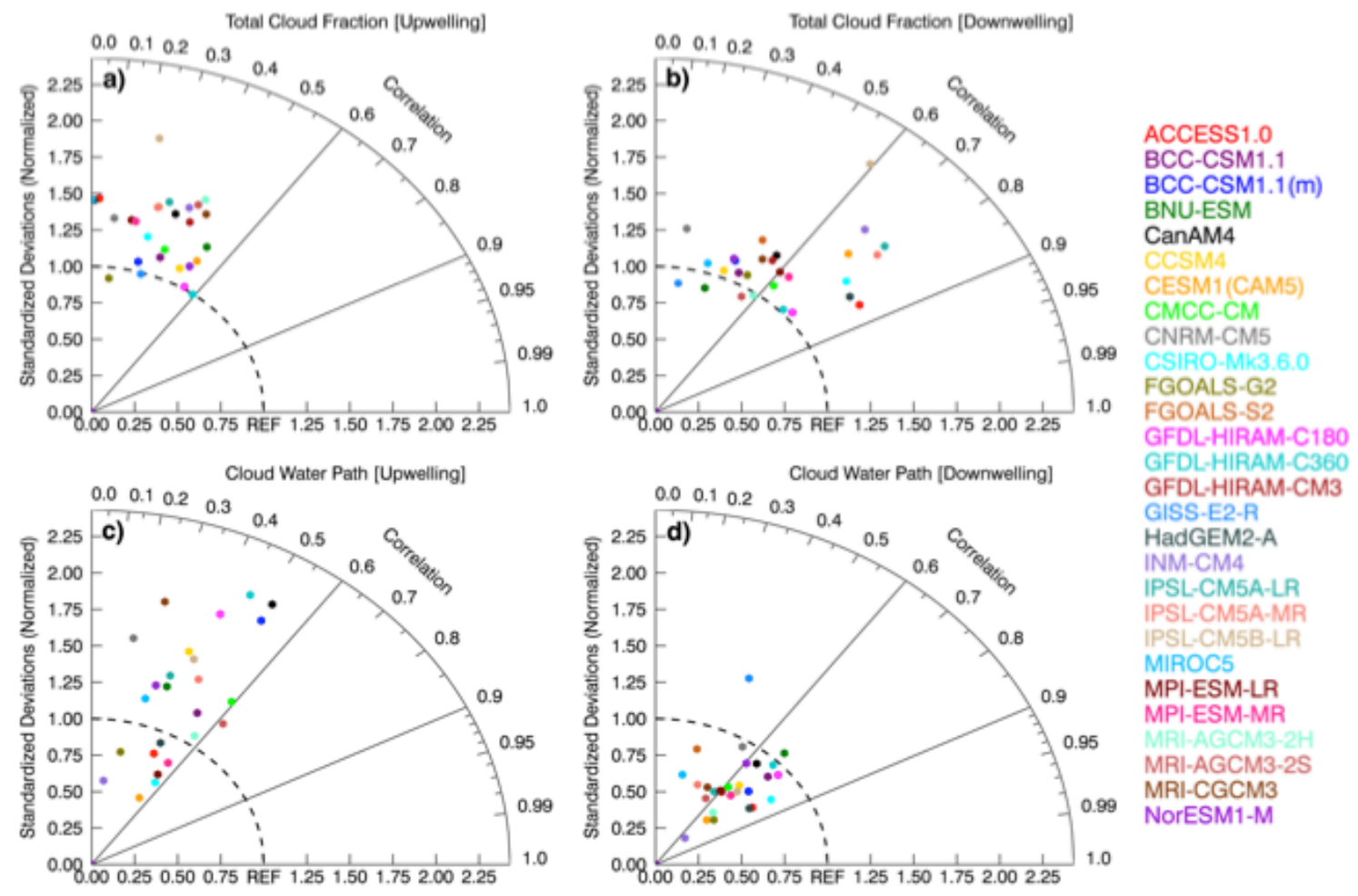

Figure 17. Taylor Diagrams displaying the 28 AMIP model simulations of CF $(a-b)$ and CWP $(c-d)$ in the upwelling (left) and downwelling (right) regimes over tropical and mid-latitude $\left( \pm 45^{\circ}\right.$ latitude) oceans. Correlations and standard deviations are normalized by CERES MODIS observations.

simulated fields together to effectively demonstrate how well they compare to some reference value (in this case, the observations) and to track changes through the consideration of correlations, spatial standard deviations (normalized by the observed value), and root mean squared errors (Taylor 2001). If the model simulations agree well with observations then the simulated result would fall within the correlation rage of $0.9-$ 
1.0 and near the reference point (normalized standard deviation, REF, $\sigma=1.0$ ). The simulated CFs in the upwelling regime fall below a 0.6 correlation (although small, the MIROC5 model has a negative correlation to observations) and their normalized standard deviations are larger than the reference value (1.0 - 2.0, Figure 17a). Similarly for CWP in the upwelling regime, simulated correlations are close to or slightly better than $\mathrm{CF}$ comparisons, however, the standard deviations range from 0.5 to 2.0 , with significantly larger values in the GISS-E2-R, FGOALS-S2, and GFDL-CM3 CWP simulations (Figure 17c). Over the downwelling regime, simulated CF and CWP correlations are slightly higher and normalized standard deviations scatter about the reference line better than their upwelling counterparts.

The results from Figure 17 translate fairly well to the overall score of simulated CRFs (Figure 18). In general, the correlations in CRFs are higher and standard deviations are lower than those in CF and CWP. Again, the correlations and standard deviations over the downwelling regime are better than those over the upwelling regime. For example, most of the CRF correlations fall between 0.6 and 0.9 , where some even exceed 0.9, and standard deviations are near the reference point in the downwelling regime. However, two models, CNRM-CM5 and MIROC5, show a small negative correlation to observations in the downwelling regime for TOA SW CRF simulations (Figure 18b).

Note that the results in Figures 17 and 18 are different from those in Figure 16. The good agreement in their calculated mean values, but low correlation to observations in the upwelling regime can be explained. MBL clouds are persistent in the downwelling 

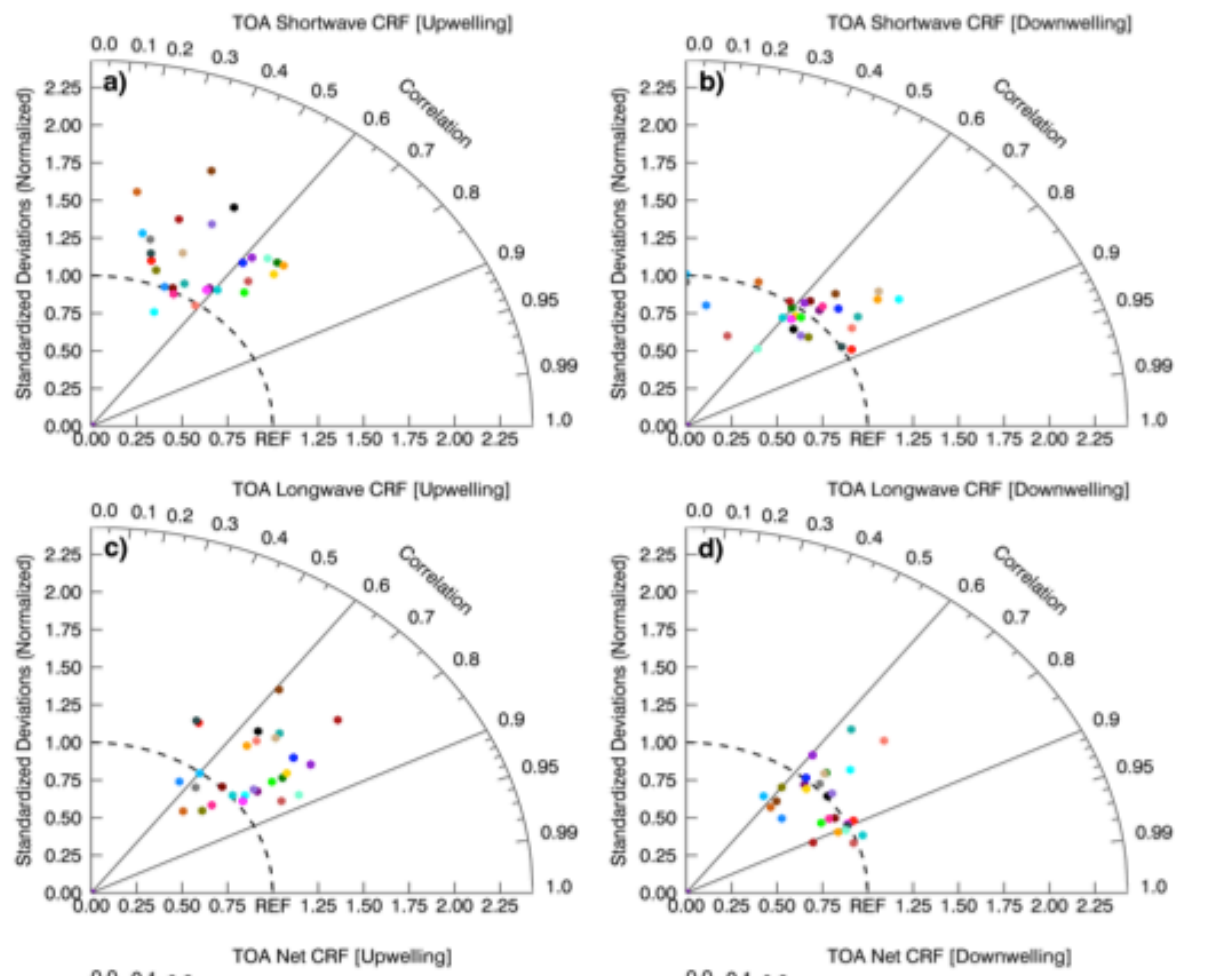

ACCESS1.0 BCC-CSM1.1(m)

BNU-ESM

CanAM4

CESM1 (CAM5)

CMCC-CM

CNRM-CM5

CSIRO-MK3.6.0

FGOALS-G2

FGOALS-S2

GFDL-HIRAM-C 180

TOA Net CRF [Dowrwelling]

GFDL-HIRAM-C 360

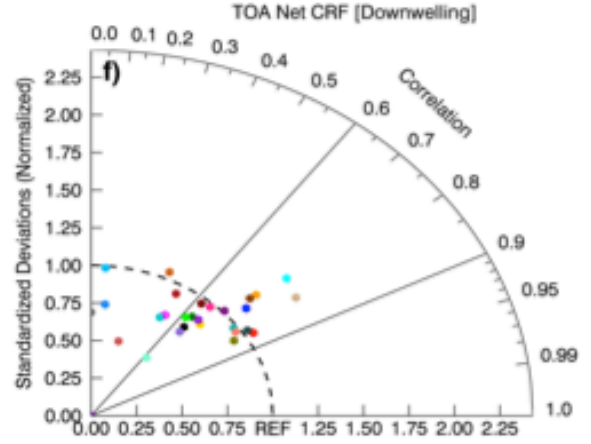

GFDL-HIRAM-CM3

GISS-E2-R

HadGEM2-A

INM-CM4

IPSL-CM5A-LR

IPSL-CMSA-MR

IPSL-CM5B-LR

MIROC5

MPI-ESM-LR

MPI-ESM-MR

MPIAGCM 3-2

MRI-AGCM3-2S

NorESM1-M

Figure 18. Same as Figure 17 but for TOA CRFs: SW $(a-b), L W(c-d)$, and net $(e-f)$. Values are normalized by CERES EBAF observations.

regime, while for the upwelling regime; there are a variety of cloud types, such as cumulus, anvil, cirrus, and mixed-phase clouds. In order to adequately resolve clouds in GCMs, different cloud-type parameterizations are implemented based upon ambient atmospheric conditions. When a diverse cloud field exists, cloud parameterizations will show difficulty in generating accurate simulations, especially if that cloud field is inhomogeneous. On the other hand, if a uniform cloud type is present (as in the 
downwelling regime), cloud parameterizations should replicate the atmospheric conditions more effectively and accurately.

\section{Sensitivity Study}

To quantitatively estimate the impacts of CF and CWP on TOA radiation budgets, the observed and multimodel ensemble mean SW, LW, and net CRFs versus CF and CWP over the atmospheric upwelling (blue) and downwelling (red) are presented in Figures 19 and 20, respectively. These results are selected from the strong upwelling and downwelling regimes (black contours) over tropical and mid-latitude oceanic regions (Figure 16). A best-fit linear regression is employed and used to determine the sensitivity between two variables (e.g. CF and SW CRF) in terms of slope. To add more certainty to this analysis, the $99.5 \%$ confidence of the slope has been determined. The margin of error in the slope is identified to be

$$
m_{E}=C_{v} \cdot S_{E}
$$

where $\mathrm{C}_{\mathrm{V}}$ is the critical value and $\mathrm{S}_{\mathrm{E}}$ is the standard error. The sample distribution is assumed to be normal and large enough to be expressed by a z-score. When the z-score has a cumulative probability of 0.995 , the corresponding critical value, $\mathrm{C}_{\mathrm{V}}$, is 2.58 . The standard err is calculate as

$$
S_{E}=\sqrt{\frac{1}{\frac{n-2}{\sum(x-\bar{x})^{2}}}}
$$

where $\varepsilon$ is the linear regression residual $(\varepsilon=y-m x-b)$. In all cases but one, the margin of error is less than the slope itself, supporting our current method for determining the sensitivity between two variables, and adds value to the analysis. In the case of the multimodel mean simulated net $\mathrm{CRF}$ sensitivity to $\mathrm{CF}$, the margin of error 
$\left(0.11 \mathrm{Wm}^{-2} \%^{-1}\right)$ is greater than the characteristic slope $\left(0.06 \mathrm{Wm}^{-2} \%^{-1}\right)$. This relationship should be used with caution.

As illustrated in Figure 19a, the observed sensitivities of the SW CRF to CF are similar in both vertical velocity regimes; the magnitude of SW CRF cooling increases significantly with increasing $\mathrm{CF}$ with a sensitivity of $-1.2 \mathrm{Wm}^{-2} \%^{-1}$ (in units of watts per square meter per percent cloudiness). The similar sensitivities $\left(-1.2\right.$ and $-1.31 \mathrm{Wm}^{-2}$ $\%^{-1}$ ) over these two regimes are understandable from the definition of SW CRF (SW $\uparrow_{\text {clr }}-$ $\mathrm{SW} \uparrow$ all $)$ because albedos of both deep convective and MBL clouds are much higher than the background ocean albedo $(\sim 6 \%)$.

Conversely, the LW CRF warming increases with increasing CF but is characterized by different sensitivities over the two regimes (Figure 19b). The observed sensitivities are 0.81 and $0.22 \mathrm{Wm}^{-2} \%^{-1}$ over the upwelling and downwelling regimes, respectively. The different LW CRF sensitivities between these two regions primarily result from the cloud-top temperature characteristics of deep convective (upwelling) and MBL (downwelling) clouds. The cloud-top temperature of deep convective clouds is rather cold ( $\sim 220 \mathrm{~K}$, Dong et al. 2008b), while MBL cloud-top temperature $(\sim 280 \mathrm{~K}$, Dong et al. 2014; $\mathrm{Xi}$ et al. 2014) is close to the underlying sea surface temperature. Based upon the definition of LW CRF $\left(\mathrm{OLR}_{\mathrm{clr}}-\mathrm{OLR}_{\mathrm{all}}\right)$, it is straightforward to explain the higher sensitivity of the LW CRF to CF in the upwelling regime. The net impact of $\mathrm{CF}$ on the TOA radiation budget is the sum of $\mathrm{SW}$ and $\mathrm{LW}$ effects, $\Delta \mathrm{CRF}_{\text {net }} / \Delta \mathrm{CF}=$ $\left(\Delta \mathrm{CRF}_{\mathrm{SW}} / \Delta \mathrm{CF}\right)+\left(\Delta \mathrm{CRF}_{\mathrm{LW}} / \Delta \mathrm{CF}\right)$. The weak sensitivity of the net CRF to $\mathrm{CF}$ in the upwelling regions is due to the complementing effects of the SW and LW CRFs. 

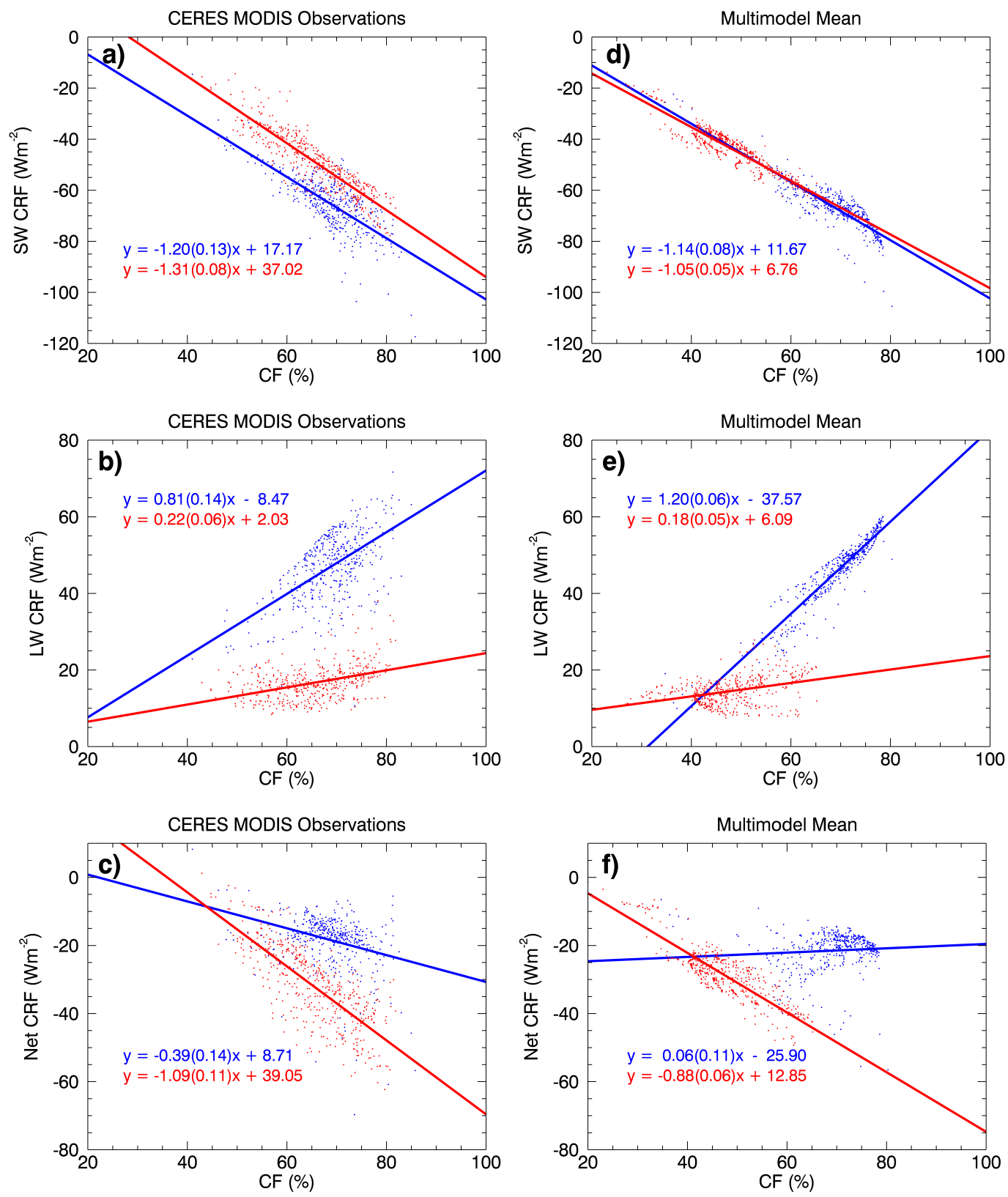

Figure 19. Sensitivities of TOA SW (a,d), LW (b,e), and net (c,f) CRFs to CF in the upwelling (blue) and downwelling (red) regimes. The data are sampled from over the tropical and mid-latitude ( $\pm 45^{\circ}$ latitude) oceans only. The left column represents the observed sensitivities from CERES MODIS/EBAF while the right column is for the multimodel ensemble. Regression lines are shown for both regimes with the uncertainty of the slope (within $99.5 \%$ confidence) in parenthesis.

The sensitivities of the multimodel mean simulated SW, LW, and net CRFs to CF (right column, Figure 19) seemingly mimic their observed counterparts, but with some 
discrepancies. For example, the sensitivities of SW CRF to CF over the upwelling and downwelling regimes $\left(-1.14\right.$ and $-1.05 \mathrm{Wm}^{-2} \%^{-1}$, respectively) are nearly the same as the observed ones. The simulated downwelling LW CRF sensitivity to CF is also similar to the observed one; however in the upwelling regime, the simulated sensitivity is 0.39 $\mathrm{Wm}^{-2} \%^{-1}$ stronger due to the inclusion of excess water (liquid, ice, or both) within the cloud column. The nearly neutral slope of the simulated net CRF to CF in the upwelling regime confirms that the model simulations effectively show a cancelation of the SW cooling and LW warming. The conclusions in Figure 19 (i.e. the magnitude of SW/LW CRF (cooling/warming) increases with increasing CF) affirm those within Dong et al. (2006) who used the DOE ARM SGP ground-based observations as a reference. The distinction between upwelling and downwelling regimes suggests that large-scale dynamics greatly influence cloud-radiation interactions and their predictability. In a later section we will investigate the effect of the biases in these sensitivities on the actual simulation of CRFs.

The sensitivities of observed SW CRFs to CWP in the upwelling and downwelling regimes, shown in Figure 20a, are almost identical with a slope of -0.29 and $-0.27 \mathrm{Wm}^{-2} / \mathrm{gm}^{-2}$, respectively. The magnitude of SW cooling increases with increasing CWP (and CF), and varies in sensitivity between these two variables. Changes in the SW albedo are strongly dependent on both CF and CWP. The multimodel ensemble simulated sensitivities of SW CRF to CWP are nearly the same over the two regions, and are similar to the observed values. Again, the comparisons in SW CRF sensitivities in Figure 20a and Figure 20d are approximately the same as those in Figure 19a and Figure 19d. The simulated LW sensitivities (Figures 20b and 20e) are not 

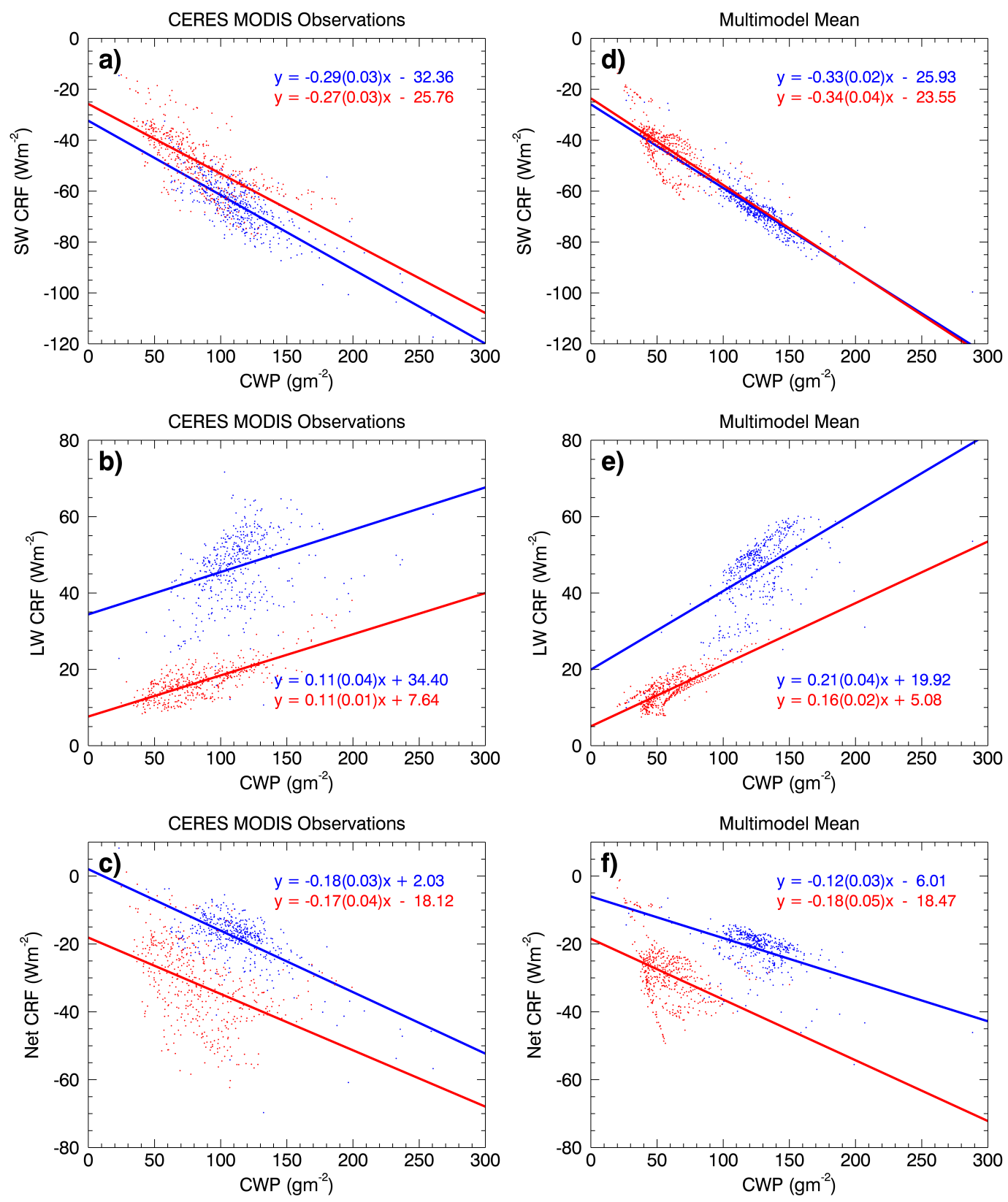

Figure 20. Same as Figure 19 but for the observed and simulated sensitivities of CRFs to CWP.

strongly regime dependent, such as in the CF results, but do show significant differences from the observations. The slope of the multimodel ensemble LW CRF to CWP in the upwelling regime (Figure 20e) is almost twice than what is observed ( 0.21 versus 0.11 $\mathrm{Wm}^{-2} / \mathrm{gm}^{-2}$ ). Biases in the simulated sensitivity between the CRFs and CF/CWP by 
model in the upwelling and downwelling regimes are summarized in Appendix $\mathrm{C}$ and Appendix D, respectively.

\section{Error Analysis - where are these errors coming from?}

This section provides a quantification of various error types due to biases in the CRF sensitivities to CF and CWP and from the simulated CF and CWP biases themselves. Such diagnoses are useful for identifying the dominant sources of model errors and areas most in need for model improvement.

The TOA CRF at each grid point is treated as a function of CF and CWP with the corresponding cloud radiative kernels,

$$
C R F_{Y, m}=\left|\left(\frac{\partial C R F_{Y}}{\partial C F}\right)\right|_{m} C F_{m}+\left|\left(\frac{\partial C R F_{Y}}{\partial C W P}\right)\right|_{m} C W P_{m}
$$

where $\mathrm{Y}=\mathrm{SW}$, LW, or net and the subscript, $\mathrm{m}$, represents the model simulated value. For this study, clouds are characterized by their residence in the upwelling and downwelling regimes (Figure 16), although it is recognized that the cloud radiative kernels may vary significantly for clouds of different heights, phases, and particle sizes within each regime. We use the regression slopes of CRFs versus CF or CWP for each regime, i.e., the sensitivity of CRF to CF or CWP shown in Figures 19 and 20, in place of cloud radiative kernels, as a first order approximation.

Hence, the total regime-averaged simulated CRF error relative to the observed CRF can be decomposed into the error associated with the discrepancy in CRF sensitivity to $\mathrm{CF}$ or $\mathrm{CWP}\left(\varepsilon_{\text {sen,CF}}\right.$ and $\varepsilon_{\text {sen,CWP }}$ ), the error resulting from the averaged $\mathrm{CF}$ or $\mathrm{CWP}$ bias for each regime $\left(\varepsilon_{C F}\right.$ and $\left.\varepsilon_{C W P}\right)$, and the co-variations $\left(\varepsilon_{c o v, C F}\right.$ and $\left.\varepsilon_{c o v, C W P}\right)$,

$$
\varepsilon_{\text {total }}=\varepsilon_{\text {sen }, C F}+\varepsilon_{\text {sen }, C W P}+\varepsilon_{C F}+\varepsilon_{C W P}+\varepsilon_{c o v, C F}+\varepsilon_{\text {cov }, C W P} .
$$

The three corresponding errors are computed as follows: 


$$
\begin{gathered}
\varepsilon_{\text {sen }, X}=\left[\left|\left(\frac{\partial C R F_{Y}}{\partial X}\right)\right|_{m}-\left|\left(\frac{\partial C R F_{Y}}{\partial X}\right)\right|_{o}\right] X_{o}, \\
\varepsilon_{X}=\left|\left(\frac{\partial C R F_{Y}}{\partial X}\right)\right|_{o}\left[X_{m}-X_{o}\right], \text { and } \\
\varepsilon_{c o v, X}=\left[\left|\left(\frac{\partial C R F_{Y}}{\partial X}\right)\right|_{m}-\left|\left(\frac{\partial C R F_{Y}}{\partial X}\right)\right|_{o}\right]\left[X_{m}-X_{o}\right],
\end{gathered}
$$

where $\mathrm{X}=\mathrm{CF}$ or CWP and the subscript, o, represents the observed value.

Table 5 shows the three sources of error for the SW, LW, and net CRF biases in the upwelling and downwelling regimes separately. The multimodel ensemble means and standard deviations are listed. In the upwelling regime, the simulated LW CRF sensitivity to CF contributes predominately to the LW CRF total error in terms of the mean and model spread $\left(22.4 \pm 20.2 \mathrm{Wm}^{-2}\right)$, as shown in Figure 19. Other sources of error such as the SW sensitivity to CF or CWP, LW sensitivity to CWP, the biases in CF and CWP, and the co-variations contribute similarly $\left(\sim 5 \mathrm{Wm}^{-2}\right.$ or less $)$ to the total CRF error in the upwelling regime.

Table 5. Summary of the different error sources in the simulated SW/LW/net CRFs with

\begin{tabular}{|c|c|c|c|}
\hline & SW CRF $\left(W^{-2}\right)$ & LW CRF $\left(W^{-2}\right)$ & Net CRF $\left(\mathrm{Wm}^{-2}\right)$ \\
\hline \multicolumn{4}{|c|}{ Cloud Fraction } \\
\hline \multicolumn{4}{|c|}{ Sensitivity Error } \\
\hline Up & $5.7 \pm 22.2$ & $22.4 \pm 20.2$ & $-7.9 \pm 16.5$ \\
\hline Down & $-17.2 \pm 11.7$ & $-1.6 \pm 6.3$ & $-15.6 \pm 13.6$ \\
\hline \multicolumn{4}{|l|}{ CF Bias } \\
\hline Up & $0.9 \pm 9.8$ & $0.6 \pm 6.6$ & $0.3 \pm 32.0$ \\
\hline Down & $-23.2 \pm 9.6$ & $-3.9 \pm 1.6$ & $-19.2 \pm 7.9$ \\
\hline \multicolumn{4}{|l|}{ Co-variance } \\
\hline Up & $-0.1 \pm 2.6$ & $0.1 \pm 3.8$ & $-0.2 \pm 2.0$ \\
\hline Down & $4.9 \pm 4.5$ & $0.2 \pm 2.4$ & $4.7 \pm 6.0$ \\
\hline \multicolumn{4}{|l|}{ Total } \\
\hline Up & $6.5 \pm 23.6$ & $23.0 \pm 22.2$ & $-7.9 \pm 16.3$ \\
\hline Down & $-35.5 \pm 12.1$ & $-5.4 \pm 3.8$ & $-30.1 \pm 12.2$ \\
\hline \multicolumn{4}{|c|}{ Cloud Water Path } \\
\hline \multicolumn{4}{|c|}{ Sensitivity Error } \\
\hline Up & $3.0 \pm 20.5$ & $5.4 \pm 13.1$ & $-0.1 \pm 12.2$ \\
\hline Down & $14.9 \pm 19.4$ & $3.1 \pm 5.8$ & $11.8 \pm 16.3$ \\
\hline CWP Bias & & & \\
\hline
\end{tabular}
contributions from CRF sensitivities to $\mathrm{CF}$ or CWP, CF or CWP biases, and co-variations in the upwelling and downwelling regimes, separately. 
Table 5 cont.

\begin{tabular}{|c|c|c|c|}
\hline & SW CRF $\left(W^{-2}\right)$ & LW CRF (Wm $\left.{ }^{-2}\right)$ & Net CRF $\left(\mathrm{Wm}^{-2}\right)$ \\
\hline Up & $4.1 \pm 23.0$ & $1.5 \pm 8.7$ & $2.5 \pm 14.3$ \\
\hline Down & $-6.9 \pm 3.9$ & $-2.7 \pm 1.5$ & $-4.2 \pm 2.4$ \\
\hline \multicolumn{4}{|l|}{ Co-variance } \\
\hline $\mathrm{Up}$ & $-5.6 \pm 14.9$ & $-0.4 \pm 7.7$ & $-6.4 \pm 10.9$ \\
\hline Down & $-6.7 \pm 11.7$ & $-1.6 \pm 3.7$ & $-5.1 \pm 9.1$ \\
\hline \multicolumn{4}{|l|}{ Total } \\
\hline Up & $1.5 \pm 17.1$ & $6.5 \pm 14.5$ & $-4.0 \pm 7.4$ \\
\hline Down & $1.4 \pm 7.8$ & $-1.2 \pm 2.0$ & $2.6 \pm 7.9$ \\
\hline
\end{tabular}

In the downwelling regime, the most dominate source of the error in CRF is associated with the under estimation of CF amount, as evidenced in Figures $2-4$. The regime-averaged SW CRF error from the CF bias amounts to $-23.3 \pm 9.6 \mathrm{Wm}^{-2}$. In addition, the errors associated with the multimodel ensemble SW CRF sensitivities to CF and CWP account for errors of $-17.2 \pm 11.7$ and $14.9 \pm 19.4 \mathrm{Wm}^{-2}$, respectively. The bias in CWP also contributes sizably, about $-6.9 \pm 3.9 \mathrm{Wm}^{-2}$, to the SW CRF error on the regime average. The compensating effects of the SW CRF sensitivity to CF and CWP result in rather small errors in the total SW and net CRF in the downwelling regime, indicating a common model deficiency. Only through detailed error analyses such as the decomposition conducted here, will we be able to better understand the processes accountable for model problems.

Total CF errors, including the errors associated with the CRF sensitivity to CF, $\mathrm{CF}$ biases, and the co-variations in both vertical velocity regimes are listed for each model in Table 6. For biases in SW CRF within the descending branch of the large-scale circulation, the errors associated with $\mathrm{CF}$ are negative for every model, indicating a universal model disparity. This is mainly due to the under estimation of both $\mathrm{CF}$ and sensitivity of SW CRF to CF. MRI-AGCM3-2S produces the largest SW CRF error by $\mathrm{CF},-60.6 \mathrm{Wm}^{-2}$, and CSIRO-Mk3.6.0 has the smallest, $-11.1 \mathrm{Wm}^{-2}$. Conversely in the 
ascending branch, the SW CRF errors by CF are positive for a majority of the 28 models, with 10 having negative errors. CSIRO-Mk3.6.0 produces the largest error in SW CRF in the upwelling regime, $-39.2 \mathrm{Wm}^{-2}$, while CCCM-CM has the smallest error of -2.6 $\mathrm{Wm}^{-2}$.

The errors associated with CF in LW CRF are predominately negative (i.e., under

Table 6. Summary of total errors in SW/LW/net CRFs by model contributed by simulated $\mathrm{CF}$ biases in both upwelling and downwelling regimes.

\begin{tabular}{|c|c|c|c|c|c|c|}
\hline \multirow[b]{2}{*}{ Model } & \multicolumn{2}{|c|}{ SW CRF $\left(\mathrm{Wm}^{-2}\right)$} & \multicolumn{2}{|c|}{ LW CRF $\left(\mathrm{Wm}^{-2}\right)$} & \multicolumn{2}{|c|}{ Net CRF $\left(\mathrm{Wm}^{-2}\right)$} \\
\hline & Up & Down & Up & Down & Up & Down \\
\hline ACCESS1.0 & -19.8 & -33.2 & 7.2 & -6.1 & -27.0 & -27.0 \\
\hline BCC-CSM1.1 & 9.1 & -30.0 & 41.8 & -7.0 & -21.5 & -23.0 \\
\hline BCC-CSM1.1 (m) & 28.5 & -29.5 & 54.1 & -0.2 & -25.6 & -19.4 \\
\hline BNU-ESM & 25.4 & -40.7 & 33.9 & -4.6 & -8.5 & -36.1 \\
\hline CanAM4 & 16.4 & -39.3 & 28.9 & -5.8 & -12.4 & -33.5 \\
\hline CCSM4 & 26.3 & -50.6 & 38.9 & -12.3 & -12.5 & -38.3 \\
\hline CESM1 (CAM5) & 26.9 & -25.6 & 42.3 & -4.6 & -15.3 & -21.0 \\
\hline CMCC-CM & -2.6 & -38.3 & 39.8 & -4.4 & -11.8 & -33.9 \\
\hline CNRM-CM5 & 23.0 & -48.0 & 6.7 & -1.7 & 16.3 & -46.2 \\
\hline CSIRO-Mk3.6.0 & -39.2 & -11.1 & 22.8 & -0.3 & 7.8 & -10.8 \\
\hline FGOALS-G2 & 18.7 & -41.3 & 9.0 & -10.7 & 9.6 & -30.5 \\
\hline FGOALS-S2 & 9.1 & -44.3 & -16.9 & -11.5 & 26 & -32.7 \\
\hline GFDL-HIRAM-C180 & 21.8 & -18.5 & 29.8 & 0.0 & -8.1 & -18.6 \\
\hline GFDL-HIRAM-C360 & 32.0 & -18.6 & 26.6 & 1.1 & 5.4 & -19.7 \\
\hline GFDL-HIRAM-CM3 & 38.3 & -20.1 & 77.8 & -6.3 & -14.7 & -13.8 \\
\hline GISS-E2-R & 22.5 & -38.0 & -6.2 & -0.3 & 28.6 & -37.4 \\
\hline HadGEM2-A & -16.6 & -34.7 & 8.8 & -7.7 & -25.3 & -27.1 \\
\hline INM-CM4 & 16.3 & -48.1 & 11.8 & -7.1 & 4.6 & -41.1 \\
\hline IPSL-CM5A-LR & -35.2 & -40.0 & 12.5 & -2.4 & -6.5 & -37.6 \\
\hline IPSL-CM5A-MR & -38.0 & -40.7 & 7.6 & -2.9 & -8.6 & -37.9 \\
\hline IPSL-CM5B-LR & -19.8 & -31.9 & 18.6 & -10.6 & -15.7 & -21.4 \\
\hline MIROC5 & 8.8 & -24.3 & -9.7 & -9.0 & 18.5 & -15.3 \\
\hline MPI-ESM-LR & -15.9 & -27.1 & 7.8 & -4.5 & -23.6 & -22.6 \\
\hline MPI-ESM-MR & -23.9 & -26.2 & -0.3 & -4.4 & -23.6 & -21.7 \\
\hline MRI-AGCM3-2H & 13.0 & -58.8 & 24.7 & -2.2 & -11.7 & -56.7 \\
\hline MRI-AGCM3-2S & -5.9 & -60.6 & 18.7 & -0.5 & -24.6 & -59.9 \\
\hline MRI-CGCM3 & 29.1 & -29.6 & 45.0 & -8.3 & -16.0 & -21.1 \\
\hline NorESM1-M & 33.2 & -45.6 & 63.2 & -7.6 & -24.2 & -38.0 \\
\hline
\end{tabular}

estimation of LW cloud warming) in the descending branch of the large-scale circulation 
for all models in the 28-model ensemble, except GFDL-HIRAM-C360. The largest error is from CCSM4 $\left(-12.3 \mathrm{Wm}^{-2}\right)$ while GFDL-HIRAM-C180 yields no error in the downwelling regime. The upwelling regimes consist of mostly positive errors associated with $\mathrm{CF}$, primarily from the over estimate of LW CRF sensitivity to $\mathrm{CF}$ in the models. GFDL-HIRAM-CM3 poses the largest error $\left(77.8 \mathrm{Wm}^{-2}\right)$ in the over estimate of LW CRF, while MPI-ESM-MR has the least amount of error $\left(-0.3 \mathrm{Wm}^{-2}\right)$. On average, the total net $\mathrm{CRF}$ error from $\mathrm{CF}$ is larger in the downwelling regime than in the upwelling counterpart.

Table 7 is equivalent to Table 6 , however it summarizes the errors associated with CWP for each model. In general, the maximum and minimum errors due to CWP errors are less than those due to $\mathrm{CF}$, and the inter-model spreads are within one order of magnitude. A summary of the other errors, by model, can be found in the Appendix.

Table 7. Summary of total errors in SW/LW/net CRFs by model contributed by simulated CWP biases in both upwelling and downwelling regimes.

\begin{tabular}{|c|c|c|c|c|c|c|}
\hline \multirow[b]{2}{*}{ Model } & \multicolumn{2}{|c|}{ SW CRF $\left(W^{-2}\right)$} & \multicolumn{2}{|c|}{ LW CRF $\left(W^{-2}\right)$} & \multicolumn{2}{|c|}{ Net CRF $\left(\mathrm{Wm}^{-2}\right)$} \\
\hline & Up & Down & Up & Down & Up & Down \\
\hline ACCESS1.0 & -2.6 & -7.5 & 7.4 & 1.0 & -10.0 & -8.5 \\
\hline BCC-CSM1.1 & 17.7 & 0.9 & 16.5 & 0.7 & 1.2 & 0.4 \\
\hline BCC-CSM1.1 (m) & 9.1 & 8.9 & 11.7 & 1.8 & -2.6 & 7.1 \\
\hline BNU-ESM & 22.7 & -6.2 & 19.3 & -0.2 & 3.5 & -5.9 \\
\hline CanAM4 & 0.3 & -0.9 & -4.7 & -0.9 & 5.1 & 0.0 \\
\hline CCSM4 & 21.9 & -3.8 & 21.8 & -1.3 & 0.2 & -2.7 \\
\hline CESM1 (CAM5) & -3.0 & 13.0 & -0.1 & -2.8 & -2.9 & 15.7 \\
\hline СМСС-СM & -22.5 & 1.5 & -10.3 & -3.2 & -7.9 & 4.6 \\
\hline CNRM-CM5 & 8.9 & -4.3 & 12.1 & -2.0 & -3.1 & -2.3 \\
\hline CSIRO-Mk3.6.0 & -10.0 & 13.0 & -1.4 & 0.6 & -8.6 & 12.4 \\
\hline FGOALS-G2 & 12.0 & -0.1 & 7.8 & -3.2 & 4.3 & 3.1 \\
\hline FGOALS-S2 & -11.9 & -1.3 & -10.8 & -5.9 & -1.1 & 4.6 \\
\hline GFDL-HIRAM-C180 & -6.3 & -5.3 & -1.8 & -0.8 & -4.5 & -4.6 \\
\hline GFDL-HIRAM-C360 & -5.8 & -6.2 & 1.9 & -0.2 & -7.7 & -6.1 \\
\hline GFDL-HIRAM-CM3 & 17.7 & -5.6 & 42.3 & -2.4 & -16.1 & -3.3 \\
\hline GISS-E2-R & -11.2 & -8.1 & 10.8 & -4.7 & -18.8 & -3.4 \\
\hline HadGEM2-A & -1.6 & -8.4 & 8.0 & 0.9 & -9.6 & -9.2 \\
\hline INM-CM4 & 17.0 & 9.1 & 17.3 & 3.7 & -0.3 & 5.6 \\
\hline
\end{tabular}


Table 7 cont.

\begin{tabular}{|c|c|c|c|c|c|c|}
\hline \multirow[b]{2}{*}{ Model } & \multicolumn{2}{|c|}{ SW CRF $\left(W^{-2}\right)$} & \multicolumn{2}{|c|}{ LW CRF $\left(W^{-2}\right)$} & \multicolumn{2}{|c|}{ Net CRF $\left(\mathrm{Wm}^{-2}\right)$} \\
\hline & Up & Down & Up & Down & Up & Down \\
\hline IPSL-CM5A-LR & -20.4 & 13.4 & -11.3 & -0.1 & -9.2 & 13.5 \\
\hline IPSL-CM5A-MR & -22.2 & 10.9 & -11.8 & -2.3 & -8.9 & 13.1 \\
\hline IPSL-CM5B-LR & -12.4 & 16.4 & -2.7 & -1.5 & -9.7 & 17.9 \\
\hline MIROC5 & 14.3 & 2.7 & 11.8 & -1.3 & 2.4 & 4.0 \\
\hline MPI-ESM-LR & -25.6 & 11.0 & -8.8 & -2.3 & -9.4 & 13.2 \\
\hline MPI-ESM-MR & -26.5 & 9.1 & -10.1 & -2.7 & -11.8 & 11.8 \\
\hline MRI-AGCM3-2H & 21.1 & -5.0 & 7.9 & -0.8 & 13.0 & -4.3 \\
\hline MRI-AGCM3-2S & 3.0 & -4.0 & -6.1 & -0.8 & 9.0 & -3.2 \\
\hline MRI-CGCM3 & 24.8 & -3.2 & 33.1 & -2.6 & -8.2 & -0.6 \\
\hline NorESM1-M & 33.2 & -1.1 & 32.7 & 0.4 & 0.6 & -1.5 \\
\hline
\end{tabular}

Residual Errors. The errors discussed above are those quantified from biases in CF and CWP (sensitivity, co-variation, etc.). However, CRFs are dependent upon other processes and characteristics of the atmosphere that have not yet been considered. Although they have not been evaluated at this time, they will surely make for a better explanation for why biases in the CRF simulations occur. Other variables, which are simulated by the GCMs and observed by satellite, and can lead to a better understanding of CRF errors; these include, but are not limited to, relative and specific humidity, water vapor path, precipitation, cloud-top pressure, and cloud-base height. 


\section{CHAPTER IV}

\section{CONCLUSIONS}

Globally simulated CF, CWP, TOA radiation budgets and CRFs from 28 CMIP5 AMIP models are evaluated and compared with multiple satellite observations (CERES, MODIS, ISCCP, CloudSat, and CALIPSO) and contemporary reanalysis during the March 2000 to February 2008 time period (eight years). The model biases are identified and quantified to facilitate model improvement in future climate simulations, particularly in the representation of clouds and how they affect TOA radiation budgets. From the eight-year comparisons between model simulations, we have made the following conclusions:

1) The modeled CFs are, on average (58.6 $\pm 5.8 \%$ ), under estimated by nearly $7 \%$ when compared to CERES MODIS (CM) and ISCCP results with an even larger negative bias $(16.7 \%)$ compared to CloudSat/CALIPSO (CC). Most of the modeled CFs and the multimodel ensemble mean agree well with both CM and ISCCP CF results in the tropics $\left(5^{\circ} \mathrm{S}\right.$ to $\left.15^{\circ} \mathrm{N}\right)$, but then diverge poleward, with a large discrepancy in the Southern Ocean. Large multimodel spread (as large as $60 \%$ ) is apparent in the polar regions; indicating not only a need for better cloud parameterizations, but also better satellite remote sensing of clouds in the Arctic and Antarctic where temperature inversions play a vital role in differentiating clouds from the underlying snow and ice fields. The CWP comparison is similar

to the results in $\mathrm{CF}$, with a negative bias of $16.4 \mathrm{gm}^{-2}$ compared to $\mathrm{CM}$. The 
model simulated TOA all-sky reflected SW and OLR fluxes, on average differ from CERES EBAF observations by 1.6 and $-0.9 \mathrm{Wm}^{-2}$, respectively. The TOA clear-sky radiation results are similar in comparison; the SW (LW) multimodel ensemble mean is greater (less) than the CERES EBAF result by $0.5(2.2) \mathrm{Wm}^{-2}$.

2) The globally averaged SW, LW, and net CRFs from CERES EBAF are -47.2, 26.2, and $-21.0 \mathrm{Wm}^{-2}$, respectively, indicating a net cooling effect of clouds on the TOA radiation budget. The differences in SW and LW CRFs between observations and the multimodel ensemble means are -1.1 and $-1.3 \mathrm{Wm}^{-2}$, respectively, resulting in a larger net cooling effect of $-2.4 \mathrm{Wm}^{-2}$ in the model simulations. The strong SW cooling and maximum LW warming effects from $5{ }^{\circ} \mathrm{N}$ to $10{ }^{\circ} \mathrm{N}$ are primarily attributed to deep convective clouds while the moderate LW warming in the $40^{\circ} \mathrm{S}$ to $60{ }^{\circ} \mathrm{S}$ latitude band is due to persistent MBL clouds.

3) Several geographic regions have been identified to have relatively large biases in most of the simulated fields and have been evaluated in this study. These regions are rather consistent from simulation to simulation and should be addressed by climate modelers and special interest groups. We suggest that field studies be designed and implemented to better understand fundamental cloud-radiative processes in the regions with relatively large biases. The regions with commonly large biased (whether positive or negative) are: the Southern Ocean, the East Indies, South America, the Indian Ocean, the Tibetan Plateau, and the Saharan Desert.

4) A further investigation of cloud properties and CRFs over the identified upwelling and downwelling regimes reveals that, typically, the model biases in the upwelling regime are much less than those over the downwelling regime. Sensitivity studies 
have shown that the observed magnitude of SW CRF cooling increases significantly with increasing $\mathrm{CF}$ with nearly the same sensitivity in both the upwelling and downwelling regimes $\left(-1.20\right.$ and $-1.31 \mathrm{Wm}^{-2} \%^{-1}$, respectively). The model simulations provide similar characteristics but with some discrepancies. The 28model ensemble under estimates the sensitivity between SW CRF and CF by 0.06 $\mathrm{Wm}^{-2} \%^{-1}$ and $0.26 \mathrm{Wm}^{-2} \%^{-1}$ in the relatively strong convective and subsidence regions, respectively. Conversely, the observed LW CRF increases with increasing $\mathrm{CF}$, but is regime dependent (a strong warming of $0.81 \mathrm{Wm}^{-2} \%^{-1}$ and a moderate warming of $0.22 \mathrm{Wm}^{-2} \%^{-1}$ in the upwelling and downwelling regimes, respectively). The difference in sensitivity is due to the distinct cloud-top temperature characteristics of deep convective (upwelling) and stratiform MBL (downwelling) clouds. The multimodel ensemble does a fair job in simulating the observed LW sensitivity in the downwelling regime $\left(-0.04 \mathrm{Wm}^{-2} \%^{-1}\right.$ bias), however it provides an overly sensitive SW CRF $\left(0.39 \mathrm{Wm}^{-2} \%^{-1}\right.$ bias $)$ in the tropics and mid-latitudes.

5) Several dominant sources of CRF errors are identified. The error sources that contribute largely to the regime-averaged CRF errors are: the modeled errors in the LW CRF sensitivity to CF in the upwelling regime, the errors in the simulated CF and CWP amounts, and the sensitivities of SW CRF to CF and CWP in the downwelling regions.

Although there are multiple studies related to the evaluation of CMIP5 GCM simulated cloud and radiation fields (TOA and surface) using satellite observations, this study provides a more comprehensive assessment of the CMIP5 AMIP simulations using multiple satellite observations. More importantly, we have investigated the impact of CF 
and CWP on the TOA radiation fluxes and CRFs, quantitatively estimated the sensitivities of SW, LW, and net CRFs to CF and CWP in relatively strong convective and subsidence regions over the oceans, and have performed a detailed error analysis. These results will provide a better means for representing the true physical interactions between clouds and TOA radiation budgets and should help modelers to better predict future climate scenarios. It is our hope that these comparisons and the statistical results from this study will aid in the advancement of the GCM simulations of clouds and TOA radiation budgets in future versions of CMIP. 


\section{CHAPTER V}

\section{FUTURE WORK}

The results obtained from this study have motivated further investigations of cloud-radiative processes. Especially, to document the vertical distribution of cloud occurrence and cloud properties and the resulting heating and cooling profile of the atmosphere by clouds, which are important for understanding cloud forcing and climate feedbacks. We plan to investigate the CloudSat/CALIPSO cloud vertical profiles, through the identification of several cloud-types (up to 10; Xi et al. 2010) and determine their distinctive effects on the TOA and surface radiation budgets. In addition, we also plan to conduct simulation experiments using a radiative transfer model, such as the Fu Liou model, to determine cloud radiative heating rate profiles for different cloud vertical structures. The goal is to determine the heating rate profile, level of sensitivity and feedback each cloud type has on the climate system. Running the radiative transfer model in the areas of high interest identified in this Master's Thesis could ultimately mitigate the consistent errors in those regions.

The MERRA Reanalysis was used to identify the areas of strong atmospheric upwelling (convection) and downwelling (subsidence) in this study. However, other global reanalyses are available at similar temporal and spatial resolutions. It will be beneficial to determine which reanalysis dataset is best for identifying the large-scale circulations, their residence, and spatial patterns. Moreover, we need to define which vertical velocity regime is more important for evaluating cloud-radiative processes. The 
ultimate goal is to provide a suggestion to climate modelers as to which cloud-type parameterization should be prioritized.

These questions shall be answered in conjunction with the objectives proposed in the NASA Earth and Space Science Graduate Fellowship awarded to the authors of this Master's Thesis. These objectives include calculating the radiative heating rate profiles using the Fu-Liou radiative transfer model with input from several NASA satellite observations and then performing a model evaluation similar to the one in this study. We want to quantify the errors in the GCMs so that they can be reduced in future versions of CMIP and for the IPCC AR6. University of North Dakota graduate students and faculty, in collaboration with Jet Propulsion Laboratory scientists, will work together to accomplish these tasks in the next several years. 
APPENDICES 


\section{APPENDIX A}

Regional biases, by model, in the upwelling regime defined by MERRA reanalysis during the eight years evaluated in this study.

\begin{tabular}{|c|c|c|c|c|c|}
\hline Model Name & $\begin{array}{c}\text { Cloud } \\
\text { Fraction }\end{array}$ & $\begin{array}{c}\text { Cloud } \\
\text { Water Path }\end{array}$ & $\begin{array}{c}\text { Shortwave } \\
\text { CRF }\end{array}$ & $\begin{array}{c}\text { Longwave } \\
\text { CRF }\end{array}$ & $\begin{array}{l}\text { Net } \\
\text { CRF }\end{array}$ \\
\hline ACCESS1.0 & -12.4 & -42.2 & 9.5 & -4.6 & 4.9 \\
\hline BCC-CSM1.1 & 5.0 & 46.5 & -11.4 & 2.7 & -8.7 \\
\hline BCC-CSM1.1 (m) & -4.2 & 61.3 & -13.3 & 10.3 & -2.9 \\
\hline BNU-ESM & -2.1 & 29.5 & -10.5 & 1.0 & -9.6 \\
\hline CanAM4 & 4.6 & 15.2 & 0.8 & 5.3 & 6.1 \\
\hline CCSM4 & -8.2 & 61.4 & -16.5 & 5.4 & -11.1 \\
\hline CESM1 (CAM5) & 4.0 & -73.4 & -6.2 & -5.2 & -11.4 \\
\hline CMCC-CM & 4.6 & -63.8 & 8.7 & 1.3 & 10.0 \\
\hline CNRM-CM5 & 4.9 & 55.3 & -10.5 & -2.9 & -13.4 \\
\hline CSIRO-Mk3.6.0 & 10.4 & -54.7 & 23.4 & 4.6 & 28.1 \\
\hline FGOALS-G2 & -8.6 & -11.7 & -7.5 & -8.4 & -16.0 \\
\hline FGOALS-S2 & -4.6 & -1.8 & -3.8 & -19.3 & -23.1 \\
\hline GFDL-HIRAM-C180 & 5.9 & 34.3 & 1.7 & -1.1 & 0.5 \\
\hline GFDL-HIRAM-C360 & 4.0 & 47.2 & 4.7 & -6.1 & -1.3 \\
\hline GFDL-HIRAM-CM3 & 19.2 & 215.7 & -11.2 & 14.9 & 3.8 \\
\hline GISS-E2-R & 6.5 & 238.0 & -11.6 & -12.1 & -23.7 \\
\hline HadGEM2-A & -11.9 & -38.1 & 9.3 & -4.2 & 5.1 \\
\hline INM-CM4 & 6.9 & -59.2 & 10.4 & -15.7 & -5.4 \\
\hline IPSL-CM5A-LR & -14.5 & -46.2 & 14.3 & -2.0 & 12.3 \\
\hline IPSL-CM5A-MR & -14.9 & -46.5 & 14.9 & -3.2 & 11.7 \\
\hline IPSL-CM5B-LR & 6.2 & -3.8 & -5.2 & 6.2 & 1.0 \\
\hline MIROC5 & -4.9 & 11.2 & -12.4 & -4.6 & -17.1 \\
\hline MPI-ESM-LR & 5.5 & -83.5 & 14.8 & -7.3 & 7.4 \\
\hline MPI-ESM-MR & 3.9 & -86.4 & 18.6 & -11.5 & 7.1 \\
\hline MRI-AGCM3-2H & 6.1 & 11.7 & -19.1 & 6.4 & -12.7 \\
\hline MRI-AGCM3-2S & 4.4 & 7.9 & -12.4 & 2.2 & -10.2 \\
\hline MRI-CGCM3 & 3.7 & 104.2 & -16.8 & 8.4 & -8.4 \\
\hline NorESM1-M & 0.6 & 60.4 & -25.0 & 13.2 & -11.8 \\
\hline Multimodel Mean & 0.7 & 13.9 & -2.2 & -0.9 & -3.2 \\
\hline
\end{tabular}

Units: Cloud Fraction (\%); Cloud Water Path $\left(\mathrm{gm}^{-2}\right) ;$ Radiation $\left(\mathrm{Wm}^{-2}\right)$ 


\section{APPENDIX B}

Regional biases, by model, in the downwelling regime defined by MERRA reanalysis during the eight years evaluated in this study.

\begin{tabular}{|c|c|c|c|c|c|}
\hline Model Name & $\begin{array}{c}\text { Cloud } \\
\text { Fraction }\end{array}$ & $\begin{array}{c}\text { Cloud } \\
\text { Water Path }\end{array}$ & $\begin{array}{c}\text { Shortwave } \\
\text { CRF }\end{array}$ & $\begin{array}{c}\text { Longwave } \\
\text { CRF }\end{array}$ & $\begin{array}{l}\text { Net } \\
\text { CRF }\end{array}$ \\
\hline ACCESS1.0 & -13.6 & -27.7 & -3.1 & 0.8 & -2.3 \\
\hline BCC-CSM1.1 & -18.9 & -2.9 & 0.9 & 0.2 & 1.1 \\
\hline BCC-CSM1.1 (m) & -20.2 & -4.4 & -1.4 & -1.3 & -2.7 \\
\hline BNU-ESM & -23.3 & -12.3 & 12.0 & -4.8 & 7.2 \\
\hline CanAM4 & -12.0 & -8.2 & 4.0 & -2.2 & 1.8 \\
\hline CCSM4 & -23.8 & -25.7 & 12.9 & -6.4 & 6.5 \\
\hline CESM1 (CAM5) & -16.2 & -51.0 & 7.7 & -8.3 & -0.6 \\
\hline CMCC-CM & -23.1 & -34.7 & 12.5 & -1.2 & 11.3 \\
\hline CNRM-CM5 & -29.7 & -30.7 & 22.6 & -5.0 & 17.6 \\
\hline CSIRO-Mk3.6.0 & -10.6 & -19.2 & -2.7 & -1.0 & -3.7 \\
\hline FGOALS-G2 & -22.1 & -40.6 & 7.2 & -2.5 & 4.7 \\
\hline FGOALS-S2 & -23.3 & -23.1 & 5.6 & -7.6 & -2.0 \\
\hline GFDL-HIRAM-C180 & -7.5 & -20.2 & 1.2 & -2.1 & -0.9 \\
\hline GFDL-HIRAM-C360 & -8.3 & -18.2 & 1.2 & -2.7 & -1.4 \\
\hline GFDL-HIRAM-CM3 & -6.5 & -34.1 & 2.0 & -2.2 & -0.1 \\
\hline GISS-E2-R & -21.7 & 8.4 & 9.9 & -4.7 & 5.1 \\
\hline HadGEM2-A & -14.1 & -27.1 & -0.9 & 0.5 & -0.4 \\
\hline INM-CM4 & -8.9 & -55.1 & 13.6 & -2.5 & 11.1 \\
\hline IPSL-CM5A-LR & -15.3 & -24.8 & -2.1 & 4.2 & 2.1 \\
\hline IPSL-CM5A-MR & -14.2 & -21.0 & -4.1 & 4.5 & 0.5 \\
\hline IPSL-CM5B-LR & -7.8 & -18.6 & -4.9 & 1.3 & -3.5 \\
\hline MIROC5 & -14.2 & -20.2 & -5.8 & -0.8 & -6.6 \\
\hline MPI-ESM-LR & -16.6 & -28.9 & 3.4 & -0.5 & 2.9 \\
\hline MPI-ESM-MR & -16.9 & -31.9 & 5.4 & -0.9 & 4.5 \\
\hline MRI-AGCM3-2H & -32.5 & -44.3 & 20.1 & -4.4 & 15.7 \\
\hline MRI-AGCM3-2S & -32.8 & -38.6 & 18.6 & -5.0 & 13.6 \\
\hline MRI-CGCM3 & -23.8 & -30.6 & 7.5 & -3.6 & 3.9 \\
\hline NorESM1-M & -17.1 & -16.3 & 6.2 & -2.6 & 3.5 \\
\hline Multimodel Mean & -17.7 & -25.1 & 5.3 & -2.2 & 3.2 \\
\hline
\end{tabular}

Units: Cloud Fraction (\%); Cloud Water Path $\left(\mathrm{gm}^{-2}\right) ;$ Radiation $\left(\mathrm{Wm}^{-2}\right)$ 


\section{APPENDIX C}

Biases, by model, in the sensitivity of CF and CWP to CRFs in the upwelling regime defined by MERRA reanalysis during the eight years evaluated in this study.

\begin{tabular}{|c|ccc|ccc|}
\hline & \multicolumn{3}{l}{ Cloud Fraction } & & \multicolumn{2}{l}{ Cloud Water Path } \\
Model Name & Shortwave & Longwave & Net & Shortwave & Longwave & Net \\
& CRF & CRF & CRF & CRF & CRF \\
\hline ACCESS1.0 & -0.09 & 0.31 & -0.39 & 0.14 & 0.17 & -0.03 \\
BCC-CSM1.1 & 0.04 & 0.51 & -0.32 & 0.03 & 0.07 & -0.05 \\
BCC-CSM1.1 (m) & 0.52 & 0.89 & -0.37 & -0.05 & 0.03 & -0.08 \\
BNU-ESM & 0.42 & 0.53 & -0.11 & 0.10 & 0.11 & -0.01 \\
CanAM4 & 0.15 & 0.34 & -0.19 & -0.03 & -0.05 & 0.02 \\
CCSM4 & 0.60 & 0.75 & -0.15 & 0.02 & 0.09 & -0.06 \\
CESM1 (CAM5) & 0.30 & 0.54 & -0.23 & 0.47 & 0.20 & 0.27 \\
CMCC-CM & -0.11 & 0.49 & -0.19 & -0.08 & -0.06 & 0.08 \\
CNRM-CM5 & 0.23 & 0.04 & 0.20 & -0.04 & 0.04 & -0.08 \\
CSIRO-Mk3.6.0 & -0.65 & 0.18 & 0.05 & 0.11 & 0.08 & 0.02 \\
FGOALS-G2 & 0.48 & 0.26 & 0.22 & 0.15 & 0.09 & 0.06 \\
FGOALS-S2 & 0.23 & -0.21 & 0.43 & -0.10 & -0.10 & -0.01 \\
GFDL-HIRAM-C180 & 0.20 & 0.34 & -0.14 & -0.11 & -0.04 & -0.07 \\
GFDL-HIRAM-C360 & 0.37 & 0.32 & 0.05 & -0.12 & -0.02 & -0.10 \\
GFDL-HIRAM-CM3 & 0.17 & 0.71 & 0.25 & -0.14 & 0.06 & -0.17 \\
GISS-E2-R & 0.20 & -0.15 & 0.35 & -0.23 & -0.04 & -0.18 \\
HadGEM2-A & -0.04 & 0.32 & -0.36 & 0.13 & 0.16 & -0.04 \\
INM-CM4 & 0.11 & 0.08 & 0.02 & 0.64 & 0.45 & 0.20 \\
IPSL-CM5A-LR & -0.33 & 0.45 & -0.02 & -0.11 & -0.09 & -0.01 \\
IPSL-CM5A-MR & -0.37 & 0.36 & -0.05 & -0.13 & -0.10 & -0.01 \\
IPSL-CM5B-LR & -0.36 & 0.18 & -0.24 & -0.10 & -0.02 & -0.08 \\
MIROC5 & 0.23 & -0.09 & 0.32 & 0.09 & 0.08 & 0.00 \\
MPI-ESM-LR & -0.30 & 0.05 & -0.35 & -0.04 & 0.02 & 0.20 \\
MPI-ESM-MR & -0.39 & -0.05 & -0.35 & -0.05 & -0.02 & 0.15 \\
MRI-AGCM3-2H & 0.08 & 0.26 & -0.19 & 0.14 & 0.05 & 0.09 \\
MRI-AGCM3-2S & -0.15 & 0.21 & -0.36 & 0.01 & -0.06 & 0.06 \\
MRI-CGCM3 & 0.34 & 0.58 & -0.24 & -0.03 & 0.10 & -0.13 \\
NorESM1-M & 0.47 & 0.90 & -0.35 & 0.09 & 0.15 & -0.06 \\
\hline MuItimodel Mean & 0.08 & 0.33 & -0.12 & 0.03 & 0.05 & 0.00 \\
\hline
\end{tabular}

Units: $C F\left(\mathrm{Wm}^{-2} \%^{-1}\right) ; C W P\left(\mathrm{Wm}^{-2} / \mathrm{gm}^{-2}\right)$ 


\section{APPENDIX D}

Biases, by model, in the sensitivity of CF and CWP to CRFs in the downwelling regime defined by MERRA reanalysis during the eight years evaluated in this study.

\begin{tabular}{|c|c|c|c|c|c|c|}
\hline \multirow[b]{2}{*}{ Model Name } & \multicolumn{3}{|c|}{ Cloud Fraction } & \multicolumn{3}{|c|}{ Cloud Water Path } \\
\hline & $\begin{array}{c}\text { Shortwave } \\
\text { CRF }\end{array}$ & $\begin{array}{c}\text { Longwave } \\
\text { CRF }\end{array}$ & $\begin{array}{l}\text { Net } \\
\text { CRF } \\
\end{array}$ & $\begin{array}{c}\text { Shortwave } \\
\text { CRF }\end{array}$ & $\begin{array}{c}\text { Longwave } \\
\text { CRF }\end{array}$ & $\begin{array}{l}\text { Net } \\
\text { CRF } \\
\end{array}$ \\
\hline ACCESS1.0 & -0.30 & -0.06 & -0.24 & 0.00 & 0.07 & -0.07 \\
\hline BCC-CSM1.1 & -0.11 & -0.06 & -0.05 & 0.02 & 0.01 & 0.01 \\
\hline BCC-CSM1.1 (m) & -0.07 & -0.13 & 0.06 & 0.13 & 0.03 & 0.10 \\
\hline BNU-ESM & -0.24 & 0.02 & -0.26 & -0.04 & 0.02 & -0.06 \\
\hline CanAM4 & -0.44 & -0.06 & -0.38 & 0.02 & 0.00 & 0.02 \\
\hline CCSM4 & -0.47 & -0.17 & -0.30 & 0.06 & 0.03 & 0.03 \\
\hline CESM1 (CAM5) & -0.09 & -0.02 & -0.07 & 0.85 & 0.09 & 0.77 \\
\hline СМСС-СМ & -0.19 & 0.02 & -0.21 & 0.23 & 0.01 & 0.22 \\
\hline CNRM-CM5 & -0.26 & 0.14 & -0.39 & 0.08 & 0.03 & 0.05 \\
\hline CSIRO-Mk3.6.0 & 0.05 & 0.04 & 0.01 & 0.29 & 0.04 & 0.25 \\
\hline FGOALS-G2 & -0.29 & -0.13 & -0.15 & 0.26 & 0.03 & 0.23 \\
\hline FGOALS-S2 & -0.33 & -0.15 & -0.18 & 0.08 & -0.06 & 0.14 \\
\hline GFDL-HIRAM-C180 & -0.15 & 0.03 & -0.18 & 0.00 & 0.02 & -0.02 \\
\hline GFDL-HIRAM-C360 & -0.14 & 0.05 & -0.19 & -0.02 & 0.03 & -0.05 \\
\hline GFDL-HIRAM-CM3 & -0.20 & -0.08 & -0.11 & 0.08 & 0.03 & 0.05 \\
\hline GISS-E2-R & -0.22 & 0.10 & -0.32 & -0.11 & -0.06 & -0.05 \\
\hline HadGEM2-A & -0.32 & -0.09 & -0.23 & -0.02 & 0.07 & -0.09 \\
\hline INM-CM4 & -0.65 & -0.09 & -0.56 & 0.88 & 0.35 & 0.53 \\
\hline IPSL-CM5A-LR & -0.40 & 0.02 & -0.42 & 0.35 & 0.04 & 0.30 \\
\hline IPSL-CM5A-MR & -0.43 & 0.01 & -0.44 & 0.27 & 0.00 & 0.27 \\
\hline IPSL-CM5B-LR & -0.38 & -0.15 & -0.22 & 0.33 & 0.01 & 0.33 \\
\hline MIROC5 & -0.11 & -0.11 & 0.00 & 0.13 & 0.01 & 0.12 \\
\hline MPI-ESM-LR & -0.11 & -0.02 & -0.09 & 0.35 & 0.02 & 0.34 \\
\hline MPI-ESM-MR & -0.08 & -0.01 & -0.07 & 0.35 & 0.01 & 0.34 \\
\hline MRI-AGCM3-2H & -0.49 & 0.16 & -0.65 & 0.19 & 0.11 & 0.08 \\
\hline MRI-AGCM3-2S & -0.54 & 0.21 & -0.75 & 0.15 & 0.08 & 0.07 \\
\hline MRI-CGCM3 & 0.04 & -0.07 & 0.11 & 0.10 & 0.01 & 0.09 \\
\hline NorESM1-M & -0.48 & -0.08 & -0.40 & 0.05 & 0.03 & 0.02 \\
\hline Multimodel Mean & -0.26 & -0.03 & -0.24 & 0.18 & 0.04 & 0.14 \\
\hline
\end{tabular}

Units: $C F\left(\mathrm{Wm}^{-2} \%{ }^{-1}\right) ; C W P\left(\mathrm{Wm}^{-2} / \mathrm{gm}^{-2}\right)$ 


\section{APPENDIX E}

From the error analysis: Sensitivity errors, by model, in the upwelling regime.

\begin{tabular}{|c|ccc|ccc|}
\hline & \multicolumn{3}{|l|}{ Cloud Fraction } & & \multicolumn{2}{l}{ Cloud Water Path } \\
Model Name & Shortwave & Longwave & Net & Shortwave & Longwave & Net \\
& CRF & CRF & CRF & CRF & CRF \\
\hline ACCESS1.0 & -6.00 & 21.00 & -27.00 & 15.50 & 19.40 & -3.90 \\
BCC-CSM1.1 & 2.90 & 35.20 & -21.90 & 2.90 & 8.00 & -5.10 \\
BCC-CSM1.1 (m) & 35.70 & 61.20 & -25.50 & -5.70 & 3.20 & -8.90 \\
BNU-ESM & 28.80 & 36.70 & -7.90 & 11.20 & 12.70 & -1.40 \\
CanAM4 & 10.20 & 23.60 & -13.30 & -3.60 & -5.60 & 2.00 \\
CCSM4 & 41.10 & 51.70 & -10.60 & 2.60 & 9.70 & -7.10 \\
CESM1 (CAM5) & 20.90 & 36.90 & -16.00 & 53.00 & 23.00 & 30.00 \\
CMCC-CM & -7.60 & 33.80 & -12.80 & -9.10 & -7.30 & 8.60 \\
CNRM-CM5 & 16.00 & 2.60 & 13.40 & -4.80 & 4.00 & -8.80 \\
CSIRO-Mk3.6.0 & -44.90 & 12.50 & 3.20 & 11.80 & 9.20 & 2.60 \\
FGOALS-G2 & 33.10 & 18.20 & 14.90 & 17.20 & 10.10 & 7.10 \\
FGOALS-S2 & 15.60 & -14.20 & 29.80 & -11.60 & -10.80 & -0.80 \\
GFDL-HIRAM-C180 & 13.50 & 23.10 & -9.60 & -12.50 & -4.30 & -8.20 \\
GFDL-HIRAM-C360 & 25.70 & 22.10 & 3.60 & -13.80 & -2.30 & -11.50 \\
GFDL-HIRAM-CM3 & 11.90 & 48.70 & -17.40 & -15.50 & 6.30 & -18.90 \\
GISS-E2-R & 13.50 & -10.40 & 23.90 & -25.90 & -5.00 & -19.90 \\
HadGEM2-A & -2.80 & 22.20 & -24.90 & 14.40 & 18.50 & -4.10 \\
INM-CM4 & 7.30 & 5.60 & 1.70 & 72.40 & 50.40 & 22.00 \\
IPSL-CM5A-LR & -22.50 & 30.70 & -1.00 & -11.80 & -10.50 & -1.40 \\
IPSL-CM5A-MR & -25.70 & 25.10 & -3.40 & -14.60 & -11.20 & -0.90 \\
IPSL-CM5B-LR & -25.00 & 12.50 & -16.70 & -11.70 & -2.40 & -9.30 \\
MIROC5 & 15.70 & -6.20 & 21.90 & 10.00 & 9.60 & 0.40 \\
MPI-ESM-LR & -20.80 & 3.10 & -23.90 & -4.90 & 2.00 & 22.00 \\
MPI-ESM-MR & -27.00 & -3.20 & -23.80 & -5.60 & -2.40 & 16.90 \\
MRI-AGCM3-2H & 5.20 & 18.20 & -13.00 & 16.00 & 6.00 & 9.90 \\
MRI-AGCM3-2S & -10.40 & 14.30 & -24.70 & 0.70 & -6.50 & 7.10 \\
MRI-CGCM3 & 23.40 & 39.90 & -16.60 & -2.90 & 11.20 & -14.10 \\
NorESM1-M & 32.20 & 62.20 & -24.20 & 10.20 & 16.90 & -6.70 \\
\hline Multimodel Mean & 5.7 & 22.4 & -7.9 & 3.0 & 5.4 & -0.1 \\
\hline
\end{tabular}

Units: $\mathrm{Wm}^{-2}$ 


\section{APPENDIX F}

From the error analysis: Sensitivity errors, by model, in the downwelling regime.

\begin{tabular}{|c|ccc|ccc|}
\hline & \multicolumn{3}{|l|}{ Cloud Fraction } & & \multicolumn{2}{l}{ Cloud Water Path } \\
Model Name & Shortwave & Longwave & Net & Shortwave & Longwave & Net \\
& CRF & CRF & CRF & CRF & CRF \\
\hline ACCESS1.0 & -19.40 & -3.90 & -15.40 & 0.10 & 6.00 & -5.90 \\
BCC-CSM1.1 & -7.30 & -3.90 & -3.40 & 1.80 & 1.00 & 0.90 \\
BCC-CSM1.1 (m) & -4.40 & -8.20 & 3.80 & 10.70 & 2.40 & 8.20 \\
BNU-ESM & -15.80 & 1.00 & -16.80 & -3.30 & 1.30 & -4.60 \\
CanAM4 & -28.80 & -3.80 & -25.00 & 1.50 & 0.00 & 1.60 \\
CCSM4 & -30.70 & -11.10 & -19.60 & 4.60 & 2.20 & 2.40 \\
CESM1 (CAM5) & -5.80 & -1.30 & -4.50 & 70.40 & 7.10 & 63.30 \\
CMCC-CM & -12.40 & 1.30 & -13.70 & 18.90 & 0.90 & 17.90 \\
CNRM-CM5 & -16.70 & 9.00 & -25.70 & 6.50 & 2.10 & 4.40 \\
CSIRO-Mk3.6.0 & 3.30 & 2.50 & 0.80 & 23.80 & 3.50 & 20.30 \\
FGOALS-G2 & -18.60 & -8.70 & -9.90 & 21.70 & 2.40 & 19.30 \\
FGOALS-S2 & -21.30 & -9.80 & -11.50 & 6.90 & -4.70 & 11.60 \\
GFDL-HIRAM-C180 & -9.70 & 1.90 & -11.70 & 0.20 & 1.80 & -1.60 \\
GFDL-HIRAM-C360 & -8.90 & 3.30 & -12.20 & -1.60 & 2.30 & -4.00 \\
GFDL-HIRAM-CM3 & -12.80 & -5.30 & -7.50 & 6.30 & 2.20 & 4.10 \\
GISS-E2-R & -14.30 & 6.70 & -20.90 & -9.40 & -5.10 & -4.40 \\
HadGEM2-A & -20.70 & -5.80 & -14.90 & -1.50 & 5.60 & -7.00 \\
INM-CM4 & -42.20 & -5.90 & -36.30 & 72.70 & 28.60 & 44.10 \\
IPSL-CM5A-LR & -26.10 & 1.30 & -27.40 & 28.80 & 3.70 & 25.10 \\
IPSL-CM5A-MR & -28.30 & 0.40 & -28.70 & 22.30 & 0.00 & 22.30 \\
IPSL-CM5B-LR & -24.70 & -10.10 & -14.70 & 27.70 & 0.60 & 27.10 \\
MIROC5 & -7.30 & -7.40 & 0.10 & 10.80 & 1.20 & 9.60 \\
MPI-ESM-LR & -7.30 & -1.10 & -6.20 & 29.00 & 1.30 & 27.70 \\
MPI-ESM-MR & -5.40 & -0.80 & -4.50 & 29.00 & 1.20 & 27.80 \\
MRI-AGCM3-2H & -32.30 & 10.30 & -42.60 & 15.40 & 8.70 & 6.70 \\
MRI-AGCM3-2S & -35.30 & 13.60 & -48.90 & 12.40 & 6.50 & 5.90 \\
MRI-CGCM3 & 2.50 & -4.80 & 7.40 & 8.20 & 1.10 & 7.10 \\
NorESM1-M & -31.50 & -5.20 & -26.30 & 4.30 & 2.80 & 1.50 \\
\hline Multimodel Mean & -17.2 & -1.6 & -15.6 & 14.9 & 3.1 & 11.8 \\
\hline
\end{tabular}

Units: $\mathrm{Wm}^{-2}$ 


\section{APPENDIX G}

From the error analysis: CF and CWP errors, by model, in the upwelling regime.

\begin{tabular}{|c|ccc|ccc|}
\hline & \multicolumn{2}{|l|}{ Cloud Fraction } & \multicolumn{2}{l}{ Cloud Water Path } \\
Model Name & Shortwave & Longwave & Net & Shortwave & Longwave & Net \\
& CRF & CRF & CRF & CRF & CRF & CRF \\
\hline ACCESS1.0 & -14.90 & -10.00 & -4.90 & -12.30 & -4.70 & -7.60 \\
BCC-CSM1.1 & 6.00 & 4.00 & 2.00 & 13.60 & 5.20 & 8.40 \\
BCC-CSM1.1 (m) & -5.00 & -3.40 & -1.70 & 17.90 & 6.80 & 11.10 \\
BNU-ESM & -2.50 & -1.70 & -0.80 & 8.60 & 3.30 & 5.30 \\
CanAM4 & 5.50 & 3.70 & 1.80 & 4.40 & 1.70 & 2.80 \\
CCSM4 & -9.90 & -6.60 & -3.20 & 17.90 & 6.80 & 11.10 \\
CESM1 (CAM5) & 4.80 & 3.20 & 1.60 & -21.40 & -8.10 & -13.30 \\
CMCC-CM & 5.50 & 3.70 & 1.80 & -18.60 & -7.10 & -11.60 \\
CNRM-CM5 & 5.90 & 3.90 & 1.90 & 16.10 & 6.10 & 10.00 \\
CSIRO-Mk3.6.0 & 12.50 & 8.40 & 4.10 & -16.00 & -6.10 & -9.90 \\
FGOALS-G2 & -10.30 & -6.90 & -3.40 & -3.40 & -1.30 & -2.10 \\
FGOALS-S2 & -5.50 & -3.70 & -1.80 & -0.50 & -0.20 & -0.30 \\
GFDL-HIRAM-C180 & 7.10 & 4.70 & 2.30 & 10.00 & 3.80 & 6.20 \\
GFDL-HIRAM-C360 & 4.80 & 3.20 & 1.60 & 13.80 & 5.20 & 8.60 \\
GFDL-HIRAM-CM3 & 23.10 & 15.50 & 7.60 & 63.00 & 23.90 & 39.10 \\
GISS-E2-R & 7.70 & 5.20 & 2.50 & 69.50 & 26.40 & 43.10 \\
HadGEM2-A & -14.30 & -9.60 & -4.70 & -11.10 & -4.20 & -6.90 \\
INM-CM4 & 8.30 & 5.60 & 2.70 & -17.30 & -6.60 & -10.70 \\
IPSL-CM5A-LR & -17.40 & -11.70 & -5.70 & -13.50 & -5.10 & -8.40 \\
IPSL-CM5A-MR & -17.90 & -12.00 & -5.90 & -13.60 & -5.20 & -8.40 \\
IPSL-CM5B-LR & 7.50 & 5.00 & 2.50 & -1.10 & -0.40 & -0.70 \\
MIROC5 & -5.80 & -3.90 & -1.90 & 3.30 & 1.20 & 2.00 \\
MPI-ESM-LR & 6.60 & 4.40 & 2.20 & -24.40 & -9.30 & -15.10 \\
MPI-ESM-MR & 4.60 & 3.10 & 1.50 & -25.20 & -9.60 & -15.70 \\
MRI-AGCM3-2H & 7.30 & 4.90 & 2.40 & 3.40 & 1.30 & 2.10 \\
MRI-AGCM3-2S & 5.20 & 3.50 & 1.70 & 2.30 & 0.90 & 1.40 \\
MRI-CGCM3 & 4.40 & 3.00 & 1.50 & 30.40 & 11.50 & 18.90 \\
NorESM1-M & 0.70 & 0.50 & 0.20 & 17.60 & 6.70 & 10.90 \\
\hline MuItimodel Mean & 0.9 & 0.6 & 0.3 & 4.1 & 1.5 & 2.5 \\
\hline
\end{tabular}

Units: $\mathrm{Wm}^{-2}$ 


\section{APPENDIX H}

From the error analysis: CF and CWP errors, by model, in the downwelling regime.

\begin{tabular}{|c|ccc|ccc|}
\hline & \multicolumn{2}{l}{ Cloud Fraction } & & \multicolumn{2}{l}{ Cloud Water Path } \\
Model Name & Shortwave & Longwave & Net & Shortwave & Longwave & Net \\
& CRF & CRF & CRF & CRF & CRF & CRF \\
\hline ACCESS1.0 & -17.80 & -3.00 & -14.80 & -7.60 & -3.00 & -4.60 \\
BCC-CSM1.1 & -24.80 & -4.20 & -20.60 & -0.80 & -0.30 & -0.50 \\
BCC-CSM1.1 (m) & -26.50 & -4.50 & -22.00 & -1.20 & -0.50 & -0.70 \\
BNU-ESM & -30.50 & -5.20 & -25.30 & -3.40 & -1.30 & -2.00 \\
CanAM4 & -15.80 & -2.70 & -13.10 & -2.20 & -0.90 & -1.40 \\
CCSM4 & -31.10 & -5.30 & -25.80 & -7.00 & -2.80 & -4.30 \\
CESM1 (CAM5) & -21.20 & -3.60 & -17.60 & -14.00 & -5.50 & -8.50 \\
CMCC-CM & -30.30 & -5.20 & -25.10 & -9.50 & -3.70 & -5.80 \\
CNRM-CM5 & -38.90 & -6.60 & -32.20 & -8.40 & -3.30 & -5.10 \\
CSIRO-MK3.6.0 & -13.90 & -2.40 & -11.50 & -5.30 & -2.10 & -3.20 \\
FGOALS-G2 & -29.00 & -4.90 & -24.00 & -11.10 & -4.40 & -6.70 \\
FGOALS-S2 & -30.60 & -5.20 & -25.30 & -6.30 & -2.50 & -3.80 \\
GFDL-HIRAM-C180 & -9.90 & -1.70 & -8.20 & -5.50 & -2.20 & -3.40 \\
GFDL-HIRAM-C360 & -10.80 & -1.80 & -9.00 & -5.00 & -2.00 & -3.00 \\
GFDL-HIRAM-CM3 & -8.60 & -1.50 & -7.10 & -9.30 & -3.70 & -5.70 \\
GISS-E2-R & -28.40 & -4.80 & -23.50 & 2.30 & 0.90 & 1.40 \\
HadGEM2-A & -18.50 & -3.20 & -15.40 & -7.40 & -2.90 & -4.50 \\
INM-CM4 & -11.60 & -2.00 & -9.70 & -15.10 & -5.90 & -9.10 \\
IPSL-CM5A-LR & -20.00 & -3.40 & -16.60 & -6.80 & -2.70 & -4.10 \\
IPSL-CM5A-MR & -18.50 & -3.20 & -15.40 & -5.70 & -2.30 & -3.50 \\
IPSL-CM5B-LR & -10.20 & -1.70 & -8.50 & -5.10 & -2.00 & -3.10 \\
MIROC5 & -18.60 & -3.20 & -15.40 & -5.50 & -2.20 & -3.30 \\
MPI-ESM-LR & -21.70 & -3.70 & -18.00 & -7.90 & -3.10 & -4.80 \\
MPI-ESM-MR & -22.20 & -3.80 & -18.40 & -8.70 & -3.40 & -5.30 \\
MRI-AGCM3-2H & -42.60 & -7.30 & -35.40 & -12.10 & -4.80 & -7.40 \\
MRI-AGCM3-2S & -43.00 & -7.30 & -35.60 & -10.60 & -4.20 & -6.40 \\
MRI-CGCM3 & -31.20 & -5.30 & -25.80 & -8.40 & -3.30 & -5.10 \\
NorESM1-M & -22.40 & -3.80 & -18.60 & -4.50 & -1.80 & -2.70 \\
\hline MuItimodel Mean & -23.2 & -3.9 & -19.2 & -6.9 & -2.7 & -4.2 \\
\hline
\end{tabular}

Units: $\mathrm{Wm}^{-2}$ 


\section{APPENDIX I}

From the error analysis: co-variance errors, by model, in the upwelling regime.

\begin{tabular}{|c|ccc|ccc|}
\hline & \multicolumn{2}{|l|}{ Cloud Fraction } & & \multicolumn{2}{l}{ Cloud Water Path } & \\
Model Name & Shortwave & Longwave & Net & Shortwave & Longwave & Net \\
& CRF & CRF & CRF & CRF & CRF \\
\hline ACCESS1.0 & 1.10 & -3.80 & 4.90 & -5.80 & -7.30 & 1.50 \\
BCC-CSM1.1 & 0.20 & 2.60 & -1.60 & 1.20 & 3.30 & -2.10 \\
BCC-CSM1.1 (m) & -2.20 & -3.70 & 1.60 & -3.10 & 1.70 & -4.80 \\
BNU-ESM & -0.90 & -1.10 & 0.20 & 2.90 & 3.30 & -0.40 \\
CanAM4 & 0.70 & 1.60 & -0.90 & -0.50 & -0.80 & 0.30 \\
CCSM4 & -4.90 & -6.20 & 1.30 & 1.40 & 5.30 & -3.80 \\
CESM1 (CAM5) & 1.20 & 2.20 & -0.90 & -34.60 & -15.00 & -19.60 \\
CMCC-CM & -0.50 & 2.30 & -0.80 & 5.20 & 4.10 & -4.90 \\
CNRM-CM5 & 1.10 & 0.20 & 1.00 & -2.40 & 2.00 & -4.30 \\
CSIRO-Mk3.6.0 & -6.80 & 1.90 & 0.50 & -5.80 & -4.50 & -1.30 \\
FGOALS-G2 & -4.10 & -2.30 & -1.90 & -1.80 & -1.00 & -0.70 \\
FGOALS-S2 & -1.00 & 1.00 & -2.00 & 0.20 & 0.20 & 0.00 \\
GFDL-HIRAM-C180 & 1.20 & 2.00 & -0.80 & -3.80 & -1.30 & -2.50 \\
GFDL-HIRAM-C360 & 1.50 & 1.30 & 0.20 & -5.80 & -1.00 & -4.80 \\
GFDL-HIRAM-CM3 & 3.30 & 13.60 & -4.90 & -29.80 & 12.10 & -36.30 \\
GISS-E2-R & 1.30 & -1.00 & 2.20 & -54.80 & -10.60 & -42.00 \\
HadGEM2-A & 0.50 & -3.80 & 4.30 & -4.90 & -6.30 & 1.40 \\
INM-CM4 & 0.70 & 0.60 & 0.20 & -38.10 & -26.50 & -11.60 \\
IPSL-CM5A-LR & 4.70 & -6.50 & 0.20 & 4.90 & 4.30 & 0.60 \\
IPSL-CM5A-MR & 5.60 & -5.50 & 0.70 & 6.00 & 4.60 & 0.40 \\
IPSL-CM5B-LR & -2.30 & 1.10 & -1.50 & 0.40 & 0.10 & 0.30 \\
MIROC5 & -1.10 & 0.40 & -1.50 & 1.00 & 1.00 & 0.00 \\
MPI-ESM-LR & -1.70 & 0.30 & -1.90 & 3.70 & -1.50 & -16.30 \\
MPI-ESM-MR & -1.50 & -0.20 & -1.30 & 4.30 & 1.90 & -13.00 \\
MRI-AGCM3-2H & 0.50 & 1.60 & -1.10 & 1.70 & 0.60 & 1.00 \\
MRI-AGCM3-2S & -0.70 & 0.90 & -1.60 & 0.00 & -0.50 & 0.50 \\
MRI-CGCM3 & 1.30 & 2.10 & -0.90 & -2.70 & 10.40 & -13.00 \\
NorESM1-M & 0.30 & 0.50 & -0.20 & 5.40 & 9.10 & -3.60 \\
\hline Multimodel Mean & -0.1 & 0.1 & -0.2 & -5.6 & -0.4 & -6.4 \\
\hline
\end{tabular}

Units: $\mathrm{Wm}^{-2}$ 


\section{APPENDIX J}

From the error analysis: co-variance errors, by model, in the downwelling regime.

\begin{tabular}{|c|ccc|ccc|}
\hline & \multicolumn{2}{l}{ Cloud Fraction } & & \multicolumn{2}{l}{ Cloud Water Path } \\
Model Name & Shortwave & Longwave & Net & Shortwave & Longwave & Net \\
& CRF & CRF & CRF & CRF & CRF & CRF \\
\hline ACCESS1.0 & 4.00 & 0.80 & 3.20 & 0.00 & -2.00 & 2.00 \\
BCC-CSM1.1 & 2.10 & 1.10 & 1.00 & -0.10 & 0.00 & 0.00 \\
BCC-CSM1.1 (m) & 1.40 & 2.50 & -1.20 & -0.60 & -0.10 & -0.40 \\
BNU-ESM & 5.60 & -0.40 & 6.00 & 0.50 & -0.20 & 0.70 \\
CanAM4 & 5.30 & 0.70 & 4.60 & -0.20 & 0.00 & -0.20 \\
CCSM4 & 11.20 & 4.10 & 7.10 & -1.40 & -0.70 & -0.80 \\
CESM1 (CAM5) & 1.40 & 0.30 & 1.10 & -43.40 & -4.40 & -39.10 \\
CMCC-CM & 4.40 & -0.50 & 4.90 & -7.90 & -0.40 & -7.50 \\
CNRM-CM5 & 7.60 & -4.10 & 11.70 & -2.40 & -0.80 & -1.60 \\
CSIRO-Mk3.6.0 & -0.50 & -0.40 & -0.10 & -5.50 & -0.80 & -4.70 \\
FGOALS-G2 & 6.30 & 2.90 & 3.40 & -10.70 & -1.20 & -9.50 \\
FGOALS-S2 & 7.60 & 3.50 & 4.10 & -1.90 & 1.30 & -3.20 \\
GFDL-HIRAM-C180 & 1.10 & -0.20 & 1.30 & 0.00 & -0.40 & 0.40 \\
GFDL-HIRAM-C360 & 1.10 & -0.40 & 1.50 & 0.40 & -0.50 & 0.90 \\
GFDL-HIRAM-CM3 & 1.30 & 0.50 & 0.80 & -2.60 & -0.90 & -1.70 \\
GISS-E2-R & 4.70 & -2.20 & 7.00 & -1.00 & -0.50 & -0.40 \\
HadGEM2-A & 4.50 & 1.30 & 3.20 & 0.50 & -1.80 & 2.30 \\
INM-CM4 & 5.70 & 0.80 & 4.90 & -48.50 & -19.00 & -29.40 \\
IPSL-CM5A-LR & 6.10 & -0.30 & 6.40 & -8.60 & -1.10 & -7.50 \\
IPSL-CM5A-MR & 6.10 & -0.10 & 6.20 & -5.70 & 0.00 & -5.70 \\
IPSL-CM5B-LR & 3.00 & 1.20 & 1.80 & -6.20 & -0.10 & -6.10 \\
MIROC5 & 1.60 & 1.60 & 0.00 & -2.60 & -0.30 & -2.30 \\
MPI-ESM-LR & 1.90 & 0.30 & 1.60 & -10.10 & -0.50 & -9.70 \\
MPI-ESM-MR & 1.40 & 0.20 & 1.20 & -11.20 & -0.50 & -10.70 \\
MRI-AGCM3-2H & 16.10 & -5.20 & 21.30 & -8.30 & -4.70 & -3.60 \\
MRI-AGCM3-2S & 17.70 & -6.80 & 24.60 & -5.80 & -3.10 & -2.70 \\
MRI-CGCM3 & -0.90 & 1.80 & -2.70 & -3.00 & -0.40 & -2.60 \\
NorESM1-M & 8.30 & 1.40 & 6.90 & -0.90 & -0.60 & -0.30 \\
\hline MuItimodel Mean & 4.9 & 0.2 & 4.7 & -6.7 & -1.6 & -5.1 \\
\hline
\end{tabular}

Units: $\mathrm{Wm}^{-2}$ 


\section{APPENDIX K}

A list of acronyms used in this manuscript

AIE

AMIP

AMSR-E

AR5

ARM

CALIOP

CALIPSO

$\mathrm{CC}$

CCCM

CERES

CF

CM

CMIP5

CPR

CRF

CWP

DOE

EBAF

ESGF

GCM

IPCC

ISCCP

IWP

ITCZ

LW

LWP

MBL

MERRA

MLR

MODIS

MPL

NASA

OLR

PCMDI

RH

RMSE

SCM

SGP

SSF

SST

SW

TOA
Aerosol Indirect Effect

Atmospheric Model Intercomparison Project Advanced Microwave Scanning Radiometer - Earth Observing System

Assessment Report 5

Atmospheric Radiation Measurement Cloud-Aerosol Lidar with Orthogonal Polarization Cloud-Aerosol Lidar and Infrared Pathfinder Satellite Observation CloudSat/CALIPSO CloudSat/CALIPSO/CERES/MODIS Clouds and Earths Radiant Energy System

Cloud Fraction CERES MODIS

Coupled Model Intercomparison Project Phase 5

Cloud Profiling Radar

Cloud Radiative Forcing Cloud Water Path

Department of Energy

Energy Balanced and Filled

Earth System Grid Federation

Global Climate Model (or General Circulation Model)

Intergovernmental Panel on Climate Change

International Satellite Cloud Climatology Project Ice Water Path

Intertropical Convergence Zone Longwave

Liquid Water Path Marine Boundary Layer Modern Era Retrospective Analysis for Research and Applications Multiple Linear Regression Moderate Resolution Imaging Spectroradiometer

Micropulse Lidar National Aeronautics and Space Administration Outgoing Longwave Radiation Program for Climate Model Diagnosis and Intercomparison

Relative Humidity

Root Mean Squared Error

Single Column Model

Southern Great Plains

Single Scanner Footprint

Sea Surface Temperature

Shortwave

Top of the Atmosphere 


\section{REFERENCES}

Berry, E. and G. Mace (2013) Cirrus Cloud Properties and the Large-Scale Meteorological Environment: Relationships Derived from A-Train and NCEPNCAR Reanalysis Data. J. Appl. Meteor. Climatol. 52, 1253-1276.

Bony S., J.-L. Dufresne, H. Le Treut, J.-J. Morcrette and C. Senior (2004) On dynamic and thermodynamic components of cloud changes. Clim. Dyn. 22, 71-86, doi: 10.1007/s00382-003-0369-6.

Bony et al. (2006) How Well Do We Understand and Evaluate Climate Change Feedback Processes? J. Clim. 19, 3445-3482.

Cess et al. (1990) Intercomparison and Interpretation of Climate Feedback Processes in 19 Atmospheric General Circulation Models. J. of Geophys. Res. 95. D10, 601615, doi: 0148-0227/90/90JD-01219505.00.

Chen L., Y. Yu, and D. Sun (2013) Cloud and water vapor feedbacks to the El Niño warming: Are they still biased in CMIP5 models? J. Clim. doi: 10.1175/JCLI-D12-00575.1.

Collins et al. (2001) Parameterization of Generalized Cloud Overlap for Radiative Calculations in General Circulation Models. J. Clim., 58, 3224-3242.

Cooper, D.L., P.C. Hess, J.L. Gleason, K.J. Priestley (2013) Clouds and Earth's Radiant Energy System (CERES) Data Management System: BiDirectional Scans (BDS) Collection Document Release 3 Version 4, ceres.larc.nasa.gov/documents/collect_guide/pdf/BDS_CG_R3V4.pdf

Doelling, D. R., N. G. Loeb, D. F. Keyes, M. L. Nordeen, D. Morstad, C. Nguyen, B.A.Wielicki, D. F. Young, and M. Sun (2013) Geostationary enhanced temporal interpolation for CERES flux products. J. Atmos. Oceanic Technol. 30, 10721090.

Dong, X., B. Xi, and P. Minnis (2006) A climatology of midlatitude continental clouds from ARM SGP site. Part II: Cloud fraction and surface radiative forcing. J. Clim. 19, 1765-1783.

Dong, X., P. Minnis, B. Xi, S. Sun-Mack, and Y. Chen (2008a) Comparison of CERESMODIS stratus cloud properties with ground-based measurements at the DOE ARM Southern Great Plains site. J. Geophys. Res. 113, D03204, doi:10.1029/2007JD008438. 
Dong, X., B. A. Wielicki, B. Xi, Y. Hu, G. G. Mace, S. Benson, F. Rose, S. Kato, T. Charlock, and P. Minnis (2008b) Using observations of deep convective systems to constrain atmospheric column absorption of solar radiation in the optically thick limit. J. Geophys. Res. 113, D10206, doi:10.1029/2007JD009769.

Dong, X., B. Xi, A. Kennedy, P. Minnis and R. Wood (2014) A 19-month record of Marine Aerosol-Cloud-Radiation Properties derived from DOE ARM AMF deployment at the Azores: Part I: Cloud Fraction and Single-layered MBL cloud Properties. J. Clim. DOI: 10.1175/JCLI-D-13-00553.1

Han, Q, W.B. Rossow, A.A. Lacis (1994) Near-global survey of effective radii in liquid water clouds using ISCCP data. J. Clim. 7, 465-497.

Hansen, J., L. Nazarenko, R. Ruedy, Mki. Sato, J. Willis, A. Del Genio, D. Koch, A. Lacis, K. Lo, S. Menon, T. Novakov, Ju. Perlwitz, G. Russell, G.A. Schmidt, and N. Tausnev (2005) Earth's energy imbalance: Confirmation and implications. Science 308, 1431-1435, doi:10.1126/science.1110252.

Hogan, R.J. and A.J. Illingworth (2000) Deriving cloud overlap statistics from radar. Q. J. R. Meteorol. Soc., 126, 2903-2909.

IPCC (2001) Climate Change 2001: The Scientific Basis. Contribution of Working Group I to the Third Assessment Report of the Intergovernmental Panel on Climate Change [Houghton, J.T., Y. Ding, D.J. Griggs, M. Noguer, P.J. van der Linden, X. Dai, K. Maskell, and C.A. Johnson (eds.)]. Cambridge University Press, Cambridge, United Kingdom and New York, NY, USA, 881pp.

IPCC AR5 (2013) Chapter 9: Evaluation of Climate Models. http://www.climatechange2013.org/images/report/WG1AR5_Chapter09_FINAL. pdf.

Jiang et al. (2012) Evaluation of cloud and water vapor simulations in CMIP5 climate models using NASA 'A-Train' satellite observations. J. Geophys. Res. 117, D14105, doi:10.1029/2011JD017237.

Kennedy, A., X. Dong, , B. Xi, P. Minnis, A. Del Genio, M.M. Khaiyer, and A. Wolf (2010) Evaluation of NASA GISS Single Column Model Simulated Clouds Using Combines Surface and Satellite Observation. J. Climate. doi:10.1175/2010JCLI3353.1.

Kennedy, A., X. Dong, B. Xi. S. Xie, Y. Zhang, and J. Chen (2011) A Comparison of MERRA and NARR Reanalysis Datasets with the DOE ARM SGP Continuous Forcing data. J. Clim 24, 4541-4557.

Klein, S, A., Y. Zhang, M.D. Zelinka, R. Pincus, J. Boyle, P.J. Gleckler (2013) Are climate model simulations of clouds improving? An evaluation using the ISCCP simulator. J. Geophys. Res. Atmos. 118 ,1329-1342. doi: 10.1002/jgrd.50141. 
Lauer, A., and K. Hamilton (2012) Simulating clouds with global climate models: A comparison on CMIP5 results with CMIP3 and satellite data. J. Clim., doi:10.1175/JCLI-D-12- 00451.1.

Li, J.-L. F., D. E. Waliser, W.-T. Chen, B. Guan, T. Kubar, G. Stephens, H.-Y. Ma, M. Deng, L. Donner, C. Seman, and L. Horowitz (2012) An observationally based evaluation of cloud ice water in CMIP3 and CMIP5 GCMs and contemporary reanalyses using contemporary satellite data. J. Geophys. Res. 117, D16105, doi:10.1029/2012JD017640.

Li, J.-L. F., D. E. Waliser, G. Stephens, S. Lee, T. L'Ecuyer, S. Kato, N. Loeb, and H.-Y. Ma (2013) Characterizing and understanding radiation budget biases in CMIP3/CMIP5 GCMs, contemporary GCM, and reanalysis. J. Geophys. Res. Atmos. 118, 8166-8184, doi:10.1002/jgrd.50378.

Lin, B., P. Minnis, T-F. Fan, Y. Hu, and W. Sun (2010) Radiation characteristics of low and high clouds in different oceanic regions observed by CERES and MODIS. Int. J. Remote Sens. 31, $6473-6492$.

Lucchesi, R. et al. (2012) File Specification for MERRA Products. GMAO Office Note No. 1 (Version 2.3), available from http://gmao.gsfc.nasa.gov/pubs/office_notes.

Loeb et al. (2012) Advances in Understanding Top-of-Atmosphere Radiation Variability from Satellite Observations. Surv. in Geophys., doi: 10.1007/s10712-012-9175-1.

Mace et al. (2005) Evaluation of Cirrus Cloud Properties Derived from MODIS Data Using Cloud Properties Derived from Ground-Based Observations Collected at the ARM SGP Site. J. of Appl. Meteor. 44, 221 - 240.

Mace, G. G., Q. Zhang, M. Vaughan, R. Marchand, G. Stephens, C. Trepte, and D. Winker (2009) A description of hydrometeor layer occurrence statistics derived from the first year of merged CloudSat and CALIPSO data, J. Geophys. Res., 114, D00A26, doi:10.1029/2007JD009755.

Minnis P., D.F. Young, B.A. Wielicki, P.W. Heck, X. Dong, L.L. Stowe, and R.M. Welch (1999) CERES cloud properties derived from multispectral VIRS data. Proc. SPIE 3867, Satellite Remote Sensing of Clouds and the Atmosphere IV, 91 (December 8, 1999); doi:10.1117/12.373047.

Minnis, P., D.F. Young, B.A. Wielicki, S. Sun-Mack, Q.Z. Trepte, Y. Chen, P.W. Heck, and X. Dong (2002) A global cloud database from VIRS and MODIS for CERES, Proc. SPIE 4891, Optical Remote Sensing of the Atmosphere and Clouds III 115 (April 9, 2003); doi:10.1117/12.467317.

Minnis, P., C.R. Yost, S. Sun-Mack, and Y. Chen (2008) Estimating the top altitude of optically thick ice clouds from thermal infrared satellite observations using CALIPSO data, Geophys. Res. Lett. 35, L12801, doi:10.1029/2008GL033947. 
Minnis et al. (2011b) CERES Edition-2 cloud property retrievals using TRMM VIRS and Terra and Aqua MODIS data, Part II: Examples of average results and comparisons with other data. IEEE Trans. Geosci. Remote Sens. 49, 4401-4430.

Morcrette and Jakob (2000) The Response of the ECMWF Model to Changes in the Cloud Overlap Assumption. Monthly Weather Review, 128, 1707-1732.

Ramanathan, V., R. D. Cess, E. F. Harrison, P. Minnis, B. R. Barkstrom, E. Ahmad, D. Hartmann (1989) Cloud-Radiative Forcing and Climate: Results from the Earth Radiation Budget Experiment. Science 243, 57-63.

Rienecker, M.M. et al. (2011) MERRA - NASA's Modern-Era Retrospective Analysis for Research and Applications. J. Clim. 24, 3624-3648, doi:10.1175/JCLI-D-1100015.1.

Rossow, W.B., A.W. Walker, and L.C. Garder (1993) Comparison of ISCCP and Other Cloud Amounts. J. Clim. 6, $2394-2418$.

Rossow, W.B., and R.A. Schiffer (1999) Advances in understanding Clouds in ISCCP. Bull. Amer. Met. Soc. 80, 2261-2287.

Schmidt, G.A. et al. (2014) Configuration and assessment of the GISS ModelE2 contributions to the CMIP5 archive. J. Adv. Model. Earth Syst. 6, doi:10.1002/2013MS000265.

Senior C.A. and J.F.B. Mitchell (1993) Carbon Dioxide and Climate: The Impact of Cloud Parameterization. J. Clim. 6, 393-418.

Stanfield R., X. Dong, B. Xi, A. Kennedy, A.D. Del Genio, P. Minnis, and J. Jiang (2014) Assessment of NASA GISS CMIP5 and Post-CMIP5 Simulated Clouds and TOA Radiation Budgets Using Satellite Observations: Part I: Cloud fraction and properties. J. Clim. doi:10.1175/JCLI-D-13-00588.1

Stephens and Webster (1984) Cloud decoupling of the surface and planetary radiative budgets. J. of Atmos., 41, 681-686.

Stephens, G.L., D.G. Vane, R.J. Boain, G.G. Mace, K. Sassen, Z. Wang, A.J. Illingworth, E.J. O'Connor, W.B. Rossow, S.L. Durden, S.D. Miller, R.T. Austin, A. Benedetti, C. Mitrescu, and CloudSat Science Team (2002) The CloudSat mission and the A-Train: A new dimension of space-based observations of clouds and precipitation. Bull. Amer. Meteorol. Soc., 83, 1771-1790, doi:10.1175/BAMS-83$12-1771$.

Su, H., J.H. Jiang, D.G. Vane, and G.L. Stephens (2008) Observed Vertical Structure of Tropical Oceanic Clouds Sorted in Large-scale Regimes. Geophys. Res. Lett. 35, doi:10.1029/2008GL035888. 
Su et al. (2013) Diagnosis of regime-dependent cloud simulation errors in CMIP5 models using 'A-Train' satellite observations and reanalysis data. J. Geophys. Res. 118, 2762-2780, doi:10.1029/2012JD018575.

Su, H., J.H. Jiang, C. Zhai, T.J. Shen, J.D. Neelin, G.L. Stephens, Y.L. Yung (2013) Weakening and Strengthening Structures in the Hadley Circulation Change under Global Warming and Implications for Cloud Response and Climate Sensitivity. In Preparation for J. Geophys. Res.

Taylor, K.E., V. Balaji, S. Hankin, M. Juckes, B. Lawrence, and S. Pascoe (2011) CMIP5 Data Reference Syntax (DRS) and Controlled Vocabularies, Version 1.2.

Taylor, K.E., R.J. Stouffer, and G.A. Meehl (2012) An Overview of CMIP5 and the Experiment Design. Bull. Amer. Meteor. Soc. 93, 485-498.

Wang, H. and W. Su (2013) Evaluating and understanding top of the atmosphere cloud radiative effects in International Panel on Climate Change (IPCC) AR5 CMIP5 models using satellite observations. J. Geophys. Res. 118, 683-699, doi:10.1029/2012JD018619.

Wielicki, B. A., B. R. Barkstrom, E. F. Harrison, R. B. Lee III, G. L. Smith, and J. E. Cooper (1996) Clouds and the Earth's Radiant Energy System (CERES): An Earth observing system experiment. Bull. Am. Meteorol. Soc. 77, 853- 868.

Wielicki, B. A., et al. (1998) Clouds and the Earth's Radiant Energy System (CERES): Algorithm overview. IEEE Trans. Geosci. Remote Sens. 36, 1127- 1141.

Xi, B., X. Dong, P.Minnis, M. Khaiyer (2010) A 10-yr climatology of cloud cover and vertical distribution from both surface and GOES observations over DOE ARM SGP site, J. Geophys. Res. 115, D12124, doi:10.1029/2009JD012800.

Xi, B., X. Dong, K. Giannecchini, P. Minnis, and S. Kato (2014a), An overview of Arctic cloud fraction and height detected by active and passive remote sensing over the ARM NSA site. Submitted to GRL.

Xi, B., X. Dong, P. Minnis, and S. Sun-Mack (2014) Comparison of CERES-MODIS Stratus Cloud Properties with Ground-Based Measurements at the DOE ARM AMF at AZORES Site, submitted to J. Geophys. Res.

Yao, M.-S., and A.D. Del Genio (2002) Effects of cloud parameterization on the simulation of climate changes in the GISS GCM. Part II: Sea surface temperature and cloud feedbacks. J. Clim. 15, 2491-2504, doi:10.1175/1520-0442.

Zhang et al. (2005) Comparing clouds and their seasonal variations in 10 atmospheric general circulation models using satellite measurements. J. Geophys. Res. 110, D15S02, doi:10.1029/2004JD005021. 
Zhu, P., J.J. Hack, and J. Kiehl (2007) Diagnosing Cloud Feedbacks in General Circulation Models. J. Clim. 20, 2602-2622. 